\author{
Universidade de São Paulo \\ Escola de Engenharia de São Carlos \\ Departamento de Engenharia Elétrica e de Computação \\ Programa de Pós-Graduação em Engenharia Elétrica
}

Igor Guerrero

\title{
Correção do espectro de potência do ruído na simulação de redução da dose de radiação em imagens de tomossíntese digital mamária
}





\section{Universidade de São Paulo \\ Escola de Engenharia de São Carlos \\ Departamento de Engenharia Elétrica e de Computação \\ Programa de Pós-Graduação em Engenharia Elétrica}

\section{Igor Guerrero}

\section{Correção do espectro de potência do ruído na simulação de redução da dose de radiação em imagens de tomossíntese digital mamária}

Dissertação de Mestrado apresentada à Escola de Engenharia de São Carlos da Universidade de São Paulo como parte dos requisitos para a obtenção do título de Mestre em Ciências - Programa de Engenharia Elétrica

Área de concentração: Processamento de Sinais e Instrumentação

Orientador: Prof. Dr. Marcelo Andrade da Costa Vieira

Trata-se da versão corrigida da dissertação. A versão original se encontra disponível na EESC/USP que aloja o Programa de Pós-Graduação de Engenharia Elétrica. 
AUTORIZO A REPRODUÇÃO TOTAL OU PARCIAL DESTE TRABALHO, POR QUALQUER MEIO CONVENCIONAL OU ELETRÔNICO, PARA FINS DE ESTUDO E PESQUISA, DESDE QUE CITADA A FONTE.

Ficha catalográfica elaborada pela Biblioteca Prof. Dr. Sérgio Rodrigues Fontes da EESC/USP com os dados inseridos pelo(a) autor(a).

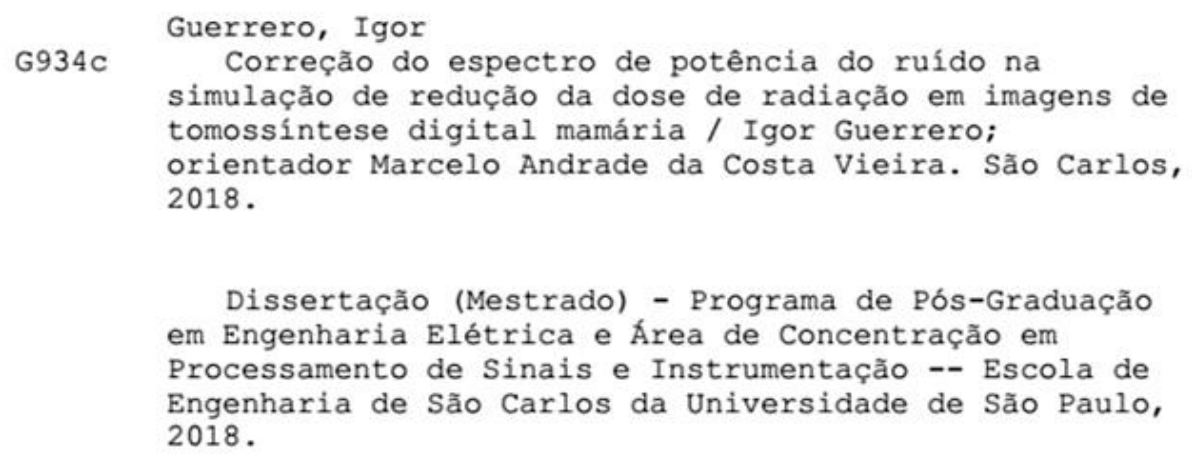

1. Tomossíntese digital mamária. 2. Redução de dose de radiação. 3. Simulação de inserção de ruído. 4. Ruído Poisson. 5. Transformada de Anscombe. 6. Espectro de potência do ruído. 7. Kernel de ruido. I. Título. 


\section{FOLHA DE JULGAMENTO}

Candidato: Engenheiro IGOR GUERRERO.

Título da dissertação: "Correção do espectro de potência do ruído na simulação de redução da dose de radiação em imagens de tomossíntese digital mamária".

Data da defesa: 21/02/2018.

Comissão Julgadora:

Resultado:

Prof. Doutor Marcelo Andrade da Costa Vieira

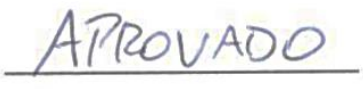

(Orientador)

(Escola de Engenharia de São Carlos/EESC)

Prof. Dr. João do Espírito Santo Batista Neto APROVADO (Instituto de Ciências Matemáticas e de Computação/ICMC)

Prof. Dr. Ricardo José Ferrari

(Universidade Federal de São Carlos/UFSCar)

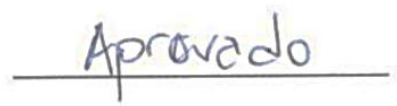

Coordenador do Programa de Pós-Graduação em Engenharia Elétrica: Prof. Associado Luis Fernando Costa Alberto

Presidente da Comissão de Pós-Graduação:

Prof. Associado Luis Fernando Costa Alberto 

À minha família 



\section{Agradecimentos}

Esse trabalho não seria possível sem o auxílio e principalmente paciência de algumas pessoas que direta ou indiretamente influenciaram em seu resultado.

Inicialmente gostaria de agradecer o professor Marcelo Andrade da Costa Vieira por todos os ensinamentos, compreensão, paciência e principalmente pela coragem de orientar um aluno sem histórico com o laboratório ou linha de pesquisa.

Ao pessoal do LAVI (Laboratório de Visão Computacional) que me receberam de maneira excepcional sempre me auxiliando sem hesitações nos momentos em que mais necessitei. Ressaltando a colaboração e gigantesca paciência do amigo Helder C. R. de Oliveira e ensinamento e compartilhamento de pesquisa do Lucas Rodrigues Borges.

Ao meu amigo Rafael Santos Moura em quem sempre pude contar.

À minha namorada Yara Boscolo Bragatto que não me deixou desanimar.

À minha família por fornecer os meios que me trouxeram até aqui.

À Universidade de São Paulo por fornecer a oportunidade e recursos para meus estudos.

Finalmente, gostaria de agradecer a OPTO Space \& Defense por me disponibilizar tempo para que eu pudesse cursar as disciplinas e comparecer às reuniões do grupo. 



\section{Resumo}

Guerrero, Igor. Correção do espectro de potência do ruído na simulação de redução da dose de radiação em imagens de tomossíntese digital mamária. 133 p.

Dissertação de Mestrado - Escola de Engenharia de São Carlos, Universidade de São Paulo, 2018.

Esse trabalho apresenta uma nova metodologia para a correção do espectro de potência do ruído no processo de simulação de aquisições de imagens de tomossíntese digital mamária (Digital Breast Tomosynthesis - DBT) com doses reduzidas de radiação. A simulação é realizada por meio da inserção de ruído quântico dependente do sinal em imagens previamente adquiridas com a dose padrão de radiação. A DBT utiliza a mesma tecnologia de raios $\mathrm{X}$ que a mamografia digital, porém com a capacidade de prover ao médico exames do volume tridimensional da mama, minimizando o problema de superposição de tecidos. Apesar de ser o sucessor da mamografia, estudos têm mostrado que a otimização da relação entre a dose de radiação e a qualidade da imagem adquirida ainda não está bem estabelecida na DBT. Devido à impossibilidade de realizar diversas exposições de radiação a uma mesma paciente para os estudos de otimização da dose de radiação, é desejável que exista um método capaz de simular com exatidão diversas exposições tendo como base uma imagem clínica de referência. Embora existam diversos métodos para a simulação da redução de dose em exames mamográficos, o mesmo não pode ser dito quanto a imagens de DBT. O método desenvolvido para simulação da redução da dose de radiação em imagens de DBT se baseia em uma abordagem de inserção de ruído por meio de uma transformada de estabilização de variância, que já foi utilizada para simulação da redução de dose em exames de mamografia digital. Porém, esse trabalho propõe a inclusão da correção do espectro de potência do ruído para otimizar o desempenho do método de inserção de ruído para exames de DBT. Os resultados obtidos mostraram que, quando comparando a imagens de referência, a as imagens simuladas apresentaram erro menores que 1\% para a análise do valor médio e desvio padrão e erro próximo de 5\% para a análise do espectro de potência, apresentado resultados até $64 \%$ melhores que métodos não otimizados para DBT.

Palavras-chave: Tomossíntese digital mamária, redução da dose de radiação, simulação da inserção de ruído, ruído Poisson, transformada de Anscombe, espectro de potência do ruído, kernel de ruído. 



\section{Abstract}

Guerrero, Igor. Noise power spectrum correction for radiation dose reduction simulation in digital breast tomosynthesis. 133 p. Master Thesis - São Carlos School of Engineering, University of São Paulo, 2018.

This work presents a new methodology for noise power spectrum correction in the simulation of digital breast tomosynthesis (DBT) images with reduced dose of radiation. The simulation is performed by inserting a signal-dependent quantum noise into previously acquired images with the standard dose of radiation. Using the same X-ray technology as a standard mammography, the DBT is capable of reconstructing the inner tissues of the patients' breasts as a three-dimensional volume, providing more resources for cancer detection than its bi-dimensional counterpart and minimizing tissue overlapping. Despite being the successor to mammography, studies have shown that the optimization of the relationship between radiation dose and image quality is not well established in DBT yet. Due to the impossibility of exposing the same patient to multiple exams with different doses each, a simulation method able to mimic clinical images with high reliability is desirable. Despite the number of methods proposed for dose reduction simulation in mammography, scarcely any may be used in DBT. The method developed for simulation of radiation dose reduction in DBT images is based on a noise insertion approach using a variance-stabilizing transformation, which has already been used to simulate dose reduction in digital mammography exams. However, this work proposes the inclusion of the noise power spectrum correction to optimize the performance of the noise insertion method for DBT exams. The results showed that, when compared with reference images, the simulated images achieved less than $1 \%$ error for mean and standard deviation values and close to $5 \%$ error for power spectrum analysis, improving in up to $64 \%$ when compared with non-optimized for DBT simulation methods.

Keywords: Digital breast tomosynthesis; Radiation dose reduction; Noise simulation; Poisson noise; Quantic noise; Anscombe transform; Noise power spectrum; Noise kernel. 



\section{Lista de Figuras}

Figura 1: Estruturas da mama.

Figura 2: Paciente durante o exame de mamografia: Década de 1950 (à esquerda) e atualmente (à direita).

Figura 3: Equipamento utilizado para o exame de mamografia digital. A mama comprimida é bombardeada por raios X. A interação da radiação com as estruturas internas gera diferentes excitações no detector.

Figura 4: Representação do efeito heel. Os elétrons bombardeados pelo catodo interagem com o material do anodo gerando raios X. Os fótons são amortizados proporcionalmente à distância percorrida dentro do anodo.

Figura 5: Esquema de funcionamento de um equipamento de DBT. Representação do emissor de raios $\mathrm{X}$ em três posições distintas e suas respectivas imagens geradas.

Figura 6: Representação da geração de fatias. (I) Dois objetos posicionados acima um do outro criam uma projeção com informação sobreposta. (II) Representação do fatiamento virtual. (III) $\mathrm{O}$ fatiamento virtual resulta em diversas fatias que representam segmentos internos dos objetos.

Figura 7: Representação da geração de fatias através da técnica Shift-and-Add. (I) Inicialmente três projeções distintas A, B e C são alinhadas. A técnica soma os valores das projeções resultando na fatia reconstruída. Alterando o posicionamento das projeções, em (II), (III) e (IV), a fatia reconstruída ressalta diferentes objetos. ...44

Figura 8: Fluxograma para exemplificar transformada de Anscombe. Um sinal S contaminado com ruído Poisson é processado dentro do domínio de Anscombe gerando três vertentes: $D_{A}, D_{B}$ e $D_{C}$. Essas vertentes sofrem a transformada inversa e retornando ao domínio do espaço.

Figura 9: Variância no domino de Anscombe e comparação da transformada inversa. (I) Relação entre sinal S e a variância dos sinais DA, DB e DC. (II) Relação entre sinal S e a transformada inversa de DA, DB e DC mostrando uma viés relativo à alteração da variância dentro do domínio de Anscombe.

Figura 10: Entradas e saídas do método proposto por Borges et al para a redução de dose em imagens mamográficas 
Figura 11: Cálculo do valor de offset e escala. Imagens não linearizadas apresentam coeficiente linear maior que zero, já imagens com dose de radiação reduzida apresentam menor intensidade quando comparadas a dose $100 \%$

Figura 12: Etapa de linearização e escalonamento das variáveis. O valor de offset é calculado baseado nas imagens uniformes é utilizado para linearizar as três imagens base. Em seguida as imagens obtidas com dose $100 \%$ têm seus valores de intensidade ajustados para condizer com o valor da imagem uniforme obtida com dose reduzida.

Figura 13: Etapa de cálculo do ruído. Uma máscara de ruído branco possui sua intensidade ajustada para condizer com o valor de variância que deve ser adicionado a imagem simulada.

Figura 14: Etapa de incorporação do ruído através da transformada de Anscombe. A imagem linearizada e ajustada e a mascara de ruído são convertidos pela transformada de Anscombe onde o ruído e inserido a imagem. Após a transformada inversa o valor de offset é adicionado para remover a linearização.

Figura 15: Equipamento Selenia Dimensions.

Figura 16: Phantom antropomórfico de propriedade do Hospital of the University of Pennsylvania. A divisão em seis fatias permite a simulação de microcalcificações na obtenção de imagens.

Figura 17: Projeção central do phantom antropomórfico em 4 doses diferentes (100\%, 85\%, $70 \%$ e $50 \%$ da esquerda para a direita respectivamente).

Figura 18: Todas as 15 projeções adquiridas com a mesma dose de radiação. .......................66

Figura 19: Ampliação das projeções inicial, central e final.

Figura 20: Fatias centrais da reconstrução em doses diferentes: $50 \%$, 70\% e $85 \%$ respectivamente

Figura 21: Região de interesse da reconstrução de doses diferentes: 50\%, 70\% e 85\% respectivamente

Figura 22: Fatias diferentes da reconstrução: 25, 35, 45, 55, 65 e 75 mm respectivamente (dose $85 \%)$.

Figura 23: Representação das projeções da tomossíntese na utilização do método proposto inicialmente para mamografia digital 2D.

Figura 24: Exemplo da importância do espectro de potência em ruído simulado. (I) Ruído com espectro de potência uniforme para todas as frequências (ruído branco). (II) 
Ruído com maior intensidade nas baixas frequências. (III) Ruído com maior intensidade nas altas frequências.

Figura 25: Exemplo de com o espectro de potência pode é alterado com o método de simulação. A curva A representa um ruído branco, B representa o espectro de potência de uma imagem ruidosa qualquer. Uma simulação ideal acarretaria na curva $\mathrm{C}$, onde a inclinação é mantida. A curva $\mathrm{D}$ representa uma simulação que altera a cor do ruído.

Figura 26: Etapas para cálculo do kernel de ruído. A imagem uniforme de referencia é segregada em diversas regiões de interesse. Cada região é enviada para o domínio de Fourier onde o valor médio é obtido. É realizada a transformada inversa e o valor final, após normalização, representa o kernel de ruído.

Figura 27: Etapa de cálculo do ruído com adição do kernel. Uma máscara de ruído branco possui sua intensidade ajustada pelo valor da variância e pelo kernel de ruído para condizer com o valor de variância que deve ser adicionado a imagem simulada .74

Figura 28: Imagem com ROIs para cálculo do valor médio e desvio padrão. À esquerda, projeção central da tomossíntese e, à direita fatia central da reconstrução.

Figura 29: Regiões utilizadas para o cálculo do espectro de potência. À esquerda, projeção central da tomossíntese e, à direita, fatia central da reconstrução.

Figura 30: Identificação das regiões utilizadas para o cálculo do erro no do espectro de potência.

Figura 31: Comparação cruzada. Cada imagem simulada é comparada com 5 imagens reais deste modo é possível aumentar os dados estatísticos melhorando a análise. .78

Figura 32: Média local dos pixels das imagens de projeção de um equipamento de DBT obtidas com um phantom homogêneo em diferentes ângulos. A imagem à esquerda corresponde à Projeção 0, adquirida com um ângulo de 7,5 à esquerda; a imagem ao centro corresponde à projeção central (Projeção 7), adquirida com ângulo $0^{\circ}$; a imagem à direita corresponde à projeção adquirida com um ângulo de 7,5ª̀ direita (Projeção 14).

Figura 33: Representação da segmentação de uma coluna em cada projeção de DBT. 81

Figura 34: Valor médio - Comparação de uma coluna de cada projeção. .81

Figura 35: Comparação do valor médio local entre diferentes doses de radiação (projeção 7).

Figura 36: Comparação do valor médio da imagem nas 15 projeções em 4 doses de radiação. 
Figura 37: Relação entre dose de entrada e valor médio dos níveis de cinza da projeção central (7) de um exame de DBT adquirido com o bloco uniforme de PMMA. ......... 84

Figura 38: Valor do offset de uma projeção de DBT pixel a pixel (projeção 07). ................... 84

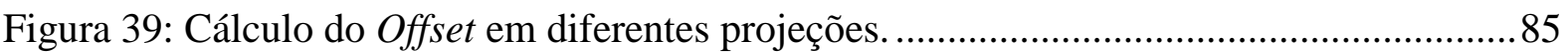

Figura 40: Desvio padrão de imagens homogêneas em diferentes projeções (0, 7 e 14

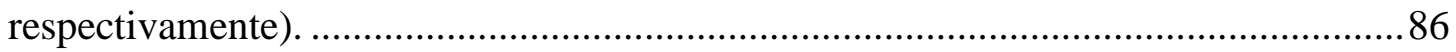

Figura 41: Desvio padrão dos valores de níveis de cinza - Comparação de uma coluna de cada projeção. 87

Figura 42: Comparação do desvio padrão da imagem nas 15 projeções em 4 doses. .87

Figura 43: Fator de escala do ruído Poisson de imagens homogêneas em diferentes projeções

(0, 7 e 14 respectivamente). .88

Figura 44: Comparação do fator de escala do ruído Poisson nas 15 projeções de DBT em 4 diferentes doses de radiação.

Figura 45: Comparação entre o tamanho das imagens de Mamografia digital e da projeção da tomossíntese mamária.

Figura 46: Comparação entre o valor médio dos níveis de cinza entre as imagens de mamografia digital e projeção de tomossíntese.

Figura 47: Imagens resultantes da relação entre mamografia e tomossíntese.

Figura 48: Comparação entre o desvio padrão dos níveis de cinza entre as imagens de mamografia digital e projeção da tomossíntese mamária.

Figura 49: Comparação entre o fator de escala do ruído Poisson entre as imagens de mamografia digital e tomossíntese mamária.

Figura 50: Comparação entre imagens de projeção reais e simuladas pelo método de Borges et al. sem kernel de ruído.

Figura 51: Erro percentual do valor médio entre as projeções simuladas pelo método de Borges et al sem kernel de ruído. .96

Figura 52: Erro percentual do desvio padrão entre as projeções simuladas sem kernel de ruído e de phantom.

Figura 53: Erro percentual do espectro de potência entre as projeções reais e simuladas pelo método de Borges et al sem kernel de ruído (ROI grande). .98

Figura 54: Espectro de potência das projeções reais e simuladas pelo método de Borges et al sem kernel de ruído para 3 doses de radiação diferentes. 
Figura 55: Erro percentual do espectro de potência entre as projeções reais e simuladas pelo método de Borges et al sem kernel de ruído em 4 quadrantes para 3 doses de radiação diferentes (ROI pequeno).

Figura 56: Comparação entre fatias reconstruídas das imagens reais e simuladas pelo método de Borges et al sem kernel de ruído. 102

Figura 57: Erro percentual entre as fatias reconstruídas das imagens reais e simuladas pelo método de Borges et al sem kernel de ruído.

Figura 58: Erro percentual do desvio padrão dos níveis de cinza (ruído) entre as fatias reconstruídas das imagens reais simuladas pelo método de Borges et al sem kernel de ruído.

Figura 59: Espectro de potência das fatias reconstruídas das imagens reais e simuladas sem kernel de ruído em 3 diferentes doses de radiação. 105

Figura 60: Erro percentual do espectro de potência (ROI grande) entre as fatias reconstruídas com imagens reais e simuladas pelo método de Borges et al sem kernel de ruído...106

Figura 61: Erro percentual do espectro de potência (ROI pequenas) entre as fatias reconstruídas com imagens reais e simuladas pelo método de Borges et al sem kernel de ruído.

Figura 62: Exemplo de kernel de ruído no domínio da frequência e espaço.......................... 108

Figura 63: Detalhes do kernel de ruído no domínio do espaço..... 109

Figura 64: Resultado da correção do espectro de potencia através da utilização do kernel de ruído em um ruído branco. A linha cinza representa o espectro de potência de uma projeção de tomossíntese, a linha tracejada laranja o espectro de uma máscara de ruído branco, que, após a correção induzida pelo kernel apresenta como resultado o espectro representado pelos pontos em azul.

Figura 65: Comparação entre imagens de phantom e simuladas com kernel de ruído projeções.

Figura 66: Erro percentual do valor médio entre as projeções simuladas com kernel de ruído e de phantom.

Figura 67: Erro percentual do desvio padrão entre as projeções simuladas com kernel de ruído e de phantom.

Figura 68: Espectro de potência das projeções simuladas e de phantom. Comparação entre imagem real, imagem simulada sem e com kernel de ruído.

Figura 69: Erro percentual do espectro de potência entre as projeções simuladas com kernel de ruído e de phantom (ROI grande).... 
Figura 70: Erro percentual do espectro de potência entre as projeções simuladas com kernel de ruído e de phantom (ROI pequeno).................................................................. 116

Figura 71: Comparação entre imagens de phantom e simuladas com kernel de ruído -

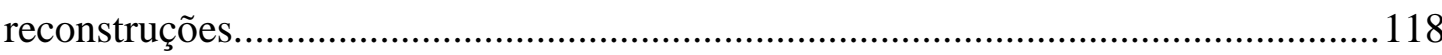

Figura 72: Erro percentual do valor médio entre as fatias simuladas com kernel de ruído e de phantom.

Figura 73: Erro percentual do desvio padrão entre as fatias simuladas com kernel de ruído e de phantom..

Figura 74: Espectro de potência das fatias simuladas com kernel de ruído e de phantom....121

Figura 75: Erro percentual do espectro de potência entre as fatias simuladas com kernel de ruído e de phantom (ROI grande).

Figura 76: Erro percentual do espectro de potência entre as fatias reconstruídas com kernel de ruído e de phantom (ROI pequeno). 


\section{Lista de Tabelas}

Tabela 1: Característica dos equipamentos de tomossíntese presentes no mercado................46

Tabela 2: Variáveis utilizadas no método proposto por Svalkvist \& Båth..............................52

Tabela 3: Relação das imagens adquiridas com o phantom. …….........................................65

Tabela 4: Relação das imagens adquiridas com o bloco homogêneo.....................................67

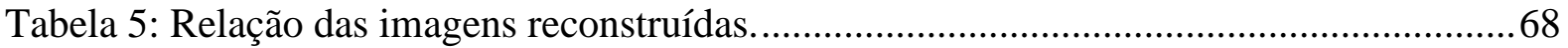

Tabela 6: Erro percentual do valor médio dos valores de pixel entre as projeções. ................83

Tabela 7: Erro percentual do desvio padrão entre projeções. ................................................ 87

Tabela 8: Comparação quantitativa entre mamografia e tomossíntese...................................94

Tabela 9: Erro percentual médio do valor médio da intensidade do pixel nas projeções simuladas pelo método de Borges et al sem kernel de ruído.......................................96

Tabela 10: Erro percentual médio do desvio padrão entre as projeções simuladas sem kernel

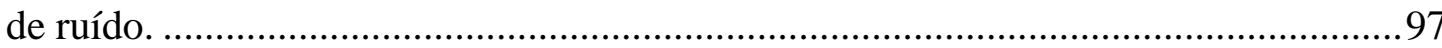

Tabela 11: Erro percentual médio do espectro de potência (ROI grande) entre as projeções reais e simuladas pelo método de Borges et al sem kernel de ruído.

Tabela 12: Erro percentual máximo do espectro de potência (ROI pequena) - projeções simuladas sem kernel de ruído.

Tabela 13: Erro percentual médio do espectro de potência (ROI pequena) - projeções simuladas sem kernel de ruído.

Tabela 14: Erro percentual médio do valor médio dos níveis de cinza entre as fatias reconstruídas das imagens reais e simuladas pelo método de Borges et al sem kernel de ruído.

Tabela 15: Erro percentual médio do desvio padrão dos níveis de cinza entre as fatias reconstruídas das imagens reais e simuladas pelo método de Borges et al sem kernel de ruído.

Tabela 16: Erro percentual médio do espectro de potência (ROI grande) entre as fatias reconstruídas com imagens reais e simuladas pelo método de Borges et al sem kernel de ruído.

Tabela 17: Erro percentual médio do espectro de potência (ROI pequena) entre as fatias reconstruídas com imagens reais e simuladas pelo método de Borges et al sem kernel de ruído. 
Tabela 18: Erro percentual médio do valor médio da intensidade do pixel nas projeções simuladas com kernel de ruído.

Tabela 19: Erro percentual médio do desvio padrão entre as projeções simuladas com kernel de ruído.

Tabela 20: Erro percentual médio do espectro de potência (ROI grande) - projeções simuladas com kernel de ruído.

Tabela 21: Erro percentual máximo do espectro de potência (ROI pequeno) - projeções simuladas com kernel de ruído.

Tabela 22: Erro percentual médio do espectro de potência (ROI pequeno) - projeções simuladas com kernel de ruído.

Tabela 23: Erro percentual médio do valor médio da intensidade do pixel nas fatias simuladas com kernel de ruído.

Tabela 24: Erro percentual médio do desvio padrão entre as fatias simuladas com kernel de ruído.

Tabela 25: Erro percentual médio do espectro de potência (ROI grande) - fatias reconstruídas com kernel de ruído.

Tabela 26: Erro percentual médio do espectro de potência (ROI pequeno) - fatias reconstruídas com kernel de ruído.

Tabela 27: Melhora percentual entre o erro percentual médio do espectro de potência dos ROI pequeno os dois algoritmos de simulação. 


\section{Lista de Siglas}

$\begin{array}{ll}\text { DBT } & \text { Digital Breast Tomosynthesis } \\ \text { DQE } & \text { Detective Quantum Efficiency } \\ \text { FDA } & \text { Food and Drug Administration } \\ \text { gl } & \text { Gray Level } \\ \text { LAVI } & \text { Laboratório de Visão Computacional } \\ \text { MTF } & \text { Modulation Transfer Function } \\ \text { NPS } & \text { Noise power spectrum } \\ \text { PMMA } & \text { Polimetil-metacrilato } \\ \text { ROI } & \text { Region of Interest } \\ \text { SNR } & \text { Signal to Noise Ratio }\end{array}$





\section{Sumário}

1. INTRODUÇÃO

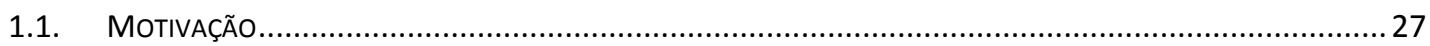

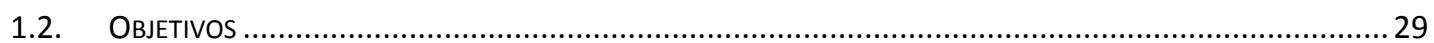

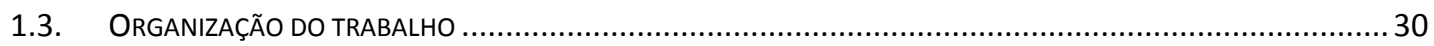

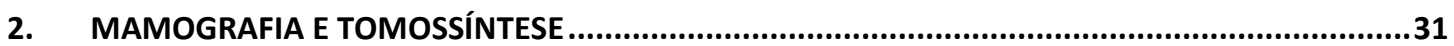

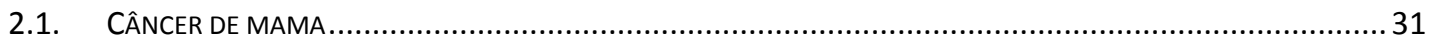

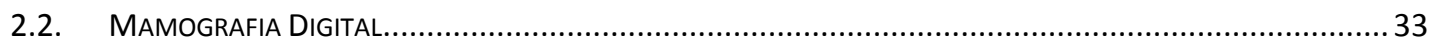

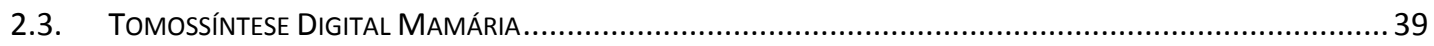

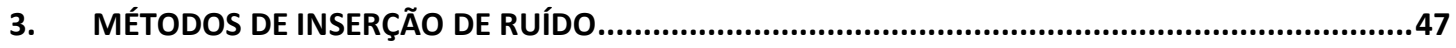

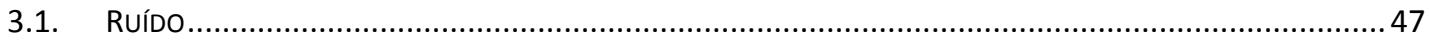

3.2. MÉTODOS DE SIMULAÇÃO DA REDUÇÃO DA DOSE DE RADIAÇÃO - ESTADO DA ARTE ................................50

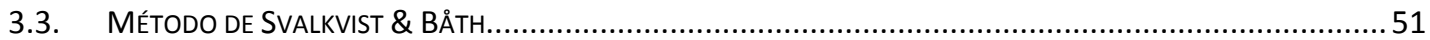

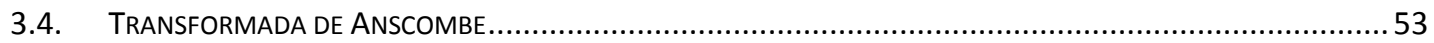

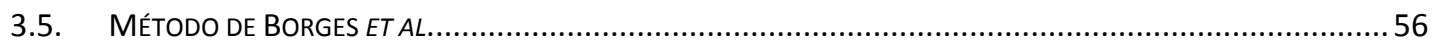

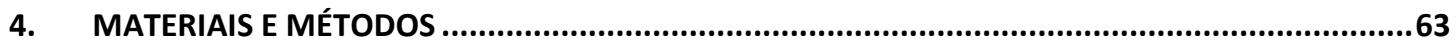

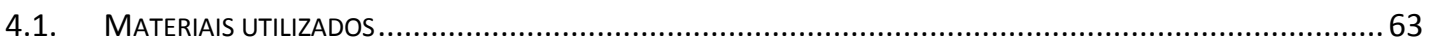

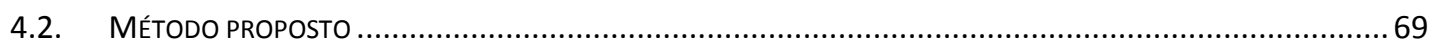

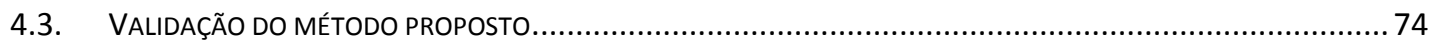

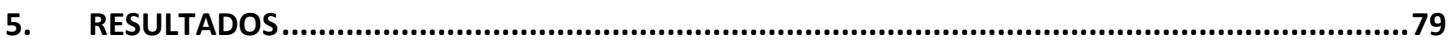

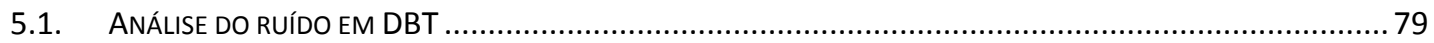

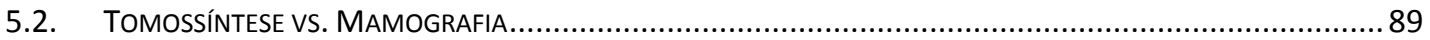

5.3. SIMULAÇÃO DA REDUÇÃO DA DOSE DE RADIAÇÃO PELO MÉTODO DE BORGES ET AL ..................................9. 94

5.4. CORREÇÃO PELO ESPECTRO DE POTÊNCIA DO RUÍDO NA SIMULAÇÃO DA REDUÇÃO DA DOSE DE RADIAÇÃO ...... 108

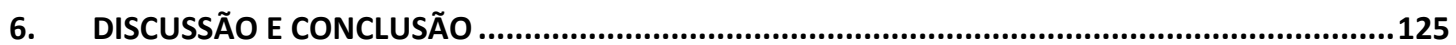

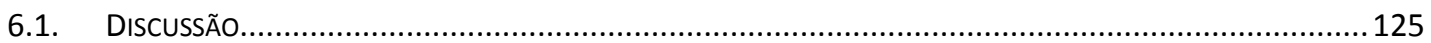

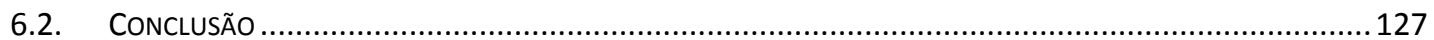

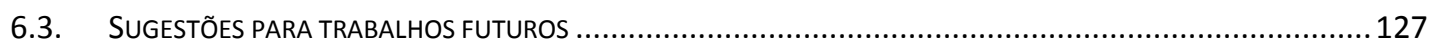

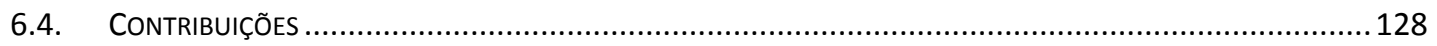




\section{Introdução}

Este capítulo é subdividido em três seções e visa introduzir o leitor a respeito das motivações que levaram ao desenvolvimento deste trabalho e seus objetivos. Adicionalmente, é detalhada a divisão estrutural do texto.

\subsection{Motivação}

O câncer de mama é o segundo tipo de câncer com maior incidência entre mulheres, ficando atrás somente do câncer de pele. Apesar de estar na segunda colocação em número de ocorrências, o câncer de mama lidera o ranking de óbitos em todo o mundo, com mais de 570 mil mortes somente no ano de 2016. No Brasil, estima-se o aparecimento de aproximadamente 58 mil novos casos em 2016, dos quais $25 \%$ resultaram em óbito (INCA, 2016).

Apesar da alta mortalidade relacionada à doença, o índice de cura da doença é elevado se detectado no início de sua formação. No âmbito local, é recomendado à própria mulher conhecer suas mamas e relatar aos especialistas qualquer alteração encontrada. Atualmente, diversos exames médicos podem ser utilizados para o rastreamento e acompanhamento da doença. Dentre esses métodos, pode-se destacar a tomografia computadorizada, ultrassonografia, mamografia e tomossíntese mamária (INCA, 2016).

Dos diversos métodos citados, o exame de mamografia é o mais utilizado por especialistas, sendo o método de rastreamento recomendado pela organização mundial de saúde para mulheres dentro da faixa etária de risco, ou seja, a partir dos 35 anos de idade (INCA, 2016). Estima-se que, no Brasil, cerca de 10.670 mulheres são salvas anualmente devido ao rastreamento precoce com exames mamográficos. Apesar do enorme benefício resultante deste exame, pesquisas mostram que a exposição continuada de mulheres à radiação ionizante pode induzir casos da doença após alguns anos (YAFFE; MAINPRIZE, 2011).

Portanto, é desejável diminuir o número de casos induzidos para garantir a segurança do exame. O único meio conhecido para a realização desta tarefa é a diminuição da dose de radiação ionizante à qual a paciente é exposta. No entanto, a qualidade da imagem mamográfica depende da dose de radiação utilizada no exame: baixas doses de radiação diminuem a relação sinal-ruído da imagem, dificultando a detecção de lesões mamárias pelos 
radiologistas (SAMEI et al., 2007) (CHAWLA et al., 2007) (SAUNDERS JR et al., 2007) (RUSCHIN et al., 2007).

Exames que envolvem radiação ionizante devem seguir o princípio ALARA (As low as reasonably achievable), que define que a dose de radiação utilizada no exame radiográfico deve ser a menor possível, desde que a imagem tenha qualidade suficiente para a análise médica. Várias pesquisas são desenvolvidas com o intuito de otimizar a relação entre dose de radiação e detecção de estruturas na imagem (SAUNDERS JR; SAMEI, 2003) (BATH et al., 2005) (SVALKVIST; BÅTH, 2010).

Para a otimização das doses de radiação são necessárias imagens clínicas, de um mesmo paciente, obtidas com diferentes doses de radiação. No entanto, na prática, essas imagens são de difícil obtenção. É inviável a utilização de pacientes, já que seriam necessárias múltiplas exposições com diferentes doses de radiação, o que elevaria consideravelmente o risco de indução do câncer de mama. A utilização de phantoms é possível, mas o mercado apresenta pequena variação de modelos, impossibilitando sua utilização para uma análise estatística da detecção em grande escala de variações anatômicas da mama.

Nesse sentido, os estudos do impacto da redução da dose de radiação no diagnóstico médico foram conduzidos a partir de métodos de simulação, que em geral efetuam a inserção de ruído quântico em imagens previamente adquiridas na dose padrão do exame, simulando aquisições com doses reduzidas. Diversos métodos de simulação de redução de dose foram desenvolvidos para suprir essa deficiência e fornecer imagens clínicas em diferentes doses de radiação (SVALKVIST; BÅTH, 2010) (BORGES et al., 2015) (VELDKAMP et al., 2009) (MACKENZIE et al., 2014) (BATH et al., 2005) (SAUNDERS JR; SAMEI, 2003). No entanto, nenhum método ainda havia sido proposto para a simulação da redução de dose em imagens de tomossíntese digital mamária (Digital Breast Tomosynthesis - DBT).

Apesar de ser o exame mais utilizado para o rastreamento do câncer de mama, a mamografia digital vem aos poucos sendo substituída pela DBT. A natureza bidimensional da mamografia causa sobreposição de tecidos mamários, que podem encobrir algumas lesões nas mamas que poderiam indicar um câncer em formação. O exame de DBT utiliza uma técnica pseudo-tomográfica que adquire múltiplas imagens em ângulos distintos de um mesmo objeto, possibilitando uma reconstrução semi-tridimensional. Essa reconstrução fornece fatias tomográficas da mama que permite ao médico analisar as imagens sem o problema da sobreposição de tecidos, melhorando os índices de detecção precoce do câncer de mama se 
comparados com a mamografia tradicional (SECHOPOULOS, 2013) (TEERTSTRA et al., 2010).

Mesmo possibilitando a criação de imagens melhores, o nível de radiação ionizante utilizado em cada imagem da tomossíntese deve ser menor, para que, com a soma de todas as imagens, a paciente receba dose similar à mamografia convencional. Assim, as imagens de projeção da DBT são mais corrompidas por ruído do que as imagens de mamografia digital 2D (YOUNG; ODUJO, 2008). Além disso, por se tratar de uma tecnologia relativamente nova, a otimização da relação entre a dose de radiação utilizada na aquisição das imagens e a qualidade da imagem gerada ainda não está bem estabelecida para a DBT. A demora na realização deste estudo está relacionada às características geométricas do exame de DBT que diferem do exame de mamografia digital 2D, além de algumas diferenças intrínsecas no processo de aquisição das imagens de projeção, que fazem com que o ruído presente nas imagens de DBT seja significativamente diferente do ruído presente nas imagens de mamografia digital 2D. Essas características acabam tornando inviável a simples transposição das ferramentas utilizadas em mamografia digital para DBT (YOUNG; ODUJO, 2008) (SECHOPOULOS, 2013).

\subsection{Objetivos}

O objetivo deste trabalho é, inicialmente, realizar um estudo sobre as características de ruído das imagens de DBT. A partir desse estudo, adaptar um método de simulação de redução de dose de radiação, previamente desenvolvido para mamografia digital 2D (BORGES et al., 2015), a fim de viabilizá-lo para sua utilização em DBT.

Em geral, o método citado adiciona uma máscara de ruído branco dependente do sinal às imagens clínicas que foram obtidas com doses padrão de radiação. $\mathrm{O}$ problema dessa abordagem é que o ruído presente nas imagens de DBT nem sempre é branco, gerando divergências na imagem simulada quando comparadas às imagens reais.

Assim, é desejável propor uma nova abordagem para correção do espectro de potência do ruído (Noise Power Spectrum - NPS) na simulação da redução da dose de radiação em imagens de DBT, de modo a incluir no modelo de Borges et al informações da dependência do ruído com a frequência espacial.

As imagens de tomossíntese com dose reduzida podem ser utilizadas em trabalhos futuros para estabelecer o ponto de operação da relação dose versus qualidade para os exames 
de DBT e alimentar métodos de filtragem de ruído que asseguram a qualidade da imagem no ponto de vista de detecção de anomalias. Se esses estudos obtiverem resultados satisfatórios, possibilitarão uma diminuição na dose de radiação recebida pela paciente, diminuindo os casos de câncer induzido pelos exames de rastreio do câncer de mama.

\subsection{Organização do trabalho}

Este trabalho está dividido em seis capítulos, que visam detalhar todas as etapas da pesquisa, abrangendo informações sobre o câncer de mama, as pesquisas relacionadas, os dados obtidos e, finalmente, os resultados e conclusões atingidas.

Este primeiro capítulo tem por objetivo criar uma visão geral do trabalho, introduzindo as noções básicas ao leitor. O segundo capítulo explica mais detalhadamente os assuntos motivadores a esse trabalho, abrangendo a situação atual do rastreio do câncer de mama e os equipamentos utilizados para a detecção precoce da doença.

O capítulo três explora os métodos existentes para a simulação de redução de dose em imagens mamográficas. Além disso, explica brevemente a transformada de Anscombe, que é uma ferramenta fundamental para o método de simulação escolhido a ser implementado para a simulação de redução de dose em imagens de tomossíntese mamária.

O novo método proposto e a maneira como ele será implementado e testado são tópicos explicados no capítulo quatro. Os resultados obtidos para a análise das imagens homogêneas e os erros percentuais encontrados na comparação das imagens simuladas com imagens reais são tópicos para o quinto capítulo.

Finalmente, o capítulo seis apresenta as discussões e conclusões obtidas por esse trabalho até o momento e os possíveis passos a serem dados para sua continuidade. 


\section{Mamografia e Tomossíntese}

Este capítulo é subdividido em três seções e visa contextualizar o leitor acerca dos principais fatores que levaram ao desenvolvimento deste trabalho. A primeira seção tem por objetivo detalhar informações sobre o câncer de mama e os motivos que fazem com que sua detecção precoce seja tão importante. A segunda seção apresenta a fundo o equipamento mais importante para o rastreio do câncer de mama: o mamógrafo.

Finalmente a última seção visa introduzir o leitor ao equipamento de tomossíntese digital mamária, relatando suas similaridades e diferenças com o equipamento de mamografia convencional.

\subsection{Câncer de mama}

A mama humana é a coleção de tecidos adiposos, conectivos e glândulas presentes entre a pele e a parede do músculo peitoral maior. Cada mama possui entre 15 e 20 glândulas (ou lóbulos) que, após o período de gravidez, produzem leite, que serve de alimento ao recémnascido. O leite é escoado através dos dutos até o mamilo. Essas estruturas podem ser vistas na Figura 1 (DOLINSKY; HILL-KAYSER, 2016).

A aparência externa da mama é diretamente relacionada à quantidade de tecidos adiposos e conjuntivos, não tendo qualquer relação com a quantidade ou capacidade produtiva das glândulas mamárias. Seres humanos do sexo masculino apresentam a mesma estrutura mamária que as fêmeas, com a exceção da produção do leite, devido à baixa quantidade do hormônio estrogênio (DOLINSKY; HILL-KAYSER, 2016).

Conjunto de células que apresentam um crescimento anormal ou fora de controle são denominadas de tumores. Tumores malignos, ao contrário dos benignos, são aqueles que possuem a habilidade de crescer e se espalhar por outros tecidos ou partes do corpo. Tumores malignos localizados dentro dos tecidos da mama levam o nome de câncer de mama (DOLINSKY; HILL-KAYSER, 2016). 


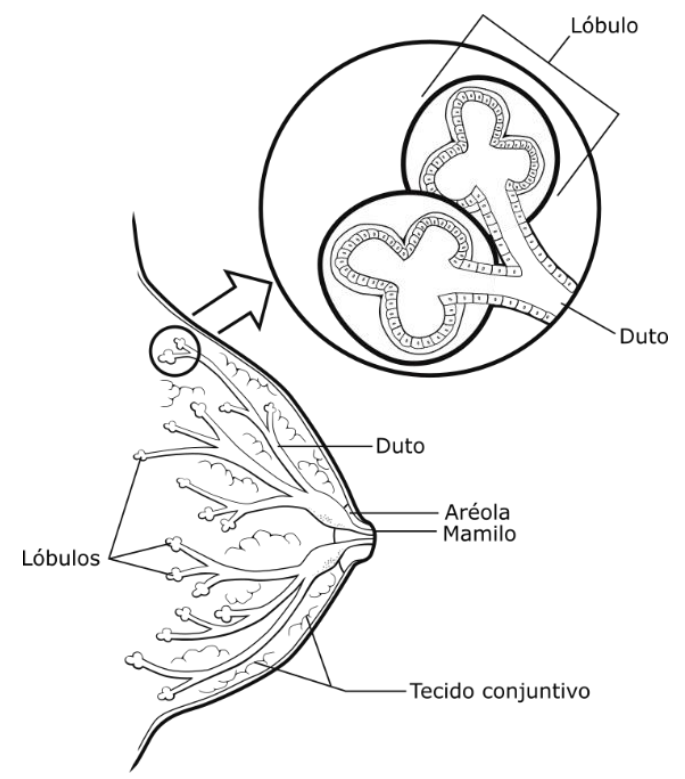

Figura 1: Estruturas da mama.

Fonte: (AMERICAN CANCER SOCIETY, 2015)

Apesar do câncer de mama ser o segundo tipo de câncer com maior incidência entre as mulheres, perdendo para os casos de pele não melanoma, é o tipo de câncer com maior número de óbitos - 570 mil óbitos em todo o planeta foram registrados somente no ano de 2016. Com esses números, o câncer de mama representou $25 \%$ do total de casos de câncer no mundo (INCA, 2016).

Os hormônios estrogênio e progesterona auxiliam no crescimento de células cancerígenas, fazendo com que mulheres sejam aproximadamente 100 vezes mais propícias a desenvolverem câncer de mama que homens. Apesar da baixa probabilidade, estima-se que, no ano de 2015, mais de 2 mil novos casos de câncer foram diagnosticados em homens nos Estados Unidos (DOLINSKY; HILL-KAYSER, 2016).

Se diagnosticado tardiamente, o câncer de mama apresenta altos índices de mortalidade, principalmente em países subdesenvolvidos ou com déficits de recursos médicos. No entanto, se a doença for diagnosticada nos seus estágios inicias, a probabilidade de cura é significativamente maior, fazendo com que a principal forma de combater a doença seja o diagnóstico precoce. Políticas de rastreio da doença em pacientes com a faixa etária de maior risco, mulheres com 40 anos de idade ou a partir dos 35 anos se existir casos da doença na família, se mostraram altamente efetivas no combate à mortalidade (OMS, 2016). 
Com uma grande vantagem sobre outras modalidades de imagens médicas, a mamografia por raios $X$ provou ser o método mais efetivo para o rastreio e tratamento da doença. Realizada anualmente até os 70 anos de idade e a cada 2 anos após esse período, esse exame possibilita a visualização dos elementos internos à mama de uma maneira simples e confiável (OMS, 2016).

Apesar dos benefícios que o exame proporciona, a exposição frequente à radiação ionizante pode induzir casos de câncer em pacientes que não apresentariam a doença caso não o realizassem. Estudos recentes mostraram algumas estimativas sobre a indução do câncer de mama pelo rastreamento e concluíram que a cada 100 mil mulheres que recebem a dose padrão de 3,7mGy de radiação em ambas as mamas, anualmente, entre as idades de 40 e 55 anos, e bianualmente até os 74 anos, serão induzidos 86 casos de câncer, que acarretarão em 11 óbitos (YAFFE; MAINPRIZE, 2011).

O maior problema quanto ao diagnóstico a partir de imagens mamográficas é que, devido à sua natureza bidimensional, as imagens apresentam elevada taxa de sobreposição de tecidos. Durante a aquisição de imagens, os tecidos posicionados próximos ao sensor são obscurecidos por tecidos superiores causando uma ausência de informação na imagem final. Com o intuito de contornar este problema, nos últimos anos o exame de tomossíntese digital mamária vem ganhando espaço como o exame sucessor da mamografia digital no rastreamento do câncer de mama. Ao utilizar múltiplas aquisições de baixa dose para a posterior reconstrução do volume mamário, a tomossíntese suprime a sobreposição de tecidos presente na mamografia 2D e possibilita um diagnóstico mais preciso, aumentando a detecção e, logo, índices de cura da doença (SECHOPOULOS, 2013).

\subsection{Mamografia Digital}

Em 1913, Albert Salomon publicou um estudo da análise de tecidos mamários a partir da utilização de imagens radiográficas. Em suas conclusões, mostrou ser possível a diferenciação entre tecidos saudáveis e tumores. Por causa da primeira guerra mundial, as pesquisas foram paralisadas, e somente em 1927 trabalhos relacionados ao tema voltaram a ser publicados (GOLD; BASSETT; WIDOFF, 1990).

Na década de 1930 o radiologista Stafford L. Warren reportou a utilização de um exame denominado mamografia em 119 pacientes, previamente à cirurgia mamária. De acordo com o 
especialista, na maioria dos casos não havia unanimidade de opinião quanto ao diagnóstico prévio à cirurgia, mas, com a utilização do exame, muito frequentemente os diagnósticos se mostravam corretos. Na realidade, somente 8 casos mostraram discrepância entre o diagnóstico baseado na imagem radiográfica e o encontrado na realidade (GOLD; BASSETT; WIDOFF, 1990).

Os resultados obtidos motivaram e impulsionaram as pesquisas na área. Nos anos seguintes, diversas pesquisas e conferências foram realizadas. Estudos constataram a eficácia do exame para o rastreamento do câncer de mama, relatando diminuição de mortes em grupos de pacientes que realizaram exames preventivos regularmente. Na década de 1960 a mamografia passou a ser um método confiável e em crescente disseminação (GOLD; BASSETT; WIDOFF, 1990).

Os movimentos feministas da década de 1970 tiveram alto poder de influência e fizeram crescer exponencialmente a procura pelo exame. Junto à popularização da mamografia, foram noticiadas as primeiras críticas em larga escala ao método (DAVIS, 2010). Até esse momento, os exames eram realizados em equipamentos de radiografia genéricos, onde o operador ajustava a tensão e corrente de exposição conforme desejado, mas em 1973 a empresa DuPont lançou no mercado o primeiro equipamento radiográfico desenvolvido especificamente para exames mamográficos, gerando imagens com melhor qualidade do que os anteriores (GOLD; BASSETT; WIDOFF, 1990). Devido ao grande número de exames realizados e à crescente preocupação quanto à qualidade dos resultados, os Estados Unidos criaram, em 1992, o Mammography Quality Standards Act, norma reguladora para equipamentos e exames mamográficos (GOLD; BASSETT; WIDOFF, 1990).

No início do século XXI foi introduzida no mercado a mamografia digital. Imperceptível ao usuário, a substituição do filme fotográfico por detectores digitais provocou melhorias na qualidade de imagem e maior contraste, principalmente em mamas densas e espessas (JOE, 2015).

Atualmente, a mamografia digital é considerada o método mais adequado para rastreamento e acompanhamento de doenças mamárias, possuindo protocolos de utilização próprios e elevado nível de segurança à paciente (JOE, 2015). A Figura 2 mostra uma representação da utilização de um equipamento moderno em contraponto a um equipamento de 1951. 

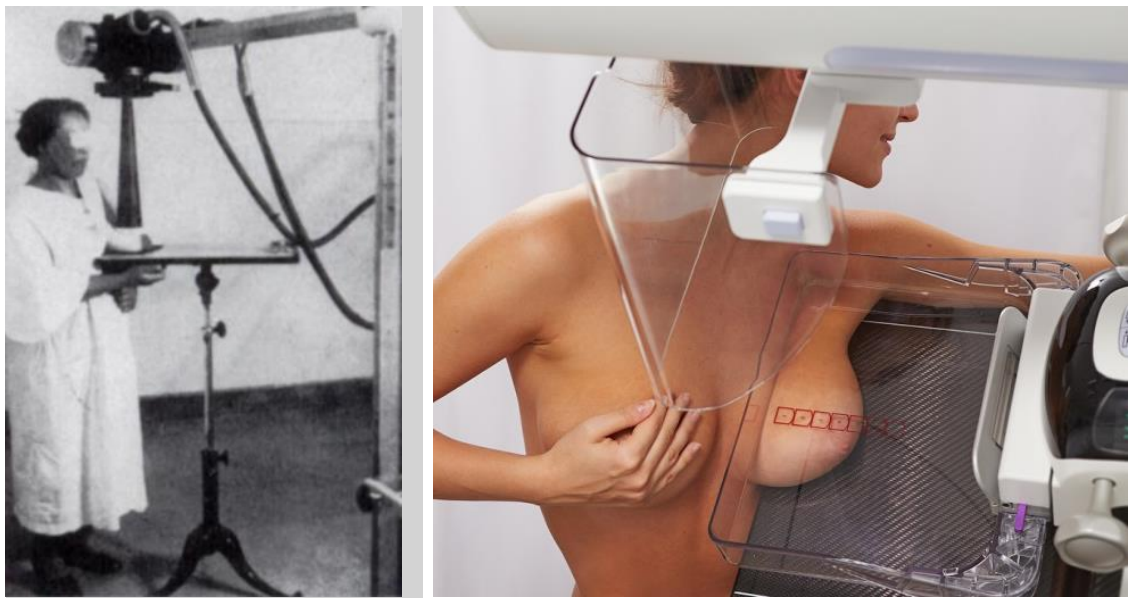

Figura 2: Paciente durante o exame de mamografia: Década de 1950 (à esquerda) e atualmente (à direita).

Fonte: (GOLD; BASSETT; WIDOFF, 1990) (ARS MEDICINAS CENTRS, 2017)

Apesar de existirem diversas marcas de mamógrafos digitais no mercado, todos possuem a mesma estrutura e modo de utilização. A Figura 3 mostra um modelo esquemático dos elementos constituintes de um equipamento mamográfico digital. Cada elemento da figura é descrito a seguir:
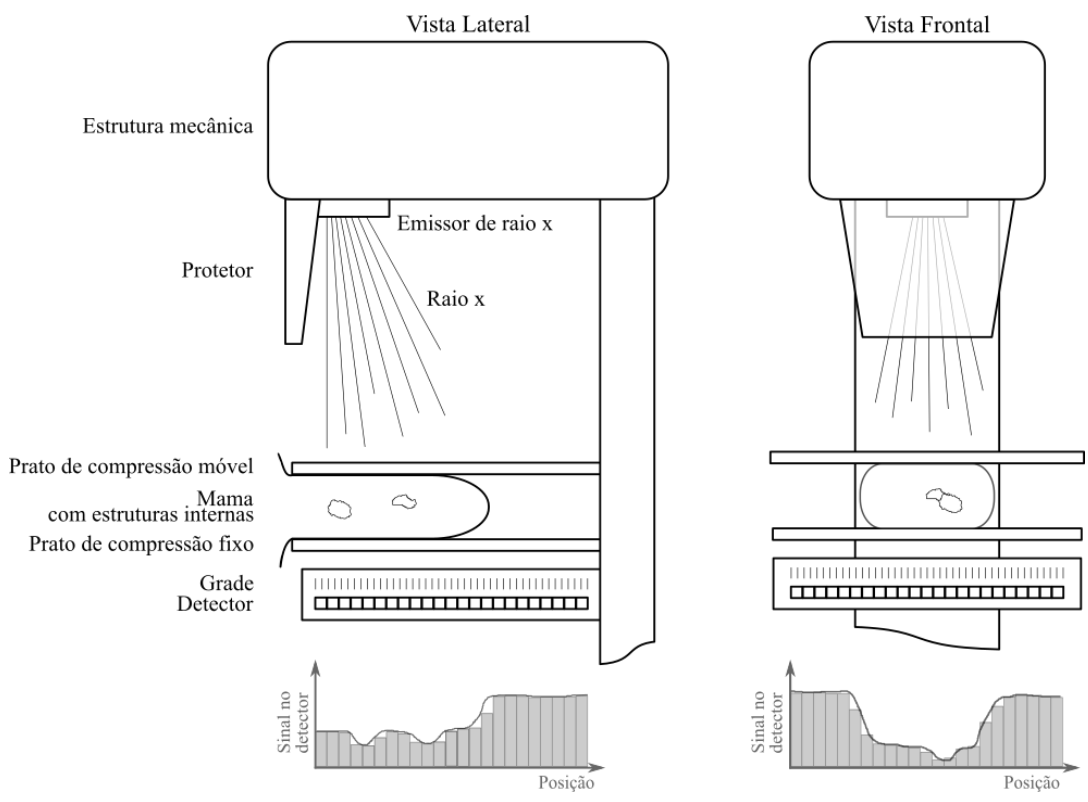

Figura 3: Equipamento utilizado para o exame de mamografia digital. A mama comprimida é bombardeada por raios X. A interação da radiação com as estruturas internas gera diferentes excitações no detector. 
$\mathrm{O}$ mamógrafo basicamente é uma máquina de raios $\mathrm{X}$ modificada para acomodar a paciente da melhor maneira possível. Na parte superior encontra-se um tubo emissor de raios $\mathrm{X}$, suportado por uma estrutura mecânica. Devido às características dos tecidos mamários, a tensão utilizada no tubo é menor quando comparada com outros exames radiográficos (YAFFE, 2000).

Os materiais que compõem o anodo (alvo) e filtro do tubo de raios $\mathrm{X}$ apresentam alta importância para a caracterização do espectro da radiação gerada. Previamente definidos pelos fabricantes, a maioria dos materiais utilizados possuem alto número atômico, como, por exemplo, molibdênio, ródio, tungstênio e até mesmo alumínio (KIMME-SMITH, 1999).

A dose de radiação ionizante utilizada deve ser grande o bastante para que os raios atravessem os tecidos e produzam imagens de boa qualidade, possibilitando um diagnóstico correto, porém pequena o suficiente para não causar danos à paciente. Esse comprometimento é o principal incentivo para a pesquisa de novas tecnologias a fim de melhorar a relação entre a qualidade da imagem mamográfica e a dose de radiação utilizada no exame, e é conhecido pelo nome de ALARA (as low as reasonably achievable).

Uma mama humana apresenta formato complexo e de difícil imageamento. A região conectada ao músculo peitoral apresenta espessura consideravelmente maior que a região areolar. Essa diferença de espessura ocasiona diferentes interações entre os fótons de raios X e os tecidos. Nas primeiras imagens de mamografia obtidas, era comum a imagem resultante apresentar uma grande mancha branca na borda externa devido ao baixo número de fótons que atingiam os filmes (JOE, 2015). Para solucionar essa assimetria, os equipamentos atuais utilizam pratos de compressão que planificam a região superior e inferior da mama, uniformizando a distribuição de tecidos (JOE, 2015).

Os fótons possuem direção definida no momento de sua geração, seguindo em linha reta a partir do anodo, através dos tecidos mamários, até serem absorvidos pelo elemento detector. No entanto, interações da radiação com os tecidos mamários podem ocasionar a criação de radiação espalhada (YAFFE, 2000). Esses fótons são prejudiciais à geração de imagens, já que inserem informações em locais incorretos, causando perda de resolução espacial (borramento). Para amenizar esse problema é inserida uma grade próxima ao detector para impedir que esses fótons atinjam o detector. Essa grade pode apresentar estrutura linear ou celular, sendo composta por diversas camadas de elementos transparentes ou opacos à 
radiação. Para diminuir a influência da espessura da parede da grade na geração da imagem, esta fica em constante vibração durante o exame (REZENTES; ALMEIDA; BARNES, 1999).

Devido à sua estrutura, raios que entram perpendicularmente ao plano da grade a atravessam sem dificuldades, porém raios que apresentam angulação diferente da esperada colidem com as paredes opacas e são absorvidos. A relação entre a radiação incidente à placa e a que consegue ultrapassá-la é denominada Bucky factor. Em um mesmo aparelho essa relação varia em decorrência da tensão utilizada na geração da radiação (REZENTES; ALMEIDA; BARNES, 1999).

Os fótons que atravessam a grade finalizam sua jornada colidindo com o elemento sensível que gera a imagem. Originalmente eram utilizados filmes plásticos cobertos com uma emulsão de materiais sensíveis a radiação. $\mathrm{Na}$ presença de fótons, os componentes reagiam marcando o local. Apesar de ser substituída pelos sensores digitais, a radiografia em filme apresentava diversos benefícios como: baixo custo; alta resolução espacial; possibilidade de análise em caixa de luz e a característica logarítmica de reação à atividade ótica (YAFFE, 2000).

O tamanho de cada elemento sensível e sua quantidade presente no detector define a resolução espacial do equipamento. Com essa medida é possível determinar o menor elemento que pode ser reproduzido em imagem com o equipamento, utilizando o teorema de Nyquist (YAFFE, 2000).

Devido ao não paralelismo entre os fótons de raios $\mathrm{X}$, estruturas anatômicas mais distantes do plano detector são representadas com uma maior magnificação que estruturas mais próxima. Esse efeito é intrínseco ao sistema e não pode ser evitado. O especialista sempre deve levar esse feito em conta ao analisar as dimensões de diversas estruturas em uma mesma mama (YAFFE, 2000).

$\mathrm{O}$ tubo de raios $\mathrm{X}$ em equipamentos mamográficos é projetado para otimizar a qualidade da radiação gerada na geração dos raios $\mathrm{X}$, os elétrons são bombardeados pelo catodo e penetram uma pequena distância dentro do material do alvo. As interações entre os elétrons e os átomos que constituem o alvo geram os fótons de raios $\mathrm{X}$ em diversas direções. Os fótons significativos para o exame são os que se encaminham em direção ao detector. Na Figura 4 é possível ver uma representação esquemática deste processo (BOONE, 2000). 


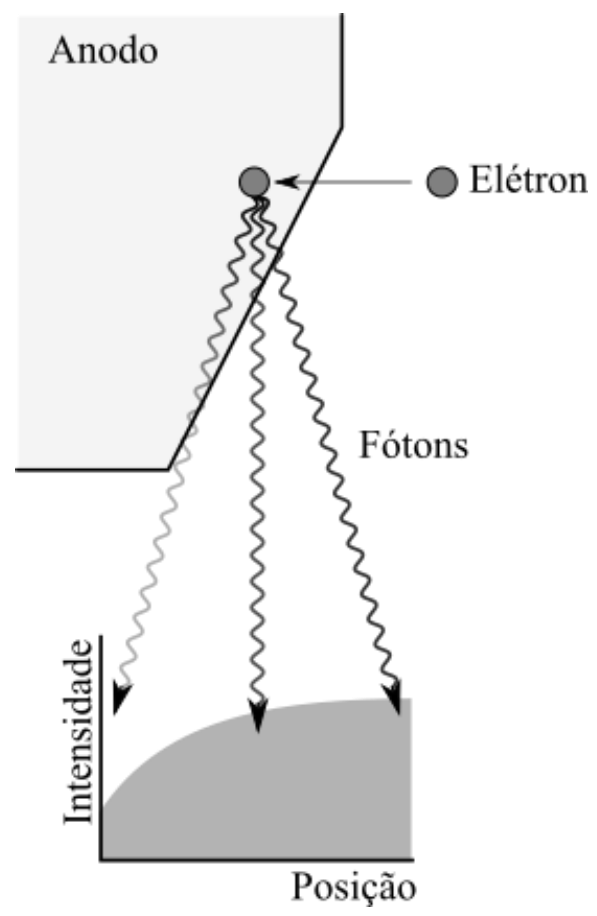

Figura 4: Representação do efeito heel. Os elétrons bombardeados pelo catodo interagem com o material do anodo gerando raios X. Os fótons são amortizados proporcionalmente à distância percorrida dentro do anodo.

Fonte: adaptado de (BOONE, 2000)

Devido ao alto teor enérgico do bombardeamento de elétrons, a parede do anodo deve ser inclinada, a fim de aumentar a área onde os raios $\mathrm{X}$ são formados (ponto focal), favorecendo a dissipação térmica. Devido a essa inclinação, os fótons que se direcionam ao detector percorrem diferentes trajetórias dentro do anodo, e, com isso, fótons que atravessam um caminho maior dentro de elementos com alto número atômico são mais amortizados que fótons que atravessam um caminho menor (Figura 4). Nos tubos de raios X utilizados em mamografia, os fótons que atravessam menor caminho dentro do detector, ou seja, mais próximos ao catodo, são utilizados para imagear a região da mama mais próxima à paciente. Adicionalmente, os fótons mais próximos ao anodo necessitam seguir um maior caminho pelo ar até atingirem o detector, e por isso esses fótons sofrem novamente maior atenuação.

A pequena diferença de energia entre os fótons gerados próximos ao anodo e ao catodo é suficiente para criar uma não uniformidade na imagem, mesmo se um objeto uniforme é irradiado. Esse fenômeno é denominado efeito heel (BOONE, 2000). A fim de minimizar esse efeito, o ganho de cada detector é calibrado de forma independente para que a imagem seja a mais uniforme possível. Essa calibração é realizada posicionando um bloco uniforme de 
acrílico polimetil-metacrilato (PMMA) sobre o prato de compressão fixo e realizando a aquisição de uma imagem. Devido à homogeneidade do bloco, a imagem deve apresentar mesmo valor de intensidade em todos os pixels. Como isso não ocorre, o software utiliza essa imagem para calcular ganhos individuais para cada pixel, com o objetivo de uniformizar a imagem artificialmente (BOONE, 2000).

Após a calibração, denominada flat-fielding, todos os pixels apresentam valor médio de intensidade muito próximos, uniformizando a imagem, porém, ao multiplicar o valor de correção pixel a pixel, a calibração multiplica também o valor do ruído presente no sinal, ocasionando que regiões que sofreram maior correção de flat- fielding apresentem maior ruído.

\subsection{Tomossíntese Digital Mamária}

A primeira menção histórica quanto à técnica da tomossíntese foi publicada em 1935 pelo neuroradiologista holandês Bernard George Ziedses des Plantes. Foi descrito que, com o método, seria possível a visualização de infinitos planos paralelos de um objeto em decorrência de algumas poucas exposições do mesmo (GOODSITT, 2014).

Utilizando um aparelho de raios $\mathrm{X}$, foram adquiridas quatro exposições, deslocadas de $90^{\circ}$, de um mesmo objeto. Através de um conjunto de espelhos, os filmes analógicos eram alinhados, a fim de criar a ilusão de fatias de reconstrução. Outras pesquisas foram realizadas, mas a técnica não apresentou grandes avanços durante os anos subsequentes (GOODSITT, 2014).

Na década de 1980 foi lançado o primeiro aparelho comercial para a realização da tomossíntese. Para garantir a qualidade das imagens, era utilizado um filme especial para a época, capaz de capturar mais de duas imagens por segundo e com alta sensibilidade. O tubo emissor de raio $\mathrm{X}$ apresentava uma trajetória circular de $360^{\circ}$ em torno do objeto, e durante o movimento eram disparadas oito projeções igualmente espaçadas. Por meio de uma caixa de luz composta por diversos espelhos, o especialista podia observar a reconstrução em fatias espaçadas em 2mm (GOODSITT, 2014).

Com o advento de detectores digitais, em 1997, foi desenvolvido o primeiro protótipo de equipamento especializado em tomossíntese digital mamária (Digital Breast Tomosynthesis - DBT). Construído a partir de um equipamento comercial, o protótipo apresentava órbita parcial e realizava nove aquisições espaçadas em $5^{\circ}$ entre si (GOODSITT, 2014). Através desta 
pesquisa, concluiu-se que a técnica possuía a capacidade de aperfeiçoar os resultados obtidos pela mamografia convencional, aumentando a detecção precoce de lesões, especialmente em mulheres com mamas densas (GOODSITT, 2014).

Em 2011, o órgão regulamentador dos Estados Unidos (Food and Drug Administration - FDA) aprovou a comercialização do primeiro equipamento comercial de DBT para ser utilizado no rastreamento do câncer de mama. Desde então, outros modelos foram lançados no mercado, mas todos apresentam a mesma estrutura exemplificada na Figura 5.

Apesar de ser uma tecnologia recente, o exame de tomossíntese apresenta rápido crescimento entre a comunidade médica. Uma pesquisa conduzida em 2014 mostrou que 27\% dos médicos membros da Society of Breast Imaging, nos Estados Unidos, estavam utilizando DBT para exames clínicos, e que $62 \%$ dos médicos que ainda não possuem o equipamento planejavam obtê-lo (HARDESTY, KREIDLER e GLUECK, 2014).

A principal característica da DBT é um pequeno deslocamento do tubo de raios $\mathrm{X}$ durante a aquisição das imagens, considerando uma trajetória circular ao redor do objeto a ser imageado. Usualmente, em tomossínteses mamárias, o centro de rotação do tubo se encontra alguns centímetros acima da base, próximo ao centro da mama (na Figura 5, o centro de rotação coincide com o objeto esférico) (GLICK, 2014).

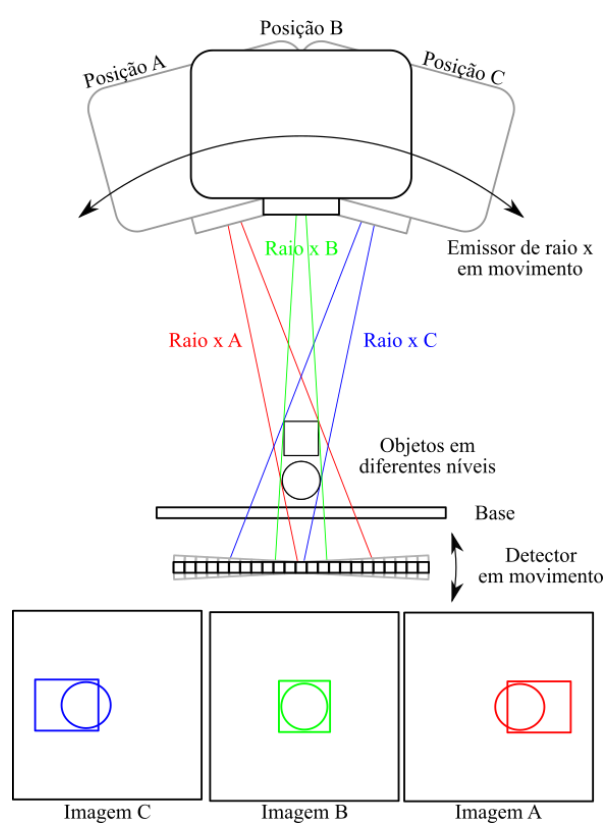

Figura 5: Esquema de funcionamento de um equipamento de DBT. Representação do emissor de raios $\mathrm{X}$ em três posições distintas e suas respectivas imagens geradas. 
Ao utilizar diferentes ângulos de incidência, o equipamento é capaz de adquirir imagens em diversas perspectivas de um mesmo objeto. Essas imagens, chamadas de projeções, são processadas para se obter a reconstrução do volume tridimensional da mama, fornecendo imagens de fatias do objeto em planos paralelos ao detector. Objetos em diferentes alturas dentro da mama são imageados de maneira diferente em projeções distintas, removendo, assim, a sobreposição de sinal presente em mamografias convencionais (SECHOPOULOS, 2013).

Na Figura 5 são desenhadas três posições distintas para representar o movimento do tubo de raio $\mathrm{X}$. As linhas coloridas representam o feixe de radiação em cada posição, possibilitando a geração de três projeções distintas. Tipicamente, o tubo de raio X apresenta movimento de arco ao redor do centro de rotação no plano perpendicular ao detector, e paralelo à sua lateral maior. Os equipamentos existentes no mercado apresentam amplitude total de movimento variável entre $15^{\circ}$ e $50^{\circ}$ (GLICK, 2014).

Pesquisas mostram que a utilização de movimentos complexos no tubo (e.g.: movimento senoidal, hipocicloidal, entre outros) podem melhorar a qualidade das imagens reconstruídas, já que permitem a visualização de mais pontos de vista de um mesmo elemento e diminuem as regiões obscuras. Apesar dessa vantagem teórica, nenhum equipamento comercial apresenta padrão de movimento diferente do linear até o presente momento. Isso é devido ao alto custo construtivo e de manutenção agregado ao produto (STEVENS; PELC, 2014).

Durante o movimento do tubo são adquiridas diversas projeções, geralmente com ângulos equidistantes entre si. Equipamentos atuais apresentam números variados de projeções, podendo variar de 7 a 70, dependendo do fabricante (STEVENS; PELC, 2014). Não existe um consenso quanto ao ângulo de movimento do tubo e número de projeções, e cada fabricante utiliza valores diferentes. A utilização de um menor ângulo de movimento resulta em uma melhor resolução espacial nas imagens das fatias (eixo x-y) mas uma resolução menor entre as fatias (eixo z), enquanto um ângulo maior diminui a resolução espacial x-y e melhora a resolução em z (GLICK, 2014).

Estudos mostram que, após um número mínimo de projeções, amostras extras não melhoram significativamente a qualidade da reconstrução. A quantidade ideal de projeções está diretamente relacionada com o ângulo de movimento do tubo, e foi concluído, experimentalmente, que os melhores parâmetros para um equipamento seriam 13 projeções em um angulo total de $60^{\circ}$ (SECHOPOULOS; GHETTI, 2009). 
Uma aquisição mais rápida é realizada disparando o feixe de raio $\mathrm{X}$ durante $\mathrm{o}$ movimento do tubo. Denominada de aquisição continua (Continuous Tube Motion - CTM), esse método diminui significativamente o tempo de duração do exame, à custa de um pequeno borramento de movimento nas projeções (STEVENS; PELC, 2014). Outro modo existente é o de aquisição pausada (Step-and-Shoot - SAS). Em contraponto à aquisição contínua, esse modo para o movimento do tubo antes do disparo. Após a obtenção da imagem, o tubo se movimenta até o próximo ponto de disparo, onde anula sua velocidade novamente (STEVENS; PELC, 2014).

Esse movimento é realizado quantas vezes forem necessárias para a aquisição de todas as projeções. Apesar de eliminar o borramento por movimento, esse método exige mais tempo para ser finalizado, aumentando assim a duração do exame e o tempo em que a paciente deve ter a mama comprimida (STEVENS; PELC, 2014).

Alguns aparelhos também apresentam rotação do plano detector proporcionalmente à rotação do tubo. Apesar de mecanicamente mais complexo, a rotação do detector garante uma menor variação quanto ao ângulo do feixe incidente, diminuindo o borramento causado pela distância entre detector e objeto, mas, assim como no movimento do tubo, acarreta na inclusão de borramento de movimento (SECHOPOULOS, 2013).

Apesar de disparar o tubo de raio $\mathrm{X}$ diversas vezes, a dose total de radiação incidente à paciente deve ser similar à dose utilizada em exames mamográficos tradicionais. Com isso, cada projeção é realizada com aproximadamente $1 / n$ da dose equivalente à mamografia, sendo $n$ o número de projeções utilizadas pelo equipamento. Devido à baixa dose de radiação, as imagens de projeção apresentam relação sinal-ruído inferiores à das imagens mamográficas convencionais. A fim de contrapor os efeitos causados por essa baixa dose, alguns recursos são utilizados (SECHOPOULOS, 2013).

O recurso mais utilizado pelos fabricantes é a remoção da grade anti-scatter do equipamento. Com a sua ausência, o bucky factor deixa de ser um fator atenuador, aumentando significativamente o sinal recebido pelos detectores, porém causando borramento extra devido à radiação espalhada (SECHOPOULOS, 2013). Alguns fabricantes preferiram desenvolver uma nova grade especialmente para a tomossíntese. A diferença entre essa grade e as tradicionais não é de conhecimento público, pois possui arquitetura proprietária (GE HEALTHCARE, 2014). 
Além disso, outra solução encontrada foi a união entre os pixels do detector denominada binning. Essa união é realizada com o intuito de aumentar o tamanho efetivo dos elementos sensíveis. Assim, um detector com pixel de 100 x 100 $\mu \mathrm{m}$, ao realizar binning de 2x2

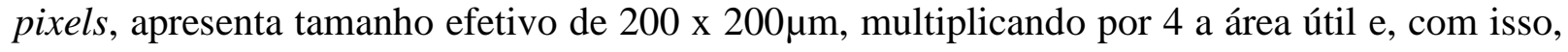
o valor a ser lido pelo sistema. Isso diminui a degradação pelo ruído quântico nas projeções da DBT. No entanto, isso também tem o efeito indesejado de diminuir a resolução espacial da imagem (SECHOPOULOS, 2013). Adicionalmente, o binning "diminui" a quantidade de pixels na imagem, possibilitando uma leitura mais rápida dos sensores, diminuindo o tempo do exame (GLICK, 2014). Este método apresenta um compromisso entre resolução espacial, intensidade de sinal e velocidade de leitura. Os fabricantes de equipamentos utilizam regras diferentes, ficando a critério de cada um a necessidade ou não deste recurso.

Para facilitar o diagnóstico médico, as imagens de projeção são processadas com o intuito de reconstruir o volume do objeto tridimensional imageado. A Figura 6 apresenta a lógica básica envolvida na formação de fatias. O objeto é posicionado acima do plano base, gerando imagens radiográficas em diversos ângulos, ou projeções. O objetivo é que, após o processamento, seja possível visualizar seções planas paralelas à base. A distância entre cada fatia cria a terceira dimensão do objeto, transformando pixels em voxels. O especialista, ao analisar o exame, pode circular pelas imagens das fatias, possibilitando uma análise detalhada do interior das estruturas mamária.

A Figura 6 apresenta uma representação esquemática da obtenção da projeção central, fatiamento virtual dos objetos e fatias finais. Idealmente, a reconstrução deveria possibilitar que cada fatia apresentasse somente as informações existentes no plano escolhido como representado. Devido a uma quantidade finita de projeções, esse fato não ocorre nos algoritmos reais, fazendo com que fatias apresentem resíduos de outros planos.

É importante observar que, devido às restrições construtivas, o algoritmo de reconstrução em exames mamários deve trabalhar com dados incompletos, já que o tubo emissor percorre somente um arco de ângulo limitado ao redor da mama. Essa característica ocasiona que exames de tomossíntese mamária necessitem de algoritmos de reconstrução próprios, diferentes dos utilizados em tomografia computadorizada, por exemplo (GOODSITT, 2014). 
( I )

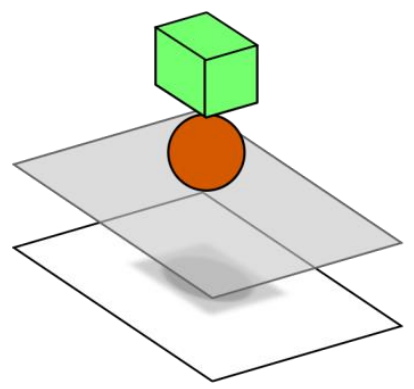

( II )

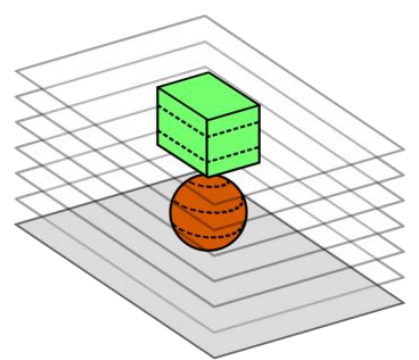

( III )

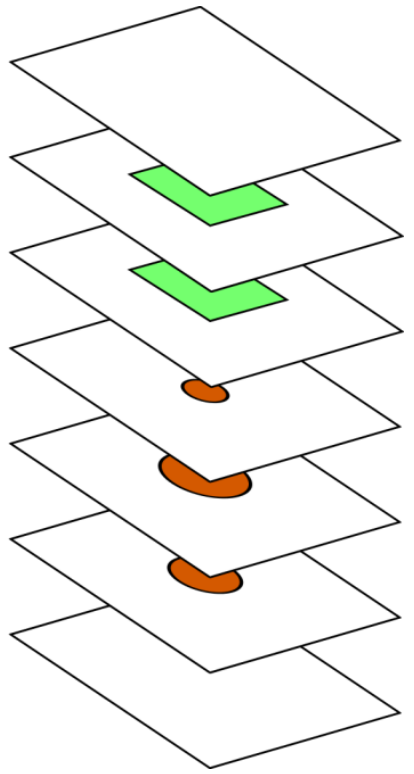

Figura 6: Representação da geração de fatias. (I) Dois objetos posicionados acima um do outro criam uma projeção com informação sobreposta. (II) Representação do fatiamento virtual. (III) $\mathrm{O}$ fatiamento virtual resulta em diversas fatias que representam segmentos internos dos objetos.

Fonte: Ilustração elaborada pelo autor

( I )
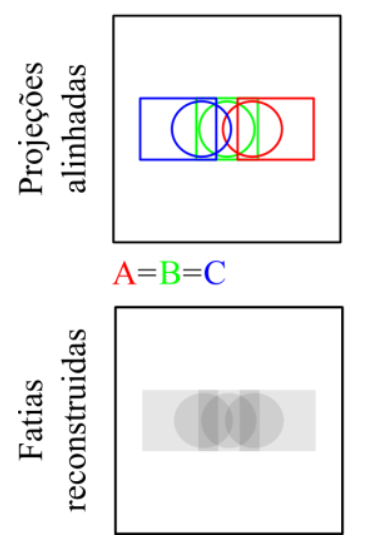

( II )

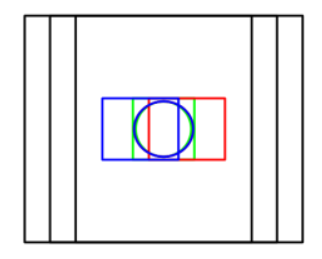

$\mathrm{ABC}$

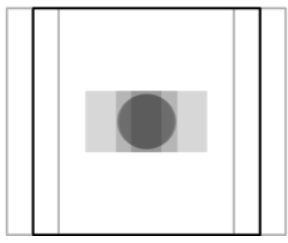

( III )

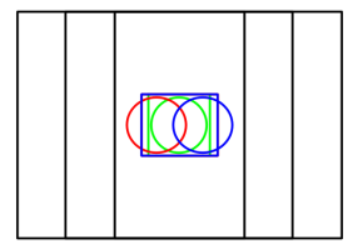

A B C

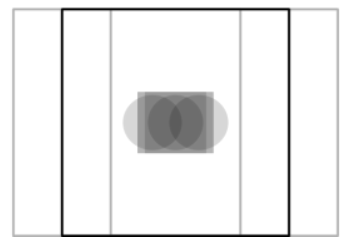

( IV )
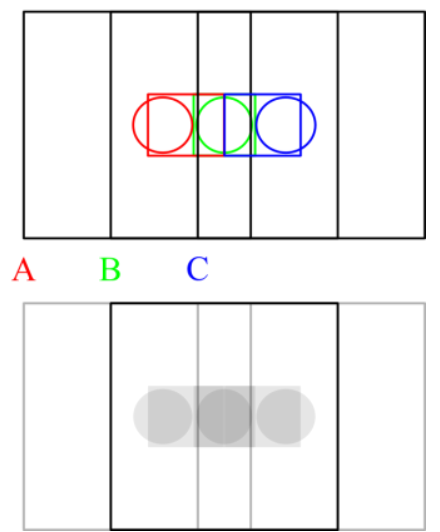

Figura 7: Representação da geração de fatias através da técnica Shift-and-Add. (I) Inicialmente três projeções distintas A, B e C são alinhadas. A técnica soma os valores das projeções resultando na fatia reconstruída. Alterando o posicionamento das projeções, em (II), (III) e (IV), a fatia reconstruída ressalta diferentes objetos. 
O algoritmo base que possibilita a reconstrução é denominado Shift-and-Add. Sua lógica utiliza o posicionamento relativo entre as projeções a fim de gerar as fatias. Assim como o nome do algoritmo diz, as projeções são empilhadas e transladadas proporcionalmente ao plano que se deseja reconstruir. Após o posicionamento, todas as projeções são somadas, gerando uma nova imagem. A Figura 7 mostra uma representação esquemática do processo (CHEN; LO; DOBBINS, 2007).

Com a soma, objetos que estão presentes no plano desejado são sobrepostos, causando pontos de maior intensidade na imagem final. Objetos presente em outros planos têm suas sombras espalhadas, gerando regiões com baixa intensidade. É possível observar que as imagens geradas apresentam dados de todas as projeções, fazendo necessária a utilização de filtros para melhorar a qualidade final da fatia (CHEN; LO; DOBBINS, 2007).

Apesar de gerar resultados satisfatórios, o algoritmo Shift-and-Add não é utilizado em equipamentos comerciais, sendo substituído por versões otimizadas que apresentam melhores resultados. Devido a questões comerciais, os fabricantes não liberaram o algoritmo real utilizado em seus equipamentos (SECHOPOULOS, 2013).

Até a data de elaboração deste trabalho, três equipamentos de DBT possuem aprovação do FDA para serem comercializados nos EUA. A Tabela 1 apresenta uma lista resumida das características de cada aparelho. É possível notar uma grande diversidade de características e como cada fabricante solucionou de maneira diferente as dificuldades de projeto.

Apesar de apresentar menor tamanho de pixel, o equipamento da Hologic utiliza binning $2 \times 2$ para aumentar a área relativa de aquisição e rotaciona o plano do detector em conjunto com o tubo de raios X. O equipamento da GE HealthCare é o único a apresentar a função Step-and-Shoot, grade anti-scatter e detector de silício. Por fim, o aparelho da Siemens possui a maior variação de ângulo do tubo, chegando a $50^{\circ}$. 
Tabela 1: Característica dos equipamentos de tomossíntese presentes no mercado.

\begin{tabular}{|c|c|c|c|}
\hline & Mammomat & SenoClaire & Selenia Dimension \\
\hline Fabricante & Siemens & Ge HealthCare & Hologic \\
\hline Ângulo & $50^{\circ}$ & $25^{\circ}$ & $15^{\circ}$ \\
\hline Número de projeções & 25 & 9 & 15 \\
\hline Binning & Não & Não & $2 \times 2$ pixels \\
\hline Grade & Retrátil & 5:1 Anti-Scatter ${ }^{\circledast}$ & Retrátil \\
\hline Anodo & $\mathrm{Mo} / \mathrm{W}$ & Mo / Rh & W \\
\hline Filtro & Mo / Rh & Mo / Rh & $\mathrm{Rh} / \mathrm{Ag} / \mathrm{Al} / \mathrm{Cu}$ \\
\hline Detector & aSe & a-Si / Csl & aSe \\
\hline Tamanho do pixel & $85 \mu \mathrm{m}$ & $100 \mu \mathrm{m}$ & $70 \mu \mathrm{m}$ \\
\hline Tamanho do detector & $24,0 \times 30,0 \mathrm{~cm}$ & $24,0 \times 30,7 \mathrm{~cm}$ & $24,0 \times 29,0 \mathrm{~cm}$ \\
\hline Tempo de exame & $<12 \mathrm{~s}$ & $<10$ s & $3,7 \mathrm{~s}$ \\
\hline Algoritmo de reconstrução & Analytical ${ }^{\circledR}$ & $\mathrm{ASiR}^{\mathrm{DBT} \mathrm{T}_{\circledast}}$ & $\mathrm{ASiR}^{\mathrm{DBT} \mathrm{T}_{\circledast}}$ \\
\hline Movimento do tubo & Contínuo & Step-and-Shoot & Contínuo \\
\hline Movimento do detector & Não & Não & Sim \\
\hline Data de aprovação no FDA & $04 / 21 / 2015$ & $08 / 26 / 2014$ & $05 / 16 / 2013$ \\
\hline Referência & $\begin{array}{c}\text { (SIEMENS } \\
\text { HEALTHINNERS, 2016) }\end{array}$ & (GE HEALTHCARE, 2014) & (HOLOGIC, 2016) \\
\hline
\end{tabular}

Fonte: (SIEMENS HEALTHINNERS, 2016) (GE HEALTHCARE, 2014) (HOLOGIC, 2016) 


\section{Métodos de Inserção de Ruído}

Este capítulo é subdividido em cinco seções e visa fazer uma breve revisão de alguns métodos de inserção de ruído para simulação da redução da dose de radiação existentes na literatura. A primeira seção, entretanto, tem por objetivo fazer uma breve introdução sobre o ruído na mamografia digital.

A segunda seção faz um breve resumo dos métodos de simulação da redução da dose de radiação disponíveis na literatura. A terceira tem como ênfase o método desenvolvido por Svalkvist e Båth em 2010 para a simulação de redução de dose em tomossíntese torácica (SVALKVIST; BÅTH, 2010).

Antes da introdução ao método de simulação de redução de dose em imagens de mamografia digital proposto por (BORGES et al., 2015) na quinta seção, a transformada de Anscombe, um passo crucial para o método, é detalhada na seção número quatro.

\subsection{Ruído}

Qualquer sistema real de aquisição de imagens está sujeito a interferência de sinais não desejáveis que prejudicam a qualidade final da imagem, ou seja, ruído. O ruído aleatório tipicamente encontrado em imagens digitais, inclusive de exames de mamografia digital e tomossíntese, pode ser descrito por um modelo misto entre ruído gaussiano e Poisson (MÄKITALO; FOI, 2014).

O ruído gaussiano branco presente em imagens mamográficas é gerado, em grande parte, por características intrínsecas à eletrônica de aquisição. Esse ruído é inserido na imagem após a interação entre fóton e elemento sensível e tem como característica a não dependência de sua magnitude com a intensidade do sinal. Desse modo, a imagem ruidosa pode ser representada por uma adição entre uma imagem ideal, livre de ruído, e uma máscara de ruído com valor médio nulo. Considerando um sinal com valor médio esperado g e variância desejada de ruído $\sigma^{2}$, pode-se equacionar a função de distribuição de probabilidade do sinal corrompido por ruído gaussiano, $\gamma_{\mathrm{i}}$, da seguinte maneira:

$$
G\left(\gamma_{i} \mid g, \sigma^{2}\right)=\frac{1}{\sqrt{2 \sigma^{2} \pi}} e^{-\frac{\left(\gamma_{i}-g\right)^{2}}{2 \sigma^{2}}}
$$


Uma representação simplificada de uma variável com ruído gaussiano:

$$
G(\gamma)=g \pm \sqrt{\sigma^{2}}
$$

Os detectores de raios $\mathrm{X}$ determinam a intensidade do sinal a ser gerado através da energia acumulada pelos fótons incidentes em cada elemento sensível durante um período de tempo predeterminado. Devido à natureza quântica das ondas eletromagnéticas, existe uma incerteza presente neste processo de aquisição, gerando assim o ruído quântico, ou ruído Poisson. Ao contrário do fenômeno descrito anteriormente, este ruído apresenta dependência entre sua magnitude e o valor do sinal.

O ruído Poisson, z, possui como característica predominante o fato do valor de sua variância possuir mesma magnitude que o valor médio $\mu$ do sinal, assim, não é possível descrevê-lo através de uma simples soma (MAKITALO; FOI, 2010):

$$
\operatorname{var}(z)=\mu
$$

Equação 3

Considerando uma variável independente $z_{i}$ contaminada com ruído Poisson e valor médio esperado $\mu \geq 0$, pode-se equacionar a função de distribuição de probabilidade discreta da seguinte maneira:

$$
P\left(z_{i} \mid \mu\right)=\frac{\mu^{z_{i}} e^{-\mu}}{z_{i} !}
$$

Assim, sabendo-se que o desvio padrão é a raiz quadrada da variância, pode-se simplificar a representação de uma variável Poisson como sendo:

$$
P\left(z_{i}\right)=\mu \pm \sqrt{\mu}
$$

Equação 5

Como a maioria dos detectores de raios $\mathrm{X}$ não são contadores de fótons, mas sim integradores de energia, o ruído Poisson possui um fator de escala que relaciona a variância do ruído com a intensidade do sinal. O ruído Poisson com escala pode ser representado por:

$$
P\left(z_{i}\right)=i \pm \sqrt{\alpha i}
$$

Equação 6

Sendo i a intensidade do sinal gerado pelo integrador de energia e $\alpha$ o fator de escala que modifica a variância do ruído. É conhecido que imagens mamográficas apresentam ruído misto entre Poisson com fator de escala $(\alpha<1)$ e gaussiano. Entretanto, devido à intensidade de sinal, o ruído Poisson é dominante sobre o gaussiano (HOLOGIC, 2016). Como as imagens de DBT são geradas no mesmo equipamento que as imagens mamográficas, é intuitivo concluir que o modelo de ruído encontrado em ambos os exames é muito similar. Porém, devido a 
fatores como a menor dose de radiação na aquisição das projeções, binning do detector e remoção de grade anti-espalhamento, além do processo de reconstrução, uma análise detalhada do ruído da DBT deve ser realizada para desenvolvimento de um método preciso de simulação da redução da dose de radiação.

A inserção de ruído em imagens ideais para a simulação da redução da dose de radiação apresenta baixa complexidade, visto que, tanto para ruído gaussiano quanto Poisson basta utilizar as equações apropriadas para a geração de uma imagem ruidosa. No entanto, a simulação baseada em imagens reais apresenta um nível maior de complexidade, primeiro porque o sinal ideal, livre de ruído, não é conhecido; além disso, a imagem em que o ruído deve ser inserido já possui certo nível de ruído gerado durante o processo de aquisição. Assim, se durante a simulação da redução da dose de radiação, o valor real do sinal e o ruído intrínseco à imagem original não for considerado no processo, o valor de ruído calculado será amplificado ocasionando erros na simulação.

A maioria dos sistemas de aquisição de imagens apresenta ruído, tanto gaussiano quanto Poisson, com magnitude uniformemente distribuída por toda a região do detector. Deste modo, se a característica do ruído for determinada em uma sub-região qualquer da imagem, a caracterização de toda a imagem pode ser extrapolada. Devido ao sistema de correção de nãouniformidade (flat-fielding) presente nos equipamentos mamográficos digitais, o fator de escala do ruído Poisson apresenta dependência espacial, possuindo menor valor nas regiões do detector mais próximas à paciente e maior valor nas regiões mais distantes (BORGES et al., 2015).

A maioria dos métodos de simulação encontrados na literatura, como por exemplo, os que utilizam espectro de potência (NPS), não consideram o ruído como sendo dependente da posição espacial. Essa característica ressalta a necessidade de um método próprio para ser utilizado em imagens de mamografia digital e DBT (VELDKAMP et al., 2009) (BORGES et al., 2015). 


\subsection{Métodos de simulação da redução da dose de radiação - Estado da arte}

Apesar de, à primeira vista, o problema da simulação de uma imagem adquirida com menor radiação possa parecer simples, é valido lembrar que as imagens utilizadas são imagens reais que possuem ruído intrínseco à aquisição, e não imagens sintéticas onde o valor do sinal é conhecido. Para solucionar este problema, vários métodos para simulação da redução da dose de radiação foram desenvolvidos.

Em 2005 foi proposto um método para simular a redução de dose em imagens de radiografias digitais através da análise do ruído da imagem mensurado pelo Espectro de Potência do Ruído (Noise Power Spectrum - NPS) e pela eficiência de detecção quântica (detective quantum efficiency - DQE). Apesar de obter bons resultados, o método é limitado por supor que o DQE é invariável às variações de dose de radiação na aquisição das imagens, fato que não é verdadeiro, especialmente se considerado aquisições com baixa dose de radiação (BATH et al., 2005) (BEUTEL; KUNDEL; METTER, 2000).

Para simular a redução de dose em imagens de radiografias torácicas, Kroft (KROFT et al., 2006) propôs a inserção de ruído pixel a pixel com base no valor de desvio padrão esperado. Através desse método, o trabalho alcança redução de até $12 \%$ da dose original. Apesar de obter uma ótima aproximação do valor do desvio padrão entre as imagens simuladas e reais, os próprios autores relatam que o método diminui a energia do sinal, o que acaba causando borramento, e que a análise do NPS da imagem simulada não condiz com o valor esperado (VELDKAMP et al., 2009).

Na literatura também é possível encontrar métodos mais completos que tentam simular simultaneamente diversas características de imagens. Saunders Jr. (SAUNDERS JR; SAMEI, 2003), por exemplo, propôs um método capaz de alterar a resolução espacial e níveis de ruído de imagens radiográficas digitais. A alteração nos níveis de ruído é feita por uma máscara de ruído branco calculado através do NPS em diversas regiões de interesse (region of interest ROI) não sobrepostas na imagem. Adicionalmente, é utilizada como variável de entrada no algoritmo a relação entre a média e variância esperada pelo sistema. A implementação do método atinge bons resultados, mas o trabalho foi proposto somente para a utilização de imagens ideais, livres de qualquer ruído, tornando esse método inviável para aplicações em imagens reais (SAUNDERS JR; SAMEI, 2003). 
Svalkvist e Båth (SVALKVIST; BÅTH, 2010) propuseram um método de simulação de redução de dose de radiação especificamente para imagens de tomossíntese torácicas. Apesar de possuir limitações que restringem seu funcionamento, o método apresenta excelentes resultados que serão estudados mais a fundo na próxima seção. Finalmente, proposto exclusivamente para imagens de mamografia digital, o método desenvolvido por Borges et al (BORGES et al., 2015) é o único método de simulação de redução de dose a considerar a distribuição não homogênea do ruído na imagem e utilizar uma transformada de estabilização de variância para criar dependência entre o sinal e ruído sem a necessidade de estimativa prévia do sinal ideal, livre de ruído. A estrutura deste método é aprofundada no item 3.5.

\subsection{Método de Svalkvist \& Båth}

Publicado em janeiro de 2010, o método proposto por Angelica Svalkvist e Magnus Båth tem como objetivo simular a redução de dose em imagens de tomossíntese da caixa torácicas (SVALKVIST; BÅTH, 2010). O método proposto requer duas imagens uniformes obtidas no mesmo aparelho, sendo uma imagem com dose padrão, que servirá como referência, e uma imagem com dose próxima à simulada. $\mathrm{O}$ trabalho mostra que não é necessário adquirir a segunda imagem exatamente na mesma dose que se deseja a simulação, bastando os valores serem próximos.

O método então utiliza a informação presente no espectro de potência do ruído (NPS) para simular imagens homogêneas, e a variância total para simular imagens clínicas. O primeiro passo apresentado é o ajuste dos valores de pixel da imagem com dose padrão com o intuito de simular o nível de intensidade de pixel próximo ao obtido com dose reduzida. Esse ajuste é realizado através da linearização da imagem original e multiplicação pela relação entre as doses de entrada e a dose simulada.

Após esse processo, a imagem obtida apresenta intensidade similar à desejada, mas nível de ruído muito inferior ao esperado para tal dose de radiação. Para ajustar o nível de ruído, é criada uma máscara de ruído gaussiano branco, através da diferença entre os valores de NPS da imagem ajustada e a obtida com dose reduzida.

A Equação 7 mostra o cálculo realizado para a obtenção do valor de NPS da máscara de ruído e a Tabela 2 detalha as variáveis utilizadas. 


$$
\begin{aligned}
& N P S(u, v)_{I_{\text {noise }}}=N P S(u, v)_{D_{\text {sim }}}-N P S(u, v)_{D_{\text {orig }}}\left(\frac{D_{\text {sim }}}{D_{\text {orig }}}\right)^{2} \quad \text { Equação } 7
\end{aligned}
$$

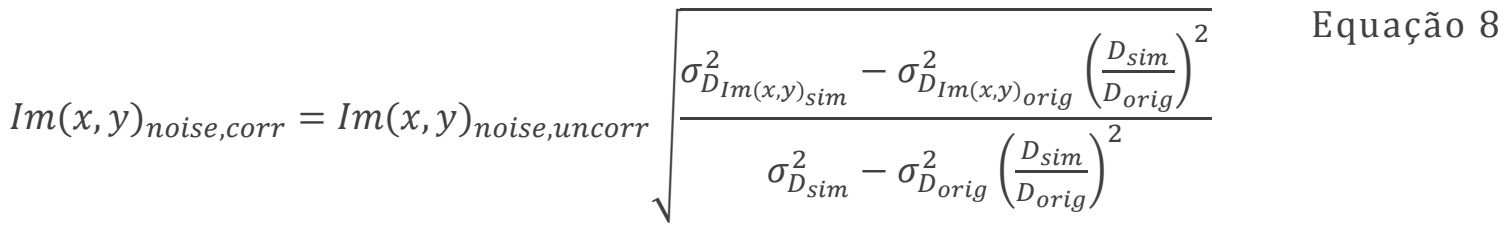

Após o cálculo da máscara de ruído, esse deve ser inserido na imagem escalada para finalizar a simulação. Entretanto essa soma não pode ser realizada de maneira trivial.

Tabela 2: Variáveis utilizadas no método proposto por Svalkvist \& Båth.

\begin{tabular}{|c|c|}
\hline Nomenclatura & Descrição \\
\hline$N P S(u . v)_{x}$ & Noise Power Spectrum da imagem $\mathrm{x}$ \\
\hline im $_{\text {noise }}$ & Máscara de ruído a ser adicionada \\
\hline $\operatorname{im}(x, y)_{\text {noise }, \text { corr }}$ & Imagem simulada com ruído dependente do sinal \\
\hline $\operatorname{im}(x, y)_{\text {noise }, \text { uncorr }}$ & $\begin{array}{l}\text { Imagem simulada com ruído não dependente do } \\
\text { sinal }\end{array}$ \\
\hline$D_{\text {sim }}$ & Dose da imagem homogênea com dose reduzida \\
\hline$D_{\text {orig }}$ & Dose da Imagem homogênea com dose padrão \\
\hline$\sigma_{x}^{2}$ & Variância de $\mathrm{x}$ \\
\hline
\end{tabular}

A máscara de ruído apresenta ruído gaussiano, ou seja, não dependente do nível de sinal, e sabe-se que imagens de tomossíntese apresentam ruído dependente do sinal. Para contornar este problema, são propostos artifícios matemáticos no domínio do espaço que visam criar dependência no ruído antes de sua inserção. Os cálculos propostos envolvem o valor de NPS, relação sinal-ruído (signal to noise ratio - SNR), função de transferência de modulação (modulation transfer function - MTF) e valor médio em uma grande área. O cálculo para inserção de ruído simplificado pode ser visto na Equação 8.

Apesar de apresentar bons resultados e não apresentar borramento na imagem simulada, esse método possui grandes problemas quando utilizado em imagens de mamografia ou tomossíntese mamária. Os próprios autores reconhecem que a utilização do valor médio dos pixels não é um bom valor para simular a dependência entre sinal e ruído, já que a imagem 
original já é contaminada por ruído e devido ao flat-fielding, o valor médio temporal e o valor médio espacial não são idênticos.

Além disso, o método considera o NPS como um descritor único e suficiente para a análise do ruído. No entanto é conhecido, e será mostrado nos itens subsequentes, que a variação espacial do ruído em imagens de tomossíntese não pode ser ignorada.

Finalmente, o método cria dependência entre o sinal e o ruído utilizando uma equação que deve ser aplicada no domínio do espaço, considerando que o valor do sinal é o mesmo valor do pixel com ruído. Outros métodos presentes na literatura utilizam transformadas para alterar o domínio dos dados e possibilitar a criação dessa dependência sem a necessidade de se conhecer o valor do sinal sem ruído.

\subsection{Transformada de Anscombe}

Transformadas de estabilização de variância têm por objetivo transformar dados de entrada que possuam ruído dependente de sinal em dados com ruído não dependente (FOI, 2016).

Em 1948, Francis John Anscombe publicou um artigo apresentado ao mundo uma transformada de estabilização de variância que viria a se tornar a transformada deste tipo mais utilizada em trabalhos científicos (FOI, 2016).

Considerando um sinal degradado por ruído Poisson dependente do sinal, $\mathrm{I}_{\mathrm{i}}$, a transformada de Anscombe descrita na equação abaixo transforma o dado resultante em um sinal com ruído gaussiano aditivo independente do sinal, com média zero e variância unitária (ANSCOMBE, 1948).

$$
A_{T}\left(I_{i}\right)=2 * \sqrt{I_{i}+\frac{3}{8}}
$$

A transformada inversa de Anscombe realiza o procedimento contrário à transformada tradicional, voltando a imagem ao domínio do espaço e transformando o ruído gaussiano em ruído Poisson. Abaixo é possível visualizar a equação da transformada inversa de Anscombe:

$$
A_{T}^{-1}\left(I_{i}\right)=\left(\frac{I_{i}}{2}\right)^{2}-\frac{3}{8}
$$


O funcionamento da transformada de Anscombe pode ser descrito pelo fluxograma da Figura 8. Um sinal S, definido no domínio do espaço e contaminado com ruído Poisson, é transformado para o domínio de Anscombe, resultando no sinal $\mathrm{D}_{\mathrm{B}}$. Este sinal apresenta ruído aditivo gaussiano com média zero e variância unitária, como pode ser visto no gráfico (I) da Figura 9.

Se o sinal $D_{B}$ não sofrer nenhuma manipulação dentro domínio de Anscombe, ele é convertido novamente para o domínio do espaço através da transformada inversa mostrada na equação 10. No gráfico (II), localizado no lado direito da Figura 9, é possível verificar que o valor resultante da transformada inversa do sinal $\mathrm{D}_{\mathrm{B}}$ é idêntico ao sinal original $\mathrm{S}$.

Considerando que o sinal $\mathrm{D}_{\mathrm{B}}$ seja filtrado no domínio de Anscombe, com o intuito de remover completamente o ruído do sinal, é gerado o sinal $\mathrm{D}_{\mathrm{C}}$, que apresenta variância nula (Figura 9 lado esquerdo). Após a transformada inversa deste sinal, o valor resultante apresenta um viés em relação ao sinal original S de exatamente -1/4 (Figura 9 lado direito) (FOI, 2016). Por isso, no caso de se utilizar a transformada de Anscombe para filtragem de ruído, a transformada inversa deve ser outra, mostrada na Equação 11:

$$
A_{T}^{-1}\left(I_{i}\right)=\left(\frac{I_{i}}{2}\right)^{2}-\frac{1}{8}
$$

Equação 11

$\mathrm{O}$ sinal $\mathrm{D}_{\mathrm{A}}$ é gerado considerando o caso de se inserir ruído na imagem no domínio de Anscombe, com a intensão de simular uma redução nas doses de radiação. Após a adição de ruído gaussiano branco com variância unitária ao sinal $\mathrm{D}_{\mathrm{B}}$, gerando um sinal com variância 2 dentro do domínio de Anscombe (Figura 9 (I)). Após a transformada inversa, o sinal resultante também destoa do sinal esperado S, mas com uma magnitude $+1 / 4$ (Figura 9 (II)).

Esse viés presente na transformada inversa de Anscombe é devido ao processamento do sinal dentro do seu domínio, e apresenta um dos maiores problemas em sua utilização. Com o intuito de mitigar esse viés, foi proposta a utilização da transformada de Anscombe inversa exata (MAKITALO; FOI, 2012). Esse método utiliza o valor da variância do sinal dentro do domínio de Anscombe para modificar o valor constante da transformada inversa, a fim de minimizar a disparidade dos resultados.

A transformada original foi proposta para a conversão de sinais com ruído Poisson puro. Com o intuito de ampliar o campo de utilização, foi proposta uma alteração na transformada original, a fim de considerar que o sinal de entrada possa também ser contaminado com ruído misto Poisson-Gaussiano (MURTAGH; STARCK; BIJAOUI, 1995). 


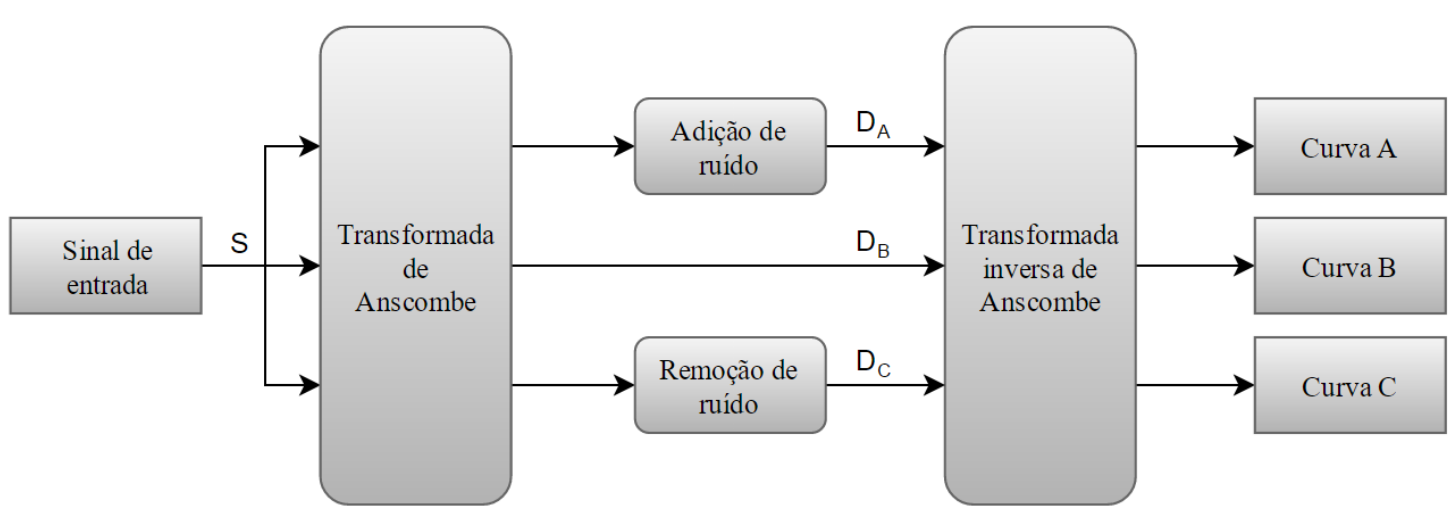

Figura 8: Fluxograma para exemplificar transformada de Anscombe. Um sinal S contaminado com ruído Poisson é processado dentro do domínio de Anscombe gerando três vertentes: $D_{A}, D_{B}$ e $D_{C}$. Essas vertentes sofrem a transformada inversa e retornando ao domínio do espaço.

Fonte: Ilustração elaborada pelo autor

( I )

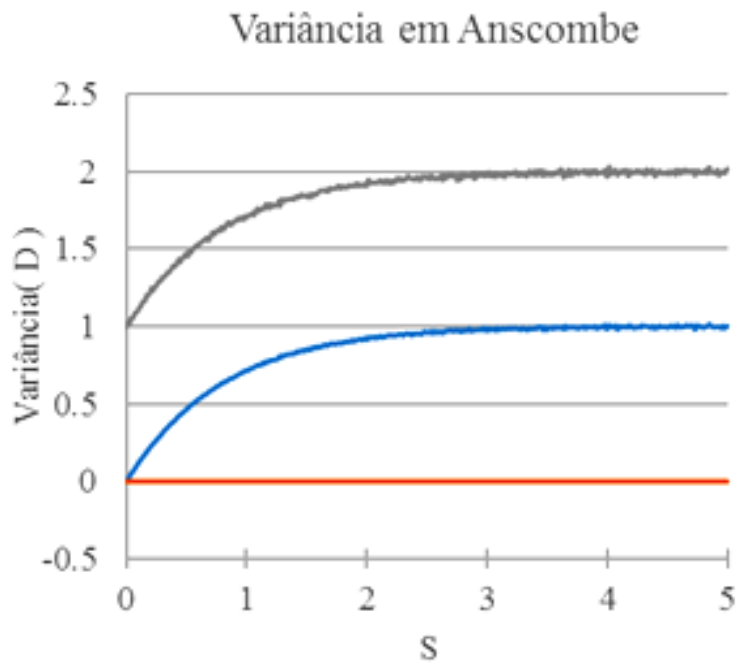

( II )

\section{Transformada inversa}

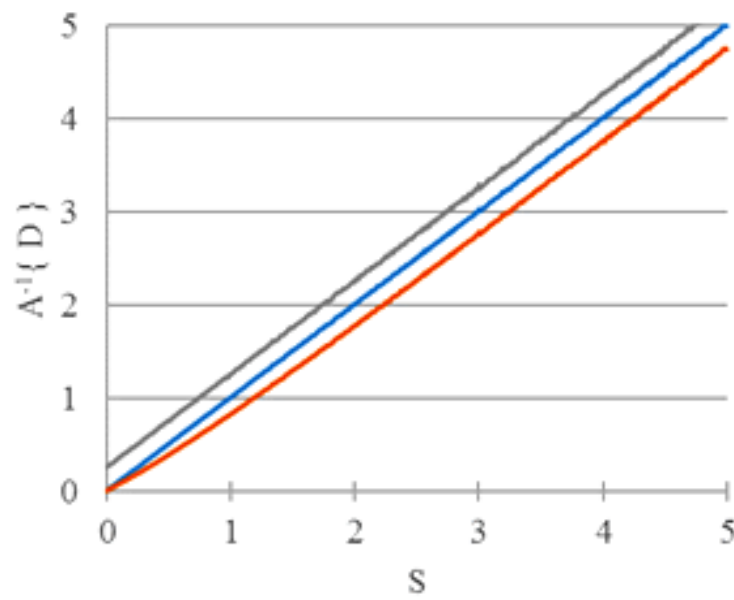

$\mathrm{S}$

$-\mathrm{D}_{\mathrm{A}}-\mathrm{D}_{\mathrm{B}}-\mathrm{D}_{\mathrm{C}}$

Figura 9: Variância no domino de Anscombe e comparação da transformada inversa. (I) Relação entre sinal S e a variância dos sinais DA, DB e DC. (II) Relação entre sinal S e a transformada inversa de DA, DB e DC mostrando uma viés relativo à alteração da variância dentro do domínio de Anscombe.

Fonte: Ilustração elaborada pelo autor 
Considerando um sinal de entrada $I_{i}$ contaminado com ruído misto Poisson-Gaussiano, sendo a parte Poisson descrita pela variável $n$ (média e variância) com fator de escala $\alpha$, e a parte gaussiana descrita pela variável $\gamma$ com valor esperado médio g e desvio padrão $\sigma$ temos:

$$
I_{i}=\gamma+\alpha n
$$

Equação 12

A transformada generalizada de Anscombe do sinal $I_{i}$ é descrita por:

$$
A_{G}\left(I_{i}\right)=\frac{2}{\alpha} * \sqrt{\alpha * I_{i}+\frac{3}{8} \alpha^{2}+\sigma^{2}-\alpha g}
$$

Equação 13

Considerando um sinal puramente Poisson, temos que $\alpha=1, \sigma=0$ e $g=0$, o que simplifica a transformada generalizada, levando-a a se tornar a transformada de Anscombe original mostrada na Equação 9.

É importante ressaltar que tanto nas imagens obtidas pela mamografia digital quanto pela DBT o fator de escala $\alpha$ não apresenta valor constante em toda a área útil da imagem. Na verdade, devido à calibração do aparelho e ao efeito heel, este fator apresenta alta dependência espacial.

Para contornar este problema, o fator de escala é obtido através da medida local do valor médio e variância conforme Equação 14.

$$
\text { Fator de escala }=\frac{\text { Variância }}{\text { Valor médio }}
$$

Equação 14

Após a obtenção do fator de escala, agora bidimensional, em toda a área da imagem e, a fim de simplificar o uso da Equação 12, é possível realizar a divisão pixel a pixel da imagem real pelo fator de escala, resultando assim em uma imagem equivalente com que apresenta ruído Poisson não escalado.

\subsection{Método de Borges et al}

No ano de 2015 foi publicado um novo método para a simulação da redução da dose de radiação em imagens mamográficas digitais (BORGES et al., 2015). A novidade desse método é que a inserção de ruído é realizada no domínio de Anscombe, onde a variância do ruído está estabilizada. Com isso, não é necessário conhecer o valor do sinal livre de ruído, pois a máscara de ruído a ser adicionada deve ser uniforme com ruído gaussiano. O uso da transformada inversa transforma o ruído gaussiano uniforme em ruído Poisson dependente do 
sinal, simulando a redução da dose de radiação sem o viés encontrado em outros métodos da literatura.

O método de Borges et al (BORGES et al., 2015) requer três imagens de entrada que são utilizadas durante o processo para a obtenção de uma imagem de mamografia com arquitetura idêntica à imagem de mamografia de entrada, porém com intensidade de sinal e ruído característicos a uma imagem obtida com uma dose menor de radiação (BORGES et al., 2015). Como pode ser visto na Figura 10, as imagens que servem como argumentos de entrada para o método são:

- Imagem mamográfica adquirida em uma dose qualquer. Esta é a imagem real de referência e com dose relativa $100 \%$.

- Imagem uniforme de uma placa de PMMA adquirida com exatamente as mesmas configurações do aparelho de raios X que a imagem anterior.

- Imagem uniforme de uma placa PMMA obtida com exatamente a mesma configuração do aparelho de raios $\mathrm{X}$, exceto pela corrente de exposição que deve apresentar valor menor ao utilizado na imagem 100\%. A dose resultante deve ser inferior à dose utilizada na imagem de referência.

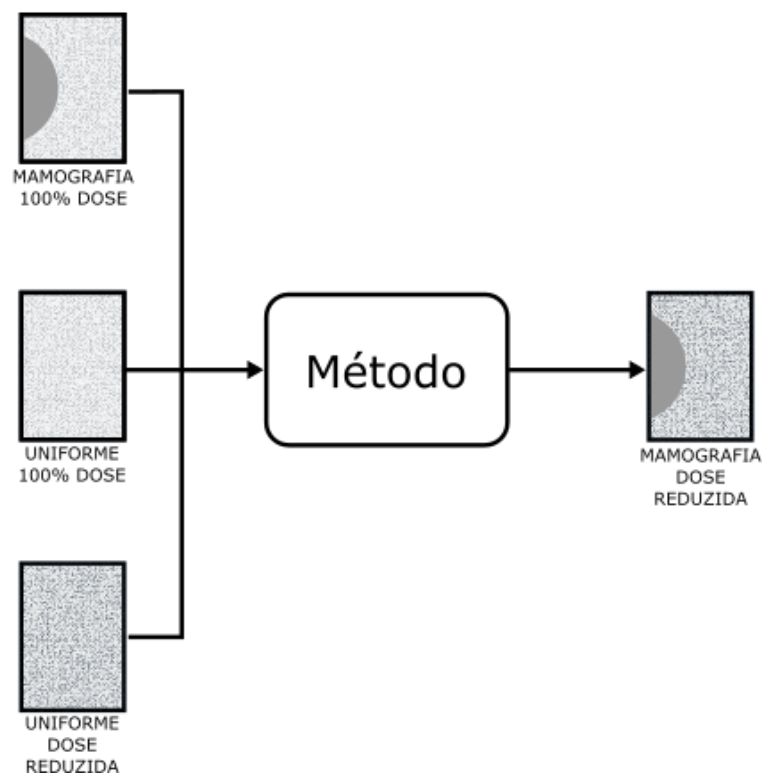

Figura 10: Entradas e saídas do método proposto por Borges et al para a redução de dose em imagens mamográficas. 
O método em si consiste de três etapas: linearização e ajuste, cálculo do ruído e incorporação do ruído.

Todos os aparelhos digitais de raios $\mathrm{X}$ comerciais adicionam um valor baixo, porém constante de sinal em toda a imagem, com o intuito de evitar a saturação em valor nulo e possibilitar a excursão de ruído. O valor deste offset, normalmente, pode ser visualizado no software de controle do aparelho ou calculado matematicamente.

Devido a este offset, a relação entre o nível de intensidade do pixel e a dose de radiação recebida por cada elemento sensível do detector somente pode ser descrita por uma equação não-linear, do estilo:

$$
y=a \cdot x+b
$$

Equação 15

Sendo " $y$ " a intensidade de sinal no pixel, "x" a dose de radiação recebida pelo elemento sensor, "a" o fator de conversão entre dose de radiação e sinal e "b" o valor de offset.

Para simplificar as análises e processos, é possível linearizar esta relação através da subtração em todos os pixels da imagem do valor de offset, criando uma nova imagem que permite um ajuste linear, $\mathrm{y}^{\mathrm{L}}$ (BATH et al., 2005):

$$
\begin{gathered}
y^{L}=y-b \\
y^{L}=a \cdot x
\end{gathered}
$$$$
\text { Equação } 16
$$

O cálculo do valor de offset pode ser realizado através da regressão linear de duas ou mais imagens uniformes adquiridas com doses distintas e conhecidas. Uma representação pode ser vista na Figura 11. Como o valor de offset é constante em cada equipamento pode-se utilizar as imagens uniformes do bloco de PMMA para esse cálculo e considerar que a imagem com dose $100 \%$ apresente a mesma característica. 

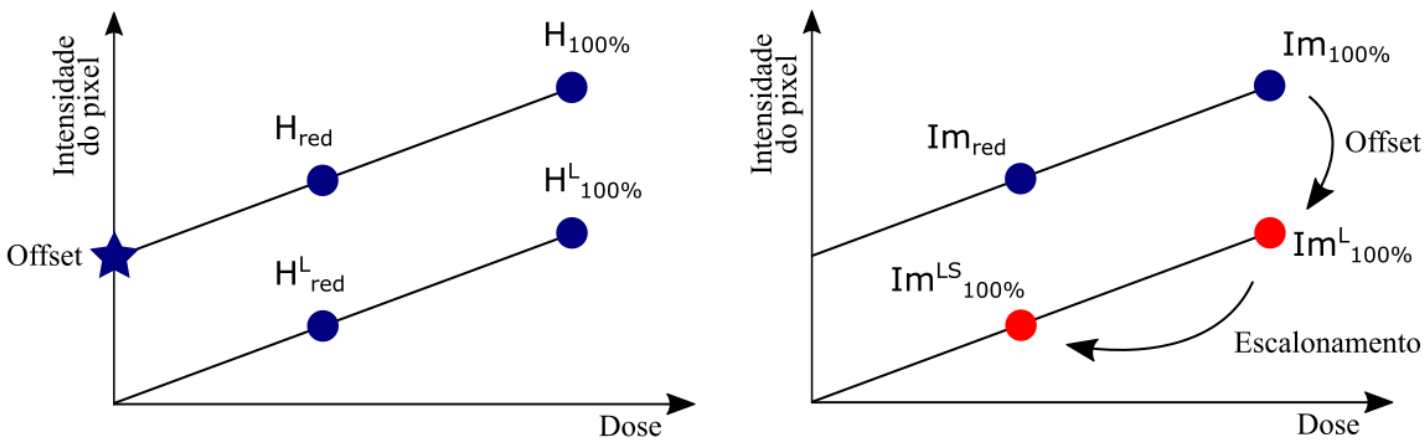

Figura 11: Cálculo do valor de offset e escala. Imagens não linearizadas apresentam coeficiente linear maior que zero, já imagens com dose de radiação reduzida apresentam menor intensidade quando comparadas a dose $100 \%$.

Fonte: Ilustração elaborada pelo autor

Após a linearização das três imagens de entrada, a amplitude do sinal deve ser ajustada. A imagem $100 \%$ é sempre adquirida com uma maior dose de radiação que a imagem a ser simulada, com isso, o nível de sinal na imagem $100 \%$ deve ser reduzido, para uma correta simulação.

Como as imagens uniformes são adquiridas na dose $100 \%$ e na dose a ser simulada, a relação entre a intensidade dos valores de pixels entre essas imagens corresponde à escala pela qual a imagem 100\% deve ser ajustada. Através do valor médio de uma simples divisão pixel a pixel das imagens uniformes é possível obter o valor da escala $\alpha$.

$$
\alpha=\operatorname{média}\left(\frac{H_{100 \%}}{H_{\text {red }}}\right)
$$

A Figura 11 também apresenta uma representação gráfica da linearização e ajuste de intensidade da imagem $100 \%$.

A Figura 12 apresenta as entradas, saídas e passos a serem seguidos na primeira etapa do método. Os índices inferiores indicam se as imagens são com dose 100\% ou dose reduzida, já os índices superiores representam se a imagem foi linearizada (L) e teve intensidade ajustada (S). A letra grega $\theta$ representa o valor de offset. 


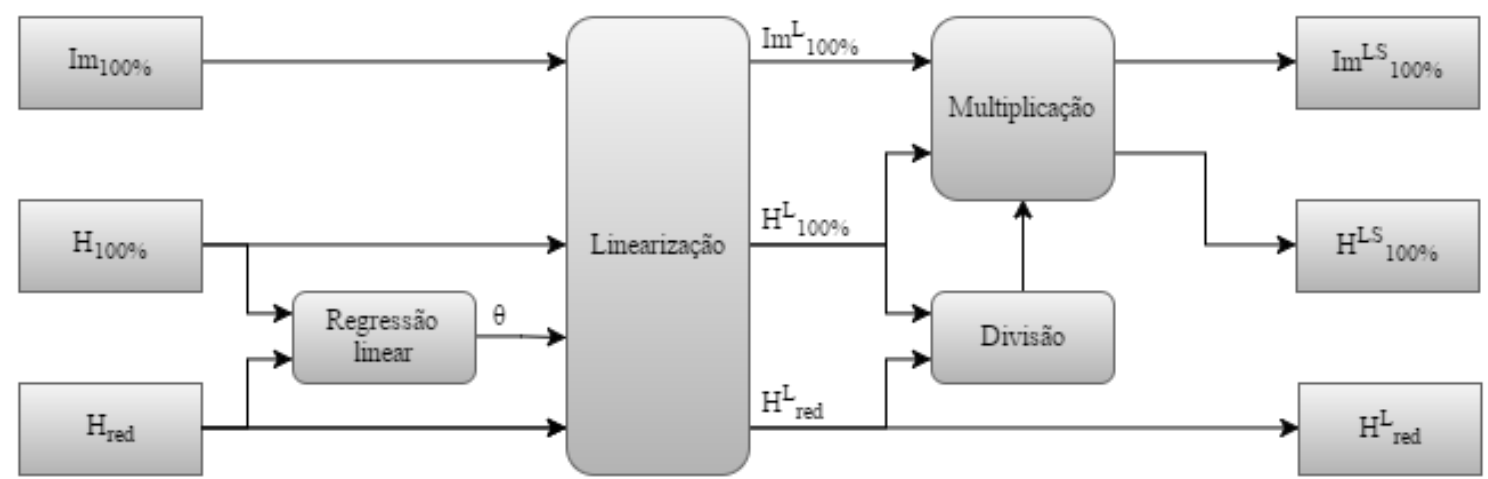

Figura 12: Etapa de linearização e escalonamento das variáveis. O valor de offset é calculado baseado nas imagens uniformes é utilizado para linearizar as três imagens base. Em seguida as imagens obtidas com dose $100 \%$ têm seus valores de intensidade ajustados para condizer com o valor da imagem uniforme obtida com dose reduzida.

Fonte: adaptado de (BORGES et al., 2015)

A segunda etapa do método visa o cálculo do ruído que deverá ser inserido na imagem com dose $100 \%$ linearizada e ajustada para que a imagem simulada apresente características semelhantes à real.

A imagem obtida com $100 \%$ de dose não é ideal, já apresentando ruído característico de mamografia, ruído este que deve ser ampliado para condizer com o ruído de uma imagem obtida com radiação menor. Com esse pensamento em vista, a variância da máscara de ruído que deve ser adicionada à imagem passa a ser a diferença entre a variância do ruído presente na imagem $100 \%$ e na imagem com dose reduzida.

$$
\operatorname{var}(\text { ruído })=\operatorname{var}\left(I_{\text {red }}\right)-\operatorname{var}\left(\operatorname{Im}_{100 \%}\right)
$$

Como a imagem com dose reduzida não existe no procedimento prático, o cálculo do ruído é feito através das imagens da placa uniforme obtidas nas mesmas doses.

$$
\operatorname{var}(\text { ruído })=\operatorname{var}\left(H_{\text {red }}^{L}\right)-\operatorname{var}\left(H_{100 \%}^{L S}\right)
$$

Após o cálculo da máscara de variância pela Equação 20, esta é multiplicada por uma matriz do mesmo tamanho, porém composta somente por ruído branco com média zero e variância unitária, gerando uma máscara de ruído que deve ser inserida na imagem. É valido 
ressaltar que, utilizando ruído branco, o método não leva em consideração o espectro de potência intrínseco as imagens de mamografia digital ou DBT.

Devido à transformada de Anscombe que será utilizada na próxima etapa, o nível médio de sinal da máscara de ruído deve ser ajustado para casar com o nível médio da imagem homogênea com dose reduzida linearizada.

A Figura 13 apresenta as entradas, saídas e passos a serem seguidos na segunda etapa do método. A variável $\mathrm{N}$ representa a máscara de ruído que deve ser inserida na imagem.

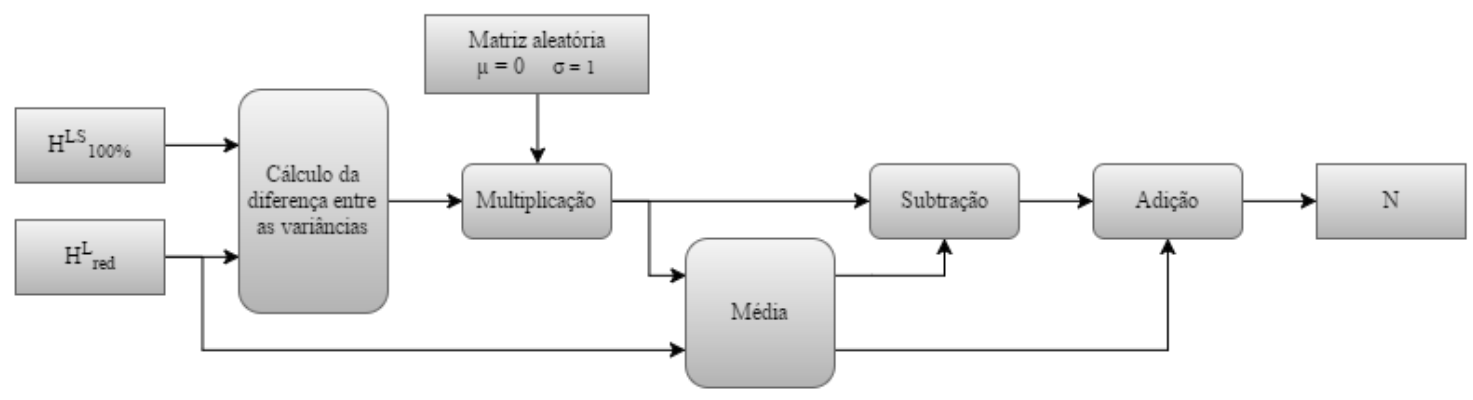

Figura 13: Etapa de cálculo do ruído. Uma máscara de ruído branco possui sua intensidade ajustada para condizer com o valor de variância que deve ser adicionado a imagem simulada.

Fonte: adaptado de (BORGES et al., 2015)

A principal diferença deste método, se comparado com outros da literatura, é a forma com que a máscara de ruído é inserida na imagem. O método de inserção mais intuitivo, uma simples adição, não pode ser considerado para o caso de imagens mamográficas, já que o ruído é predominantemente Poisson e dependente do sinal. Uma soma representa uma inserção independente do nível pré-existente de sinal, não se adequando à situação. Para contornar este problema, o autor utilizou a transformada de Anscombe para transformar o ruído não aditivo dependente do sinal em ruído aditivo independente do sinal.

Primeiramente, tanto a imagem com dose $100 \%$ linearizada e ajustada quanto a máscara de ruído são enviadas para o domínio de Anscombe. Para possibilitar que máscara de ruído volte a representar somente ruído com valor médio nulo, é realizada a subtração do mesmo nível adicionado, porém também convertido para o domínio de Anscombe.

No domínio de Anscombe, com a máscara de ruído ajustada, é possível realizar a sua adição com a imagem, criando assim uma nova imagem ruidosa. Em seguida, deve-se fazer o 
procedimento inverso com a imagem ruidosa a fim de retirá-la do domínio de Anscombe utilizando a transformada inversa de Anscombe.

Finalmente, o valor de offset deve ser inserido na imagem para que a simulação seja completa. Todas as operações podem ser vistas na Equação 21.

$$
I m_{\text {red }}^{\operatorname{sim}}=A^{-1}\left\{\mathrm{~A}\left[\operatorname{Im}_{100 \%}^{L S}\right]+\mathrm{A}[\mathrm{N}]-\mathrm{A}\left[\overline{H_{\text {red }}^{L}}\right]\right\}+\theta \quad \text { Equação } 21
$$

A Figura 14 apresenta as entradas, saídas e passos a serem seguidos na terceira etapa do método. A saída $\operatorname{Im}_{\text {red }}$ representa a imagem simulada representante da imagem de mamografia adquirida com dose reduzida de radiação.

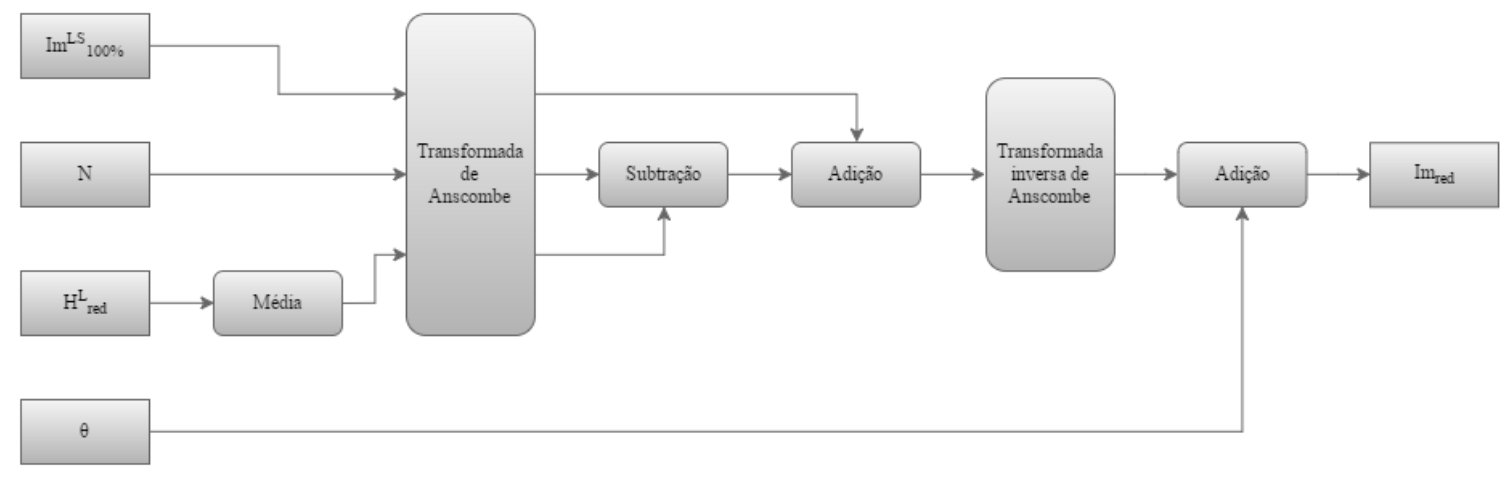

Figura 14: Etapa de incorporação do ruído através da transformada de Anscombe. A imagem linearizada e ajustada e a mascara de ruído são convertidos pela transformada de Anscombe onde o ruído e inserido a imagem. Após a transformada inversa o valor de offset é adicionado para remover a linearização.

Fonte: Adaptado de (BORGES et al., 2015) 


\section{Materiais e Métodos}

Este capítulo é subdividido em três seções, que visam abranger todo o método proposto nesse trabalho para incluir a correção do espectro de potência no processo de simulação de redução da dose de radiação em imagens de tomossíntese mamária. Inicialmente são descritos os materiais utilizados para a aquisição das imagens de tomossíntese utilizadas nesse trabalho. Em seguida é detalhada todas as etapas do método de simulação proposto e, finalmente, são detalhadas as métricas utilizadas para avaliar a qualidade das imagens simuladas em comparação com as imagens reais adquiridas com dose reduzida de radiação.

\subsection{Materiais utilizados}

\subsubsection{Equipamento}

O aparelho utilizado para a obtenção de todas as imagens utilizadas neste trabalho foi o equipamento modelo Selenia Dimensions do fabricante Hologic representado na Figura 15 e de propriedade do Hospital da Universidade da Pensilvânia (Hospital of the University of Pennsylvania).

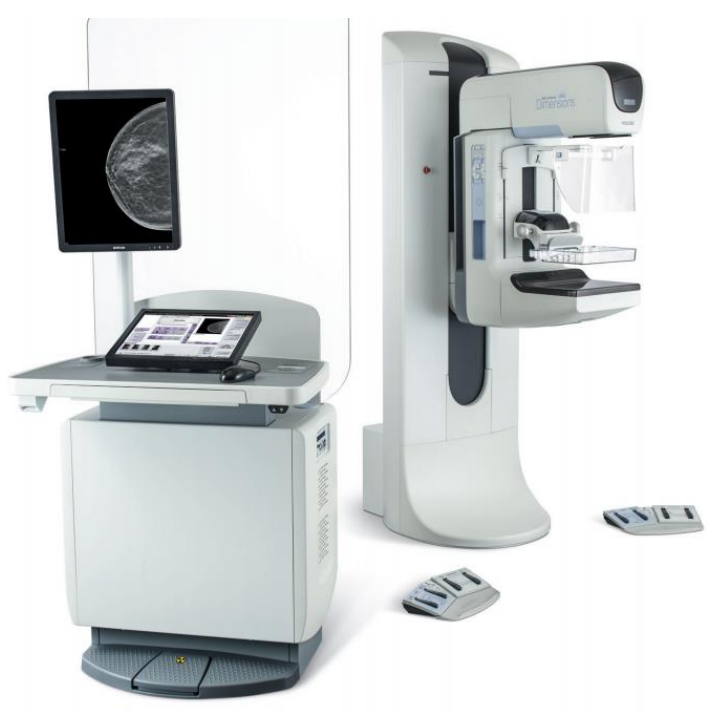

Figura 15: Equipamento Selenia Dimensions.

Fonte: (HOLOGIC, 2016) 


\subsubsection{Aquisição das imagens}

Devido à necessidade de imagens com diferentes doses de radiação para a validação quantitativa do método, não é possível utilizar imagens clínicas de uma paciente real, já que a dose de radiação recebida seria muito elevada e danosa a sua saúde.

Para contornar este problema foi utilizado um simulador antropomórfico de mama (phantom), que simula os tecidos e a anatomia mamária, também de propriedade do Hospital of the University of Pennsylvania,. Este phantom é fabricado com materiais que possuem as mesmas características de absorção de radiação que uma mama real e pode ser utilizado para produzir imagens que se assemelham a uma mamografia de um paciente. Além disso, a forma do phantom também se assemelha as estruturas físicas encontradas em uma mama real (COCKMARTIN et al., 2014).

Conforme representado na Figura 16 o phantom pode ser dividido em seis fatias para a adição de estruturas que simulam microcalcificações, sendo utilizado também para a validação de softwares de auxílio ao diagnostico (CAD).

Inicialmente, foram realizadas cinco capturas do phantom com a dose padrão calculada automaticamente pelo equipamento. Levando em conta as propriedades da "mama" e sua espessura (51mm no caso do phantom), o aparelho definiu uma tensão no tubo de $31 \mathrm{kVp}$ e uma corrente de exposição de $60 \mathrm{mAs}$, gerando uma radiação equivalente a 5,62mGy. Neste modelo de equipamento, cada captura equivale a quinze projeções cada uma com um ângulo de aquisição diferente.

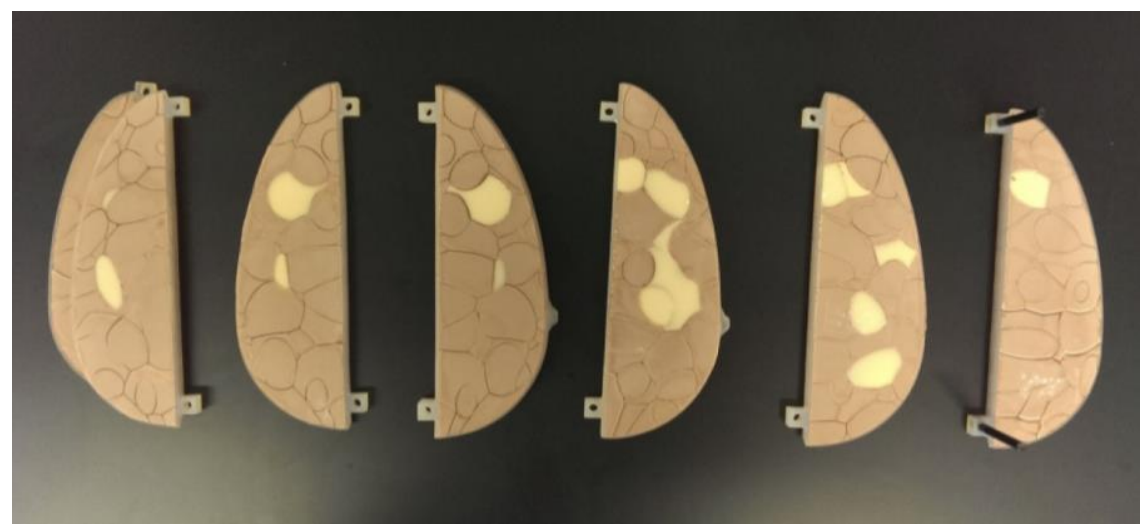

Figura 16: Phantom antropomórfico de propriedade do Hospital of the University of Pennsylvania. A divisão em seis fatias permite a simulação de microcalcificações na obtenção de imagens. 
Tabela 3: Relação das imagens adquiridas com o phantom.

\begin{tabular}{cccccc}
\hline $\begin{array}{c}\text { Número de } \\
\text { exposições }\end{array}$ & $\begin{array}{c}\text { Número de } \\
\text { Projeções }\end{array}$ & $\begin{array}{c}\text { Tensão no } \\
\text { tubo de } \\
\text { raios X }\end{array}$ & $\begin{array}{c}\text { Produto } \\
\text { corrente/tempo }\end{array}$ & $\begin{array}{c}\text { Dose de } \\
\text { radiação }\end{array}$ & $\begin{array}{c}\text { Dose Relativa } \\
\text { (considerando } \\
\text { a dose } \\
\text { padrão) }\end{array}$ \\
\hline 5 & 15 & $31 \mathrm{kVp}$ & $60 \mathrm{mAs}$ & $5,62 \mathrm{mGy}$ & $100 \%$ \\
\hline 5 & 15 & $31 \mathrm{kVp}$ & $52 \mathrm{mAs}$ & $4,78 \mathrm{mGy}$ & $85 \%$ \\
\hline 5 & 15 & $31 \mathrm{kVp}$ & $42 \mathrm{mAs}$ & $3,94 \mathrm{mGy}$ & $70 \%$ \\
\hline 5 & 15 & $31 \mathrm{kVp}$ & $30 \mathrm{mAs}$ & $2,81 \mathrm{mGy}$ & $50 \%$ \\
\hline
\end{tabular}

Em seguida, o equipamento foi colocado no modo manual e seus parâmetros alterados manualmente. A tensão no tubo foi mantida, porém o tempo de exposição foi reduzido de modo a adquirir imagens com doses de radiação reduzidas para $85 \%, 70 \%$ e $50 \%$ da dose padrão definida pelo modo automático. Em cada configuração foram realizadas mais cinco capturas. No total, foram obtidas 300 imagens (projeções de DBT) com dimensões 1664 x 2048 pixels. A Tabela 3 mostra um resumo da composição do banco de imagens utilizado nesse trabalho.

Analisando as imagens adquiridas é possível observar, como esperado, maior qualidade das imagens com maior dose de radiação, enquanto as imagens com menor radiação apresentam pior relação sinal/ruído. A Figura 17 mostra um exemplo de uma projeção central (ângulo $0^{\circ}$ ) nas diferentes doses de radiação, ressaltando que as imagens são somente para avaliação qualitativa, já que utilizam contraste e ganho automático.

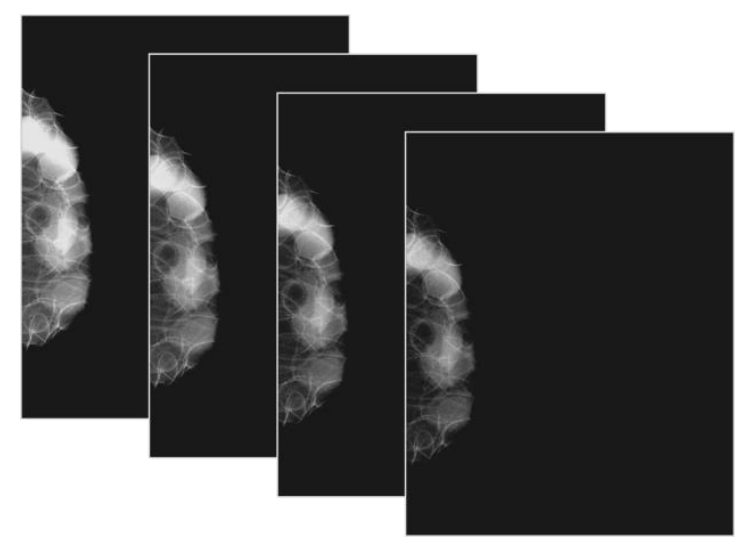

Figura 17: Projeção central do phantom antropomórfico em 4 doses diferentes $(100 \%$, $85 \%, 70 \%$ e $50 \%$ da esquerda para a direita respectivamente). 
Analisando as projeções dentro da mesma captura é possível notar a diferença de posicionamento das estruturas internas do phantom, já que o tubo se movimenta em cada aquisição. A Figura 18 mostra todas as projeções alinhadas, enquanto a Figura 19 mostra somente as projeções $n^{\circ} 00,07$ e 14 , adquiridas com o tubo inclinado em $-7,5^{\circ}, 0^{\circ}$ e $+7,5^{\circ}$, respectivamente.

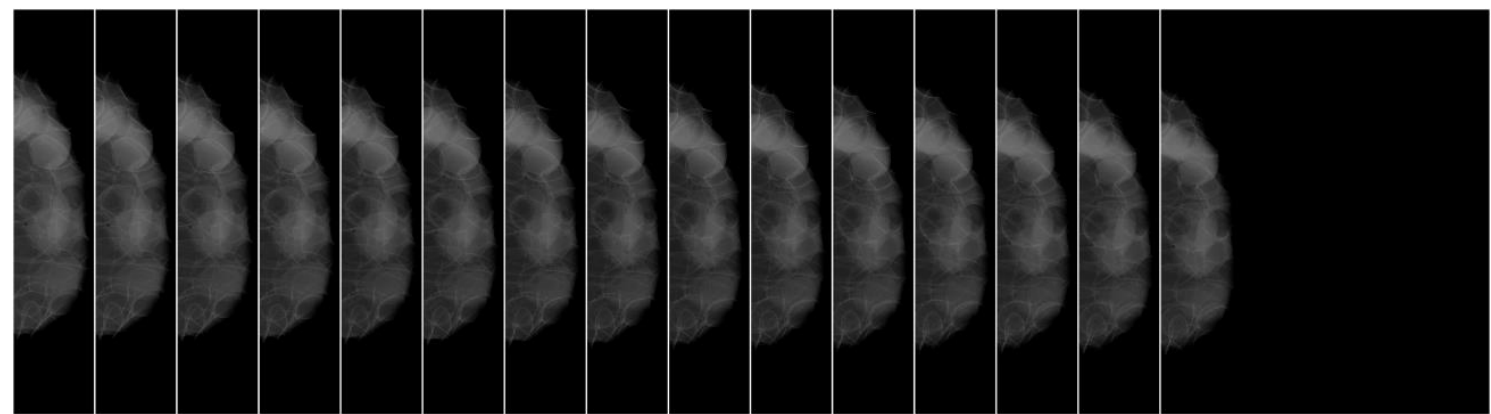

Figura 18: Todas as 15 projeções adquiridas com a mesma dose de radiação.

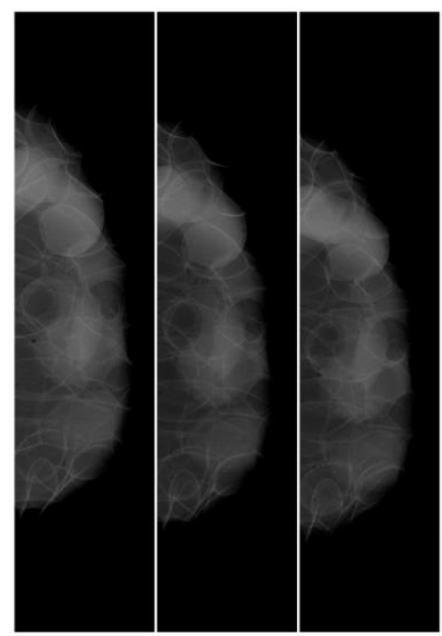

Figura 19: Ampliação das projeções inicial, central e final.

As imagens homogêneas foram adquiridas utilizando os mesmos parâmetros de exposição que as imagens de phantom, sendo que a única diferença é que, ao invés de utilizar o phantom antropomórfico, foi utilizado um bloco uniforme de acrílico com $4 \mathrm{~cm}$ de espessura. Esse bloco é utilizado para a calibração do equipamento e sempre está disponível para o operador, sem custo adicional. Para este trabalho, foi utilizada somente uma exposição em cada configuração, totalizando 4 capturas (60 imagens), como pode ser visto na Tabela 4. 
Tabela 4: Relação das imagens adquiridas com o bloco homogêneo.

\begin{tabular}{cccccc}
\hline $\begin{array}{c}\text { Número de } \\
\text { exposições }\end{array}$ & $\begin{array}{c}\text { Número de } \\
\text { Projeções }\end{array}$ & $\begin{array}{c}\text { Tensão no } \\
\text { tubo de } \\
\text { raios X }\end{array}$ & $\begin{array}{c}\text { Produto } \\
\text { corrente/ } \\
\text { Tempo }\end{array}$ & $\begin{array}{c}\text { Dose de } \\
\text { radiação }\end{array}$ & $\begin{array}{c}\text { Dose Relativa } \\
\text { (considerand } \\
\text { o a dose } \\
\text { padrão) }\end{array}$ \\
\hline 1 & 15 & $31 \mathrm{kVp}$ & $60 \mathrm{mAs}$ & $5,62 \mathrm{mGy}$ & $100 \%$ \\
\hline 1 & 15 & $31 \mathrm{kVp}$ & $52 \mathrm{mAs}$ & $4,78 \mathrm{mGy}$ & $85 \%$ \\
\hline 1 & 15 & $31 \mathrm{kVp}$ & $42 \mathrm{mAs}$ & $3,94 \mathrm{mGy}$ & $70 \%$ \\
\hline 1 & 15 & $31 \mathrm{kVp}$ & $30 \mathrm{mAs}$ & $2,81 \mathrm{mGy}$ & $50 \%$ \\
\hline
\end{tabular}

\subsubsection{Reconstrução}

Após cada aquisição de um conjunto de imagens, ou seja, 15 projeções para cada uma das doses em 5 realizações, as imagens serviram como entrada ao software de reconstrução Briona (KUO et al., 2011), para a geração das fatias da reconstrução.

Com espaçamento de $1 \mathrm{~mm}$, cada subconjunto gerou 51 fatias distintas que representam a vista representativa de um plano paralelo às placas de compressão do aparelho, sendo a fatia equivalente a $0 \mathrm{~mm}$ a mais próxima da placa inferior.

No total foram reconstruídas 765 imagens, seguindo o padrão informado na Tabela 5. Vale ressaltar que as imagens adquiridas com a dose padrão de radiação (100\%) não necessitam ser reconstruídas para este trabalho, já que não serão utilizadas nas métricas quantitativas.

Observando as imagens na Figura 20, é possível analisar que, diferentemente das projeções cruas, as reconstruções não apresentam nítida alteração nos valores de brilho e contraste entre diferentes doses, já que o algoritmo equaliza todas as imagens para melhor visualização do profissional responsável.

A Figura 20 apresenta a fatia central $(25 \mathrm{~mm})$ da reconstrução nas três doses diferentes. Uma magnificação de uma região de interesse aleatória é exibida da Figura 21 e possibilita a visualização dos diferentes níveis de ruído presentes em cada dose.

Dentro de uma mesma realização em uma mesma dose, cada fatia apresenta informações distintas, provendo ao médico especialista noção espacial das estruturas dentro da mama. Algumas fatias são apresentadas na Figura 22 e possibilitam a observação da variação que uma mesma estrutura sofre em decorrer da espessura da mama. 
Tabela 5: Relação das imagens reconstruídas.

\begin{tabular}{cccc}
\hline $\begin{array}{c}\text { Número de } \\
\text { exposições }\end{array}$ & $\begin{array}{c}\text { Número de } \\
\text { Fatias }\end{array}$ & Dose de radiação & $\begin{array}{c}\text { Dose Relativa } \\
\text { (considerando a } \\
\text { dose padrão) }\end{array}$ \\
\hline 5 & 51 & $4,78 \mathrm{mGy}$ & $85 \%$ \\
\hline 5 & 51 & $3,94 \mathrm{mGy}$ & $75 \%$ \\
\hline 5 & 51 & $2,81 \mathrm{mGy}$ & $50 \%$ \\
\hline
\end{tabular}

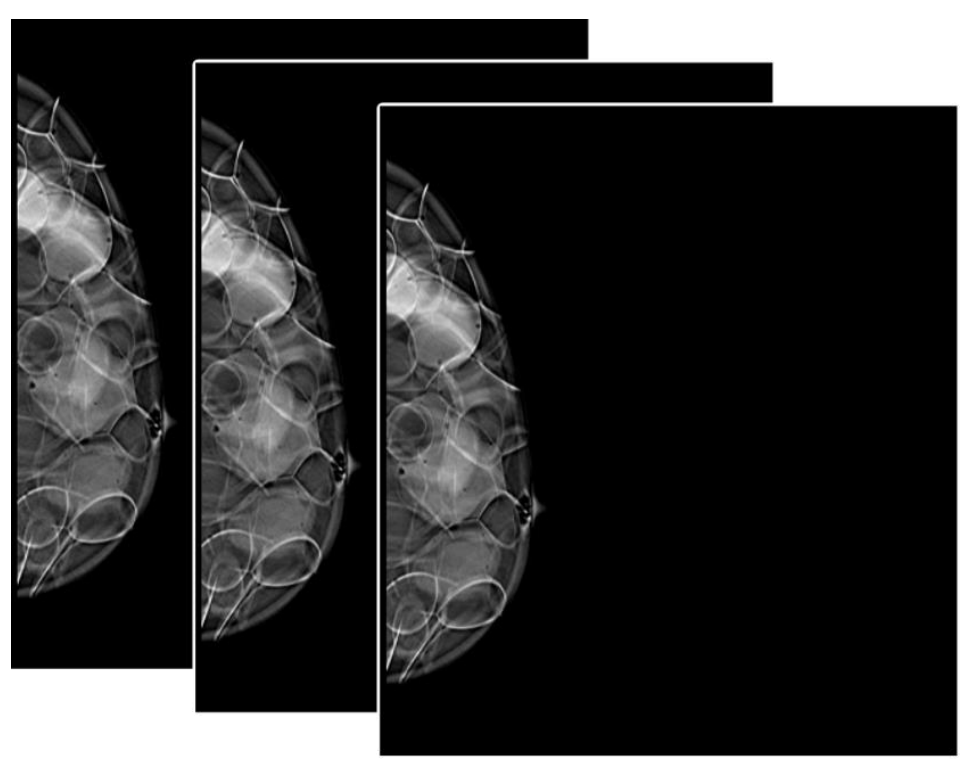

Figura 20: Fatias centrais da reconstrução em doses diferentes: 50\%, $70 \%$ e $85 \%$ respectivamente.
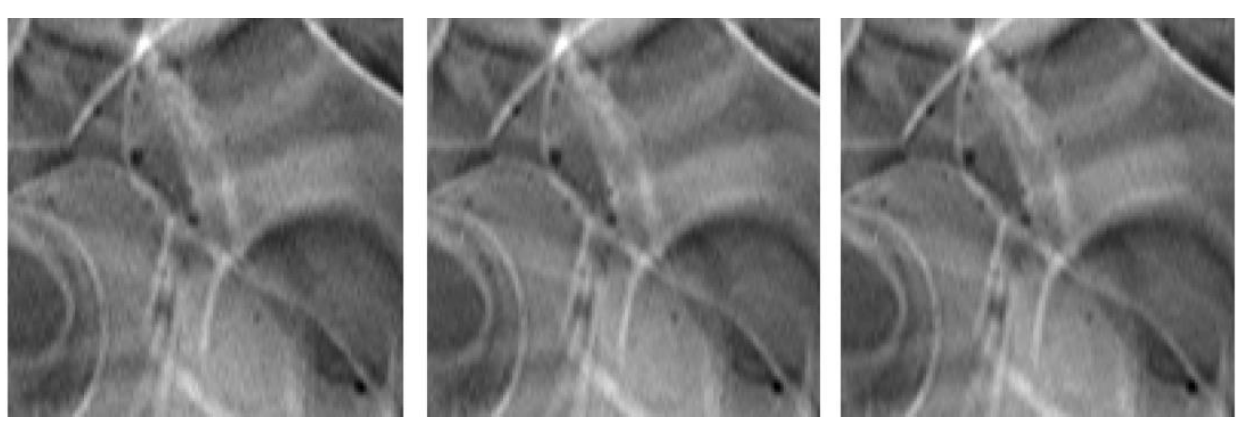

Figura 21: Região de interesse da reconstrução de doses diferentes: 50\%, 70\% e 85\% respectivamente. 


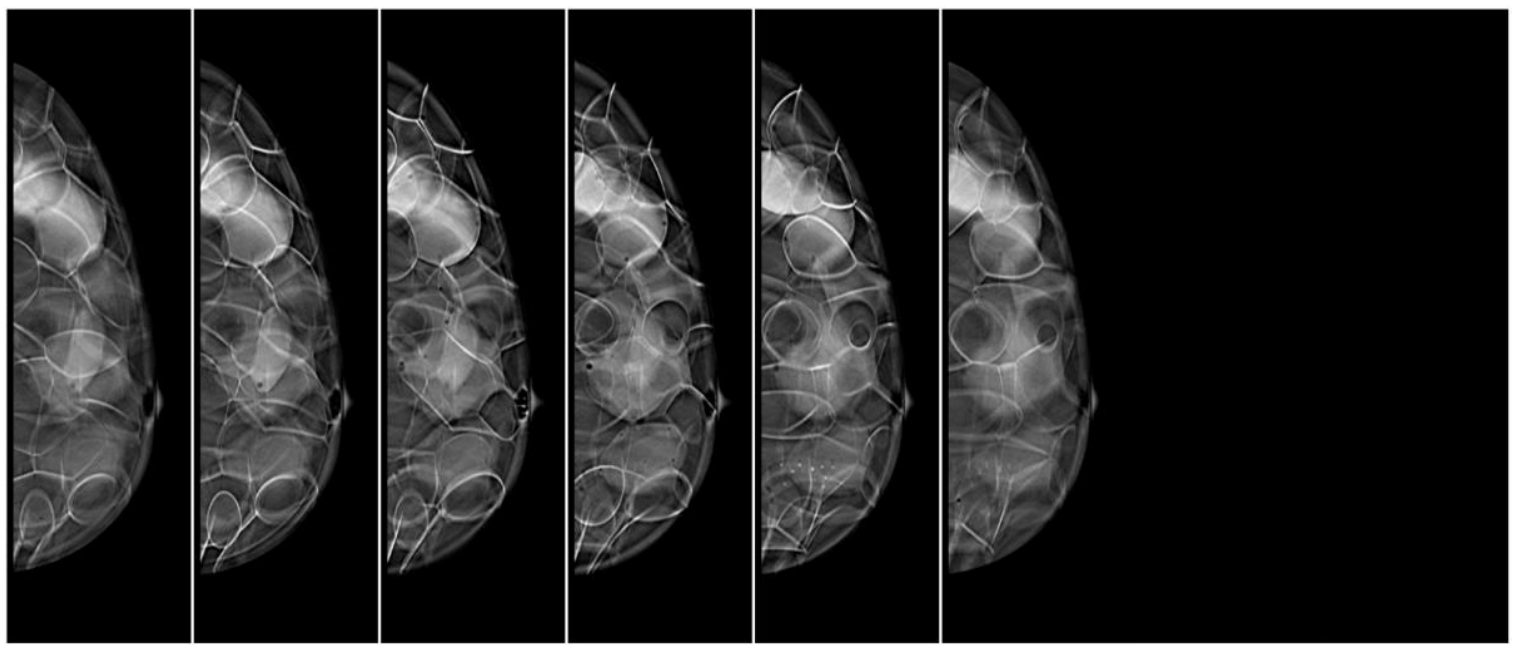

Figura 22: Fatias diferentes da reconstrução: 25, 35, 45, 55, 65 e $75 \mathrm{~mm}$ respectivamente (dose $85 \%)$.

\subsection{Método proposto}

\subsubsection{Aplicação direta do método de simulação de redução de dose para imagens} de DBT

Inicialmente um dos objetivos deste trabalho é a utilização do método desenvolvido por (BORGES et al., 2015) em imagens de DBT. Originalmente desenvolvido para mamografia digital, o método requer uma imagem adquirida com a dose padrão de radiação (100\%) e duas imagens uniformes para a simulação de redução de dose. Essas imagens uniformes devem ser adquiridas na mesma dose da imagem original, ou seja, $100 \%$ da dose padrão e outra na dose que se deseja simular. O método calcula a quantidade de ruído que deve ser inserida na imagem original a partir da análise da diferença do ruído entre as duas imagens uniformes.

Apesar desse método ter sido originalmente proposto para imagens de mamografia digital 2D, ele foi adaptado para ser utilizado também para simulação da redução da dose de radiação em imagens de tomossíntese mamária. Devido ao fato de um exame de tomossíntese resultar na geração de 15 projeções, o método deve ser aplicado em cada imagem de projeção individualmente, antes do processo de reconstrução das fatias tomográficas.

Apesar das imagens do bloco uniforme apresentarem uma aparência homogênea, um estudo mais detalhado possibilita a observação de que, na tomossíntese, todas as projeções são distintas. Devido a isto, assim como nas imagens em que será aplicado o método de simulação, 
deve-se utilizar todas as projeções de ambas as imagens homogêneas, sempre mantendo a relação entre as projeções, ou seja, para simular a redução de dose para a projeção 7 , utiliza-se também a projeção 7 de ambas as imagens uniformes. A Figura 23 exemplifica a utilização do método com todas as projeções, diferenciando a aplicação com a apresentada na Figura 10.

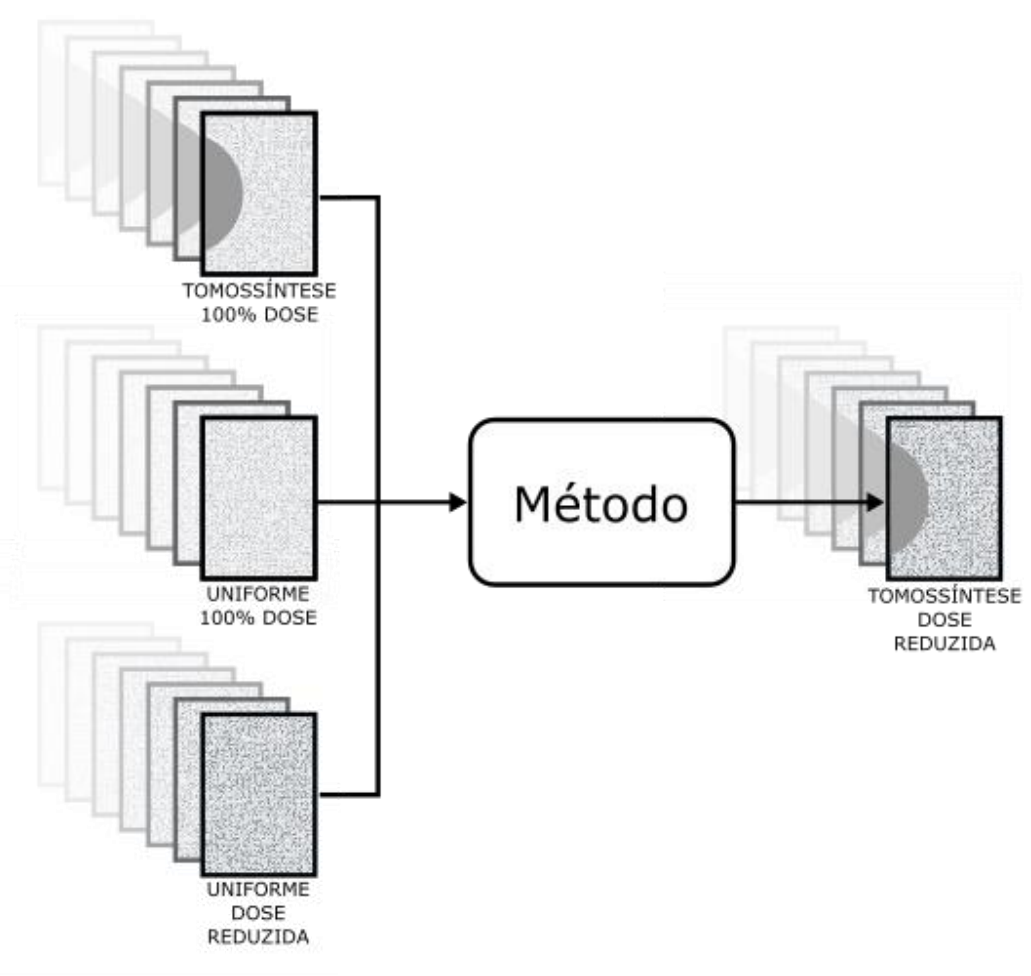

Figura 23: Representação das projeções da tomossíntese na utilização do método proposto inicialmente para mamografia digital $2 \mathrm{D}$.

Fonte: Ilustração elaborada pelo autor

\subsubsection{Alteração do espectro de potência com kernel de ruído}

O método proposto por Borges et al (BORGES et al., 2015) descrito anteriormente, apesar de ser preciso para mamografia digital, utiliza uma máscara de ruído branco no processo de simulação de redução de dose. Essa máscara é calculada a partir da diferença entre as duas imagens uniformes e insere ruído na quantidade correta para que a imagem resultante apresente a mesma relação sinal-ruído que uma imagem adquirida com dose de radiação reduzida. No entanto, em nenhum momento a cor do ruído (ou o espectro de potência do ruído) é levada em consideração. 
Uma ilustração do impacto que o espectro de potência tem na geração de ruído pode ser visto na Figura 24. Na representação as três regiões superiores, apesar de visivelmente distintas, apresentam ruído com valor médio nulo e variância unitária. A diferença entre essas imagens está somente na cor do ruído, exemplificada pelo seu espectro de potência. A imagem da esquerda apresenta ruído com cor branca, logo o espectro é uniforme independente da frequência espacial. A imagem central apresenta ruído com grande intensidade nas baixas frequências e menor nas altas frequências. Já a imagem da direita apresenta um comportamento oposto à imagem central, com maior quantidade de ruído de alta frequência do que de baixa.

( I )
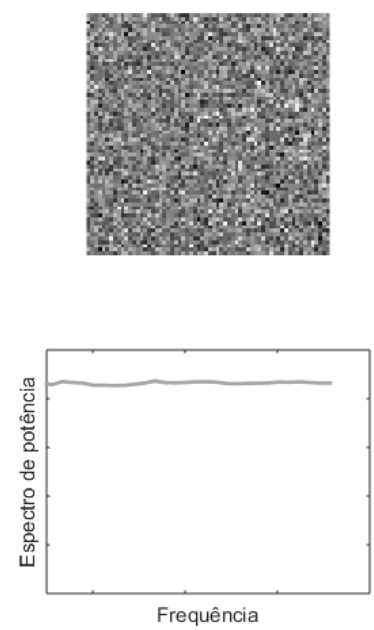

( II )
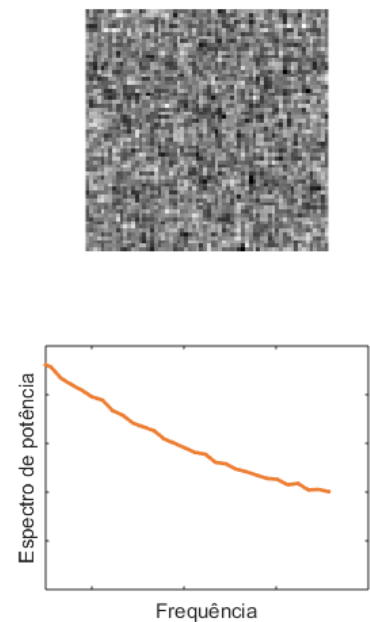

( III )
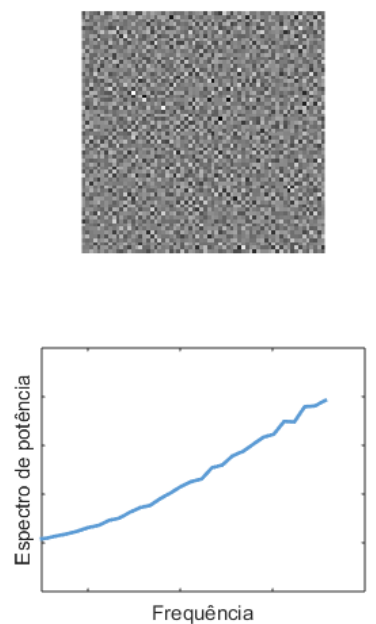

Figura 24: Exemplo da importância do espectro de potência em ruído simulado. (I) Ruído com espectro de potência uniforme para todas as frequências (ruído branco). (II) Ruído com maior intensidade nas baixas frequências. (III) Ruído com maior intensidade nas altas frequências.

Fonte: Ilustração elaborada pelo autor

O ruído presente nas imagens de DBT (tanto nas projeções como nas fatias reconstruídas) possui uma cor característica. Os métodos de simulação, em geral, inserem uma máscara de ruído branco na imagem original para simular a redução na dose de radiação. Isso acaba gerando um erro no espectro de potência de ruído da imagem simulada, em relação à imagem real, pois a simulação acaba descaracterizando a coloração original do ruído, deixando o espectro de potência mais uniforme do que deveria. A Figura 25 exibe uma representação simplificada desse processo: A curva laranja A representa o espectro de potência de uma máscara de ruído branco, logo possui intensidade constante para todas as frequências. 


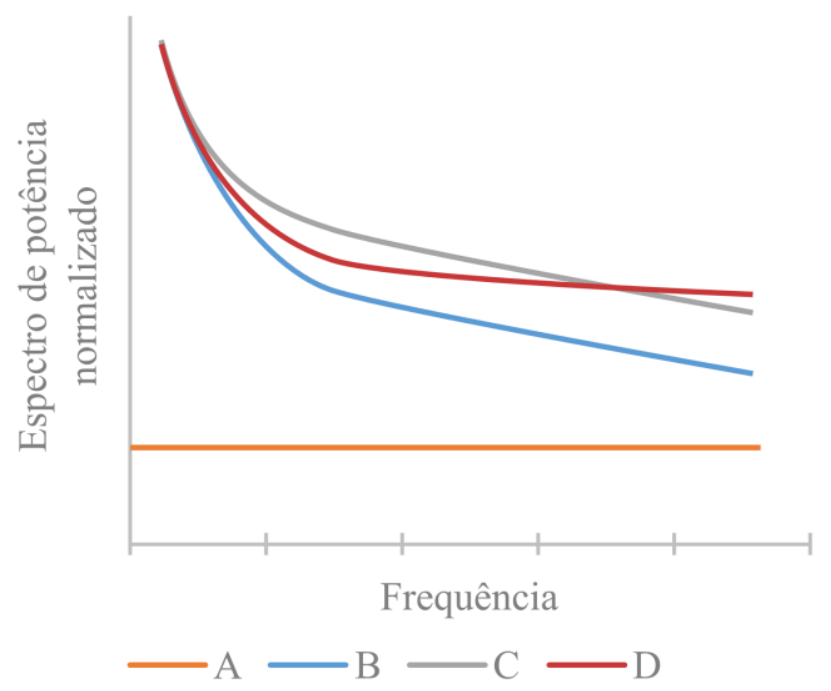

Figura 25: Exemplo de com o espectro de potência pode é alterado com o método de simulação. A curva A representa um ruído branco, B representa o espectro de potência de uma imagem ruidosa qualquer. Uma simulação ideal acarretaria na curva C, onde a inclinação é mantida. A curva D representa uma simulação que altera a cor do ruído.

Fonte: Ilustração elaborada pelo autor

A curva B em azul representa o espectro de potência normalizado de uma imagem com alta dose de radiação. A inclinação da curva demonstra uma relação não uniforme entre a intensidade e a frequência, que caracteriza a cor do ruído. Considerando uma simulação de redução de dose ideal, o resultado seria equivalente ao apresentado na curva $\mathrm{C}$ em cinza, onde a intensidade é relativamente maior, porém a inclinação da curva se mantem quando comparado à curva $\mathrm{B}$.

A adição de ruído branco teria como resultado uma simulação com intensidade de espectro de potência média próxima a ideal, porém a inclinação da curva apresenta inclinação menor do que o desejado, mais próximo do ruído branco, como exemplificado pela curva $\mathrm{D}$ em vermelho.

Assim, o método proposto nesse trabalho tem como objetivo minimizar esse problema de inserção de ruído branco na simulação da redução da dose de radiação. A proposta consiste em extrair a informação da cor do ruído da imagem original e a partir dessa informação gerar um filtro digital (kernel). A convolução desse kernel com a máscara de ruído branca previamente calculada para ser inserida na imagem original, modifica a cor do ruído da máscara fazendo com que ele possua a mesma cor do ruído original da imagem, minimizando o erro na simulação da redução da dose de radiação. 
Este kernel é calculado através do valor médio do espectro de potência bidimensional em diversas regiões de interesse em uma das imagens homogêneas utilizadas para simulação da redução da dose de radiação pelo método proposto por Borges et al. Inicialmente a imagem homogênea é dividida em diversas regiões de interesse (n) quadradas e de mesmo tamanho. Como as imagens de mamografia e DBT apresentam ruído dependente do espaço é desejável que as regiões de interesse estejam próximas à região central de posicionamento da mama.

Em seguida, todas essas pequenas regiões são transportadas para o domínio de Fourier, gerando o espectro de potência bidimensional. Cada um desses espectros representa a coloração original do ruído da imagem. A fim de suavizar o espectro, uma média pixel a pixel é realizada nas $n$ amostras. O espectro de ruído bidimensional obtido representa a coloração característica do ruído da imagem homogênea.

Para a geração do kernel é realizada a transformada inversa de Fourier retornando os dados ao domínio do espaço. Finalmente, seguindo a Equação 22, uma normalização de variância é realizada para que, ao realizar a convolução desse kernel com a máscara de ruído uniforme, o espectro de potência seja alterado, mas o valor da variância seja mantido.

$$
\operatorname{kernel} \operatorname{normalizado}(x, y)=\frac{\operatorname{kernel}(x, y)}{\sqrt{\sum_{x} \sum_{y} \operatorname{kernel}(x, y)^{2}}}
$$

A sequência de etapas para a obtenção do kernel de ruído pode ser vista na Figura 26.

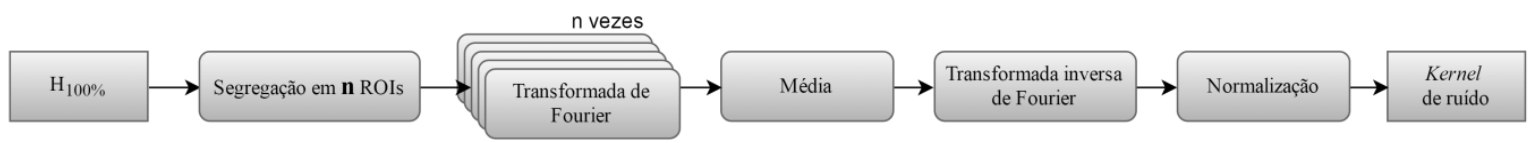

Figura 26: Etapas para cálculo do kernel de ruído. A imagem uniforme de referencia é segregada em diversas regiões de interesse. Cada região é enviada para o domínio de Fourier onde o valor médio é obtido. É realizada a transformada inversa e o valor final, após normalização, representa o kernel de ruído. 
Após o cálculo do kernel de ruído deve-se realizar a sua convolução com a máscara de ruído branco presente na segunda etapa do método desenvolvido por (BORGES et al., 2015), deste modo a estrutura final presente na Figura 27 deve substituir a estrutura original do método mostrado na Figura 13.

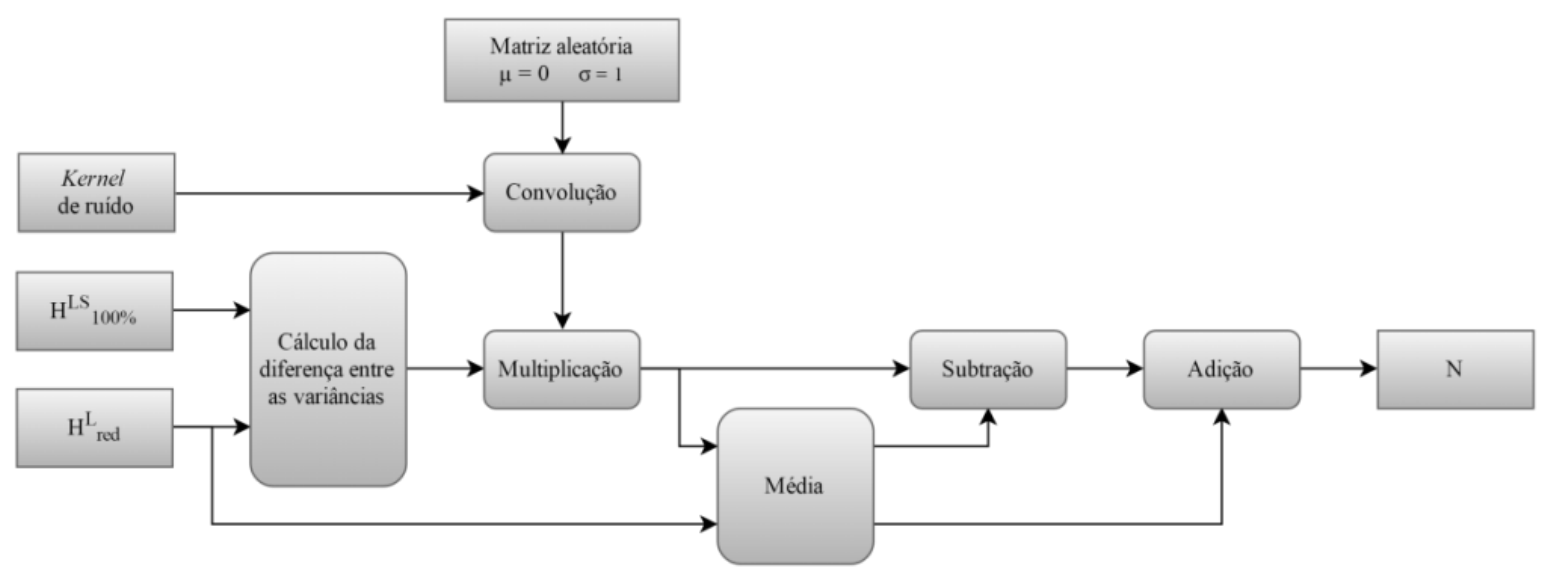

Figura 27: Etapa de cálculo do ruído com adição do kernel. Uma máscara de ruído branco possui sua intensidade ajustada pelo valor da variância e pelo kernel de ruído para condizer com o valor de variância que deve ser adicionado a imagem simulada.

\subsection{Validação do método proposto}

Considerando que o objetivo do trabalho é a obtenção de imagens de tomossíntese com dose reduzida de radiação através de simulação, é necessária a utilização de medidas quantitativas para a avaliação dos resultados obtidos. As avaliações foram conduzidas comparando as imagens reais de DBT, obtidas experimentalmente em diferentes doses de radiação, com as imagens obtidas por meio do método de simulação proposto nesse trabalho. As análises foram realizadas tanto nas imagens de projeção (antes da reconstrução) como também nas fatias reconstruídas. Três métodos diferentes de avaliação foram utilizados nesse trabalho. 


\subsubsection{Média local dos níveis de cinza das imagens reais e simuladas antes e após a reconstrução}

Considerando que tanto as imagens simuladas quanto reais são escalares, ou seja, constituídas por pixels, o método mais intuitivo de comparação é a relação entre os valores de intensidade de cada pixel. Devido ao grande número de pixels em cada imagem, foi definida uma região de tamanho 256 x 1024 localizada na área central da mama. Essa região foi subdividida em 256 sub-regiões de interesse (ROIs) com dimensões 32 x 32 pixels e sem sobreposição entre si. Uma imagem com um exemplo dessas regiões pode ser vista na Figura 28.
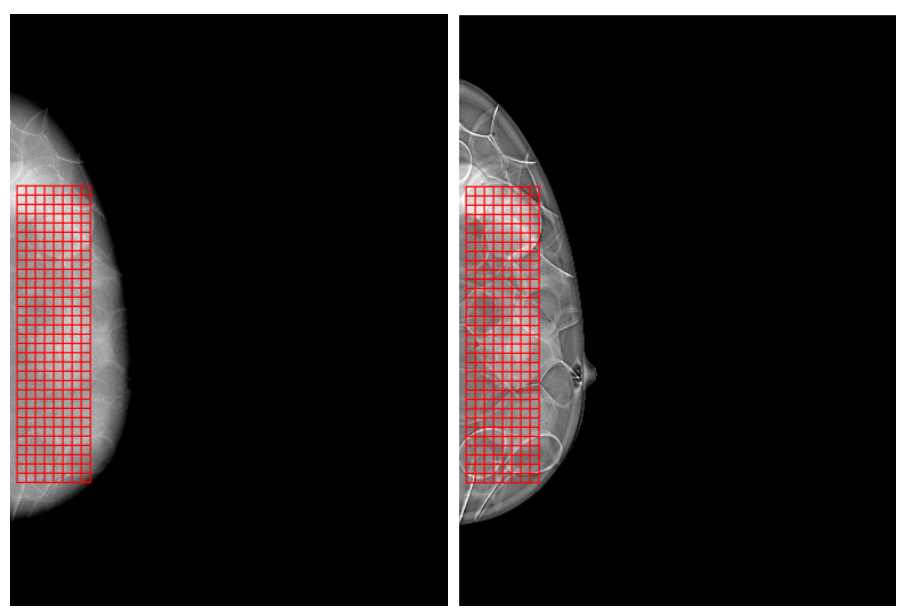

Figura 28: Imagem com ROIs para cálculo do valor médio e desvio padrão. À esquerda, projeção central da tomossíntese e, à direita fatia central da reconstrução.

Fonte: Ilustração elaborada pelo autor

Após o cálculo do valor médio dos pixels em cada ROI, tanto para as imagens simuladas quanto para as imagens reais, em todas as doses e em todas as realizações, foi calculado o erro percentual relativo em todos os casos.

\subsubsection{Desvio padrão local dos níveis de cinza das imagens reais e simuladas antes e após a reconstrução}

Utilizando as mesmas regiões de interesse, foi avaliado o ruído das imagens reais e simuladas a partir do cálculo do desvio padrão dos valores de intensidade dos pixels, já que se 
trata de uma medida da dispersão de uma variável aleatória. O valor absoluto do desvio padrão das imagens não é de importância para este trabalho, já que, em imagens mamográficas, esses valores são indicativos da arquitetura e textura dos tecidos. O interesse aqui é em avaliar se o ruído das imagens reais e simuladas são equivalentes. Para a validação do método de simulação proposto foi considerado o erro percentual entre os valores do desvio padrão medido tanto nas imagens reais quanto nas simuladas.

\subsubsection{Espectro de potência das imagens}

Adicionalmente à média e ao desvio padrão, foi escolhido comparar as imagens também no domínio da frequência. Para isso, foi utilizada a mesma região de 256 x 1024 pixels localizada na área central da mama, porém, seccionada somente em quatro ROIs como exibido na Figura 29 e Figura 30. Novamente, foi escolhido apresentar os dados com o erro percentual entre as imagens reais e simuladas.
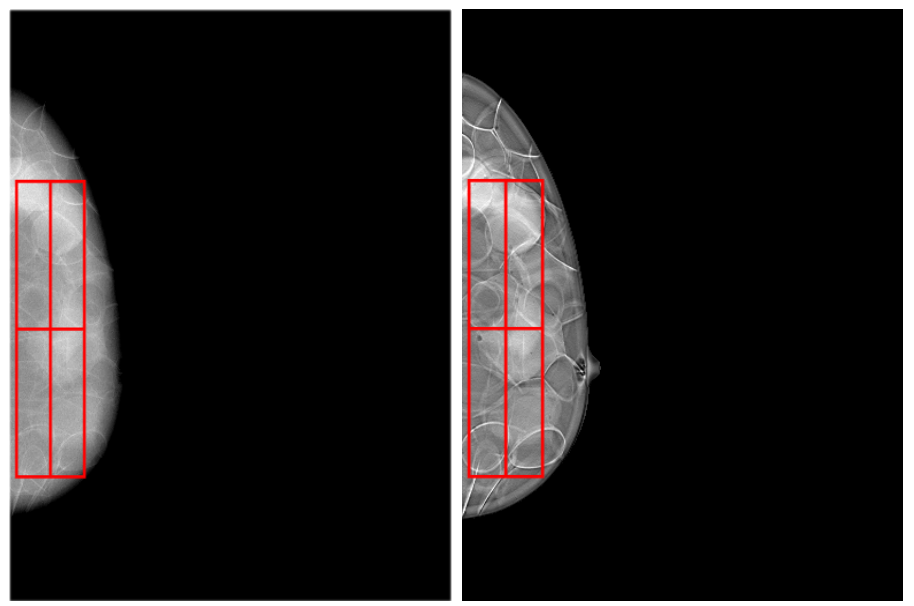

Figura 29: Regiões utilizadas para o cálculo do espectro de potência. À esquerda, projeção central da tomossíntese e, à direita, fatia central da reconstrução.

Fonte: Ilustração elaborada pelo autor 


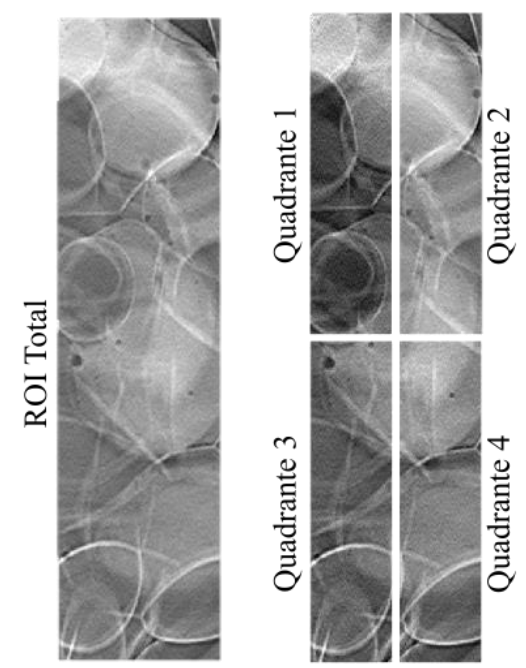

Figura 30: Identificação das regiões utilizadas para o cálculo do erro no do espectro de potência.

Fonte: Ilustração elaborada pelo autor

\subsubsection{Avaliação cruzada}

Considerando que foram adquiridas cinco realizações de cada conjunto de imagens, pode-se aumentar os dados estatísticos fazendo análise cruzada das imagens reais com as imagens simuladas. Com isso, garantimos que cada imagem simulada seja avaliada cinco vezes, cada uma com um conjunto diferente de imagens reais. Desse modo, é possível aumentar o número de comparações para 25.

É valido ressaltar que as três métricas escolhidas foram utilizadas para avaliar tanto as projeções da tomossíntese quanto as fatias da reconstrução, ambas passando pela avaliação cruzada para melhorar a dispersão estatística. Se considerarmos que para o valor médio em cada conjunto de imagem foram analisadas 256 ROIs, com 15 projeções e 25 combinações de comparação, foram calculados 96.000 dados. Já para a análise das imagens reconstruídas esse número sobe para 320.000 dados. 


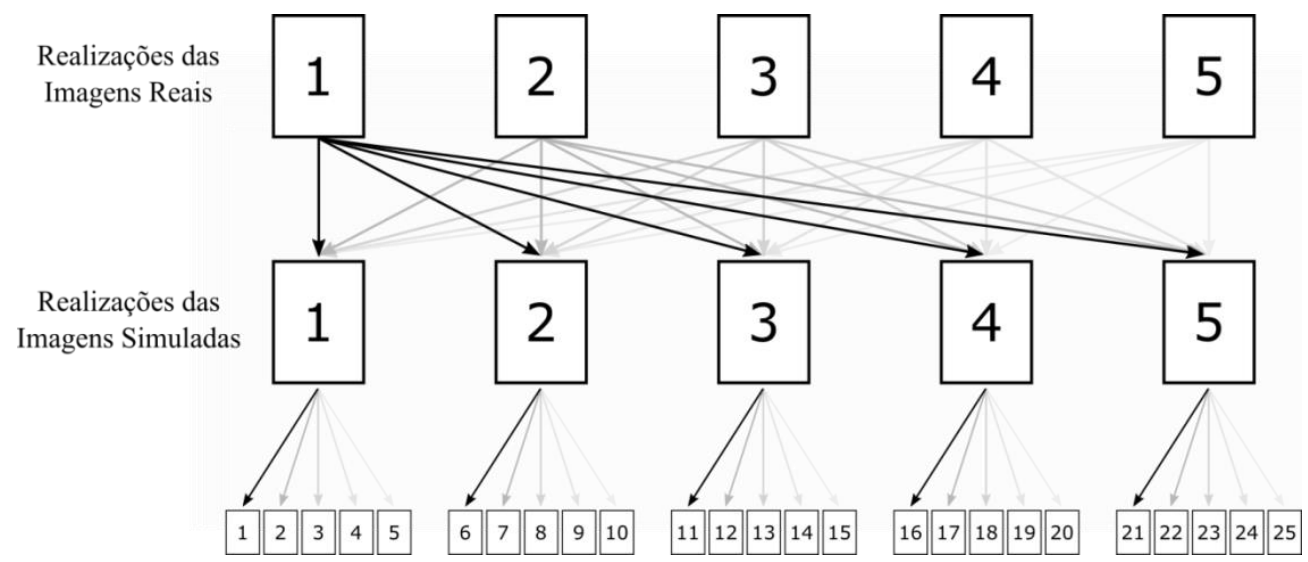

Figura 31: Comparação cruzada. Cada imagem simulada é comparada com 5 imagens reais deste modo é possível aumentar os dados estatísticos melhorando a análise.

Fonte: Ilustração elaborada pelo autor 


\section{Resultados}

Este capítulo é subdividido em quatro seções e tem por objetivo apresentar os resultados obtidos na pesquisa. A primeira seção apresenta a análise das características de ruído de um equipamento de DBT comercial, utilizando um conjunto de imagens homogêneas. A segunda seção relata as diferenças entre as imagens obtidas nos exames de mamografia e de tomossíntese. A terceira seção apresenta os resultados com as imagens de projeção de tomossíntese simuladas utilizando o método proposto por (BORGES et al., 2015), que foi adaptado para aplicação em imagens de DBT. A última seção apresenta os resultados da simulação de redução da dose de radiação com a correção do espectro de potência do ruído utilizando o método proposto por este trabalho.

\subsection{Análise do ruído em DBT}

Inicialmente, foi realizada uma investigação para verificar se as imagens uniformes de diferentes projeções em um mesmo equipamento e com mesma dose apresentam comportamentos semelhantes. Essa análise é essencial tanto para a utilização do algoritmo de (BORGES et al., 2015) quanto para o desenvolvimento do algoritmo próprio. Se fosse comprovado que as imagens homogêneas eram equivalentes para diferentes projeções, os algoritmos de simulação poderiam ser simplificados, utilizando a mesma imagem homogênea para todas as projeções. Considerando que as imagens apresentassem características distintas em cada projeção, seria necessária a utilização de uma imagem homogênea para a simulação de cada projeção individualmente.

\subsubsection{Média local das imagens homogêneas}

A Figura 32 apresenta o valor da média local (filtro da média com janela quadrada $32 \times 32$ pixels) em três diferentes projeções de DBT adquiridas em um equipamento comercial utilizando um bloco uniforme de acrílico. É possível observar que a variação de intensidade dos pixels (mensurados em níveis de cinza - gray level - gl) dentro de uma mesma imagem é muito pequena $(\sim 5 \%)$, de $570 \mathrm{gl}$ no centro da imagem para $550 \mathrm{gl}$ nas bordas. Essa pequena 
variação é coerente com o esperado, já que os detectores são calibrados para possuírem uma correção de não-uniformidade (flat-fielding) já descrito no Capítulo 2. Para facilitar a visualização das imagens, foi utilizada a técnica de cores falsas.
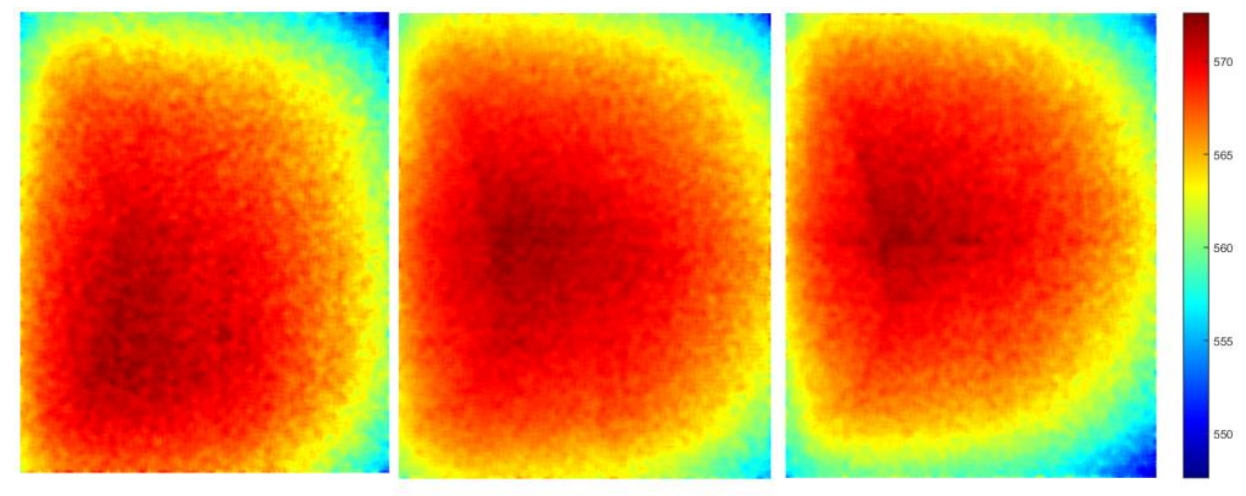

Figura 32: Média local dos pixels das imagens de projeção de um equipamento de DBT obtidas com um phantom homogêneo em diferentes ângulos. A imagem à esquerda corresponde à Projeção 0 , adquirida com um ângulo de 7,5 à esquerda; a imagem ao centro corresponde à projeção central (Projeção 7), adquirida com ângulo $0^{\circ}$; a imagem à direita corresponde à projeção adquirida com um ângulo de $7,5^{\circ}$ à direita (Projeção 14).

A variação mais perceptível é a translação da imagem no eixo de movimentação do braço do equipamento de tomossíntese. Na Figura 32, a imagem à esquerda corresponde à projeção adquirida com o ângulo máximo de 7,5 à esquerda (Projeção 0). Note que ela apresenta sua região mais intensa nitidamente mais próxima à borda inferior esquerda. No decorrer das projeções essa região se desloca em direção à borda superior direita, como mostram as imagens ao centro, que corresponde à projeção central adquirida com ângulo $0^{\circ}$ (Projeção 7), e a imagem à direita, que corresponde à projeção adquirida com ângulo máximo de 7,5 à direita (Projeção 14). Essa variação nos valores dos pixels é causada pelo movimento do tubo de raios $\mathrm{X}$, e mostra que cada projeção apresenta características distintas uma das outras.

Devido à dificuldade de analisar e exibir visualmente as 15 projeções, foi escolhido segmentar uma coluna de cada projeção e concatená-las a fim de criar uma superfície. Sabendo que cada imagem de projeção de DBT tem dimensões de 1664 x 2048 pixels, foi escolhido segmentar a coluna 400 , pois representa $1 / 4$ da imagem e fica próxima à área de posicionamento da mama. A Figura 33 mostra uma representação visual dessas colunas. 


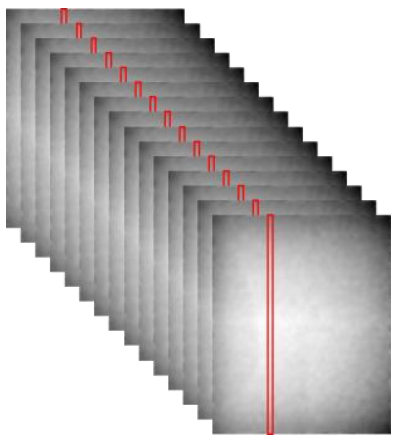

Figura 33: Representação da segmentação de uma coluna em cada projeção de DBT.

Analisando a superfície criada através da concatenação das colunas das projeções (Figura 34), é possível observar que as projeções centrais apresentam maiores valores de nível de cinza, enquanto que as projeções iniciais e finais apresentam valores $4,4 \%$ menores.

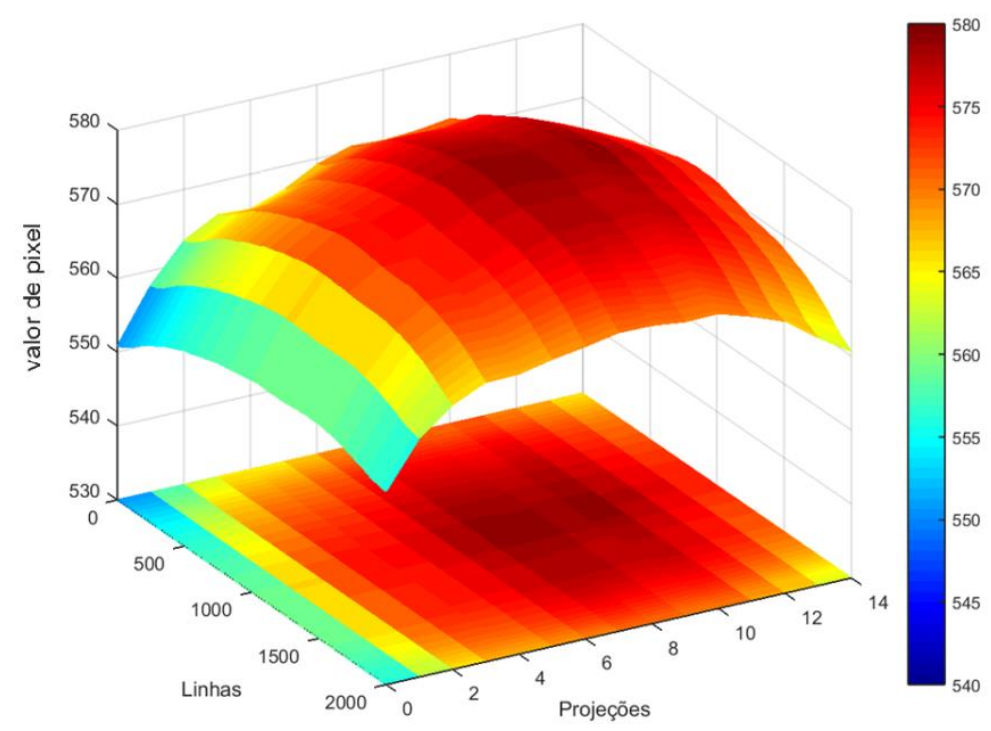

Figura 34: Valor médio - Comparação de uma coluna de cada projeção.

Considerando outras doses de radiação de entrada é possível observar a alta proporcionalidade entre dose de entrada e valor médio. A dose de entrada foi controlada variando-se o tempo de exposição do equipamento. Os parâmetros radiográficos para a dose padrão (100\%) foram ajustados automaticamente pelo equipamento. Utilizando os mesmos parâmetros radiográficos da imagem padrão (100\%), variou-se o tempo de exposição para valores correspondentes à $85 \%, 70 \%$ e $50 \%$ da exposição padrão, para se obter doses de 
radiação mais baixas. A Figura 35 mostra um gráfico tridimensional com a média local da projeção 7 em quatro doses de radiação diferentes.

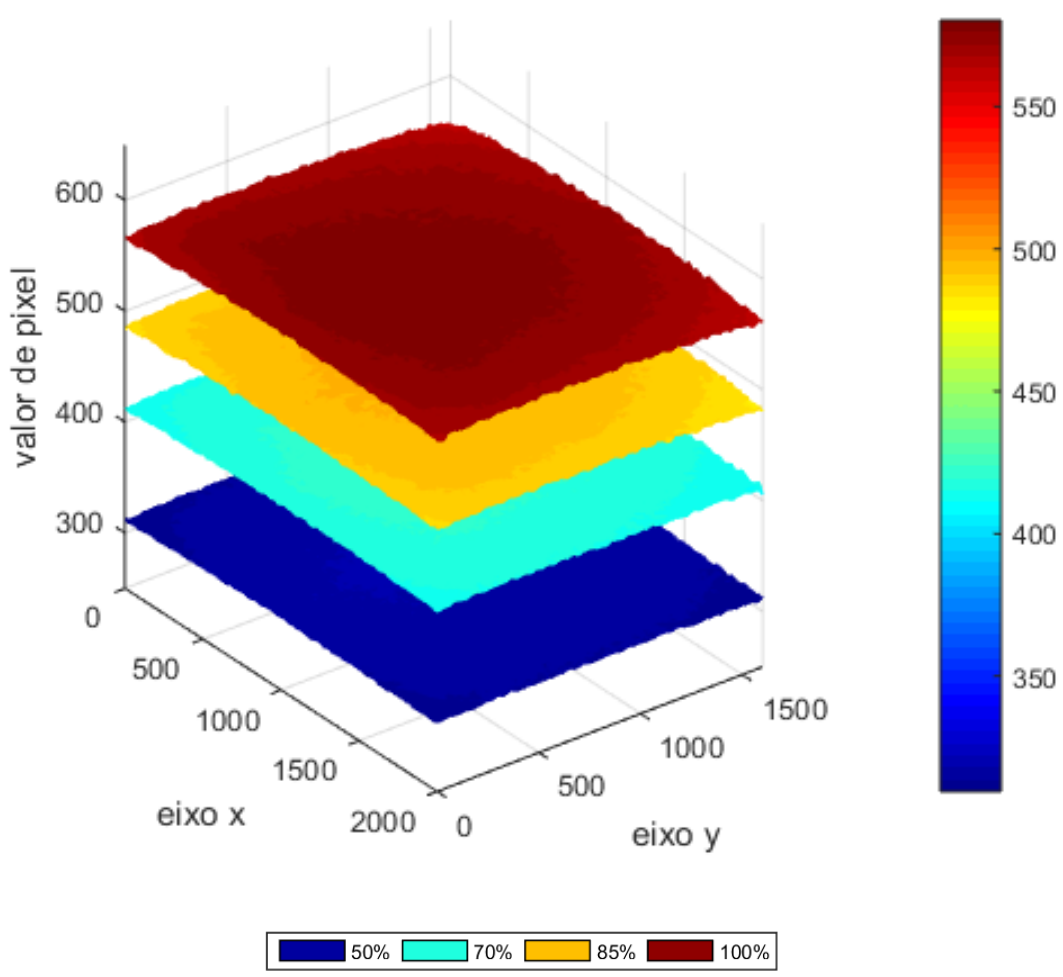

Figura 35: Comparação do valor médio local entre diferentes doses de radiação (projeção 7).

Para simplificar a visualização da comparação entre o valor médio de cada projeção, foi calculado o valor médio da imagem toda (2000x1600 pixels, pequenas bordas foram retiradas). A Figura 36 mostra esses resultados para cada uma das quinze projeções e em quatro doses de entrada. É possível observar a mesma característica previamente vista para a dose $100 \%$ em doses menores: projeções centrais apresentam maior valor médio que projeções iniciais e finais. 


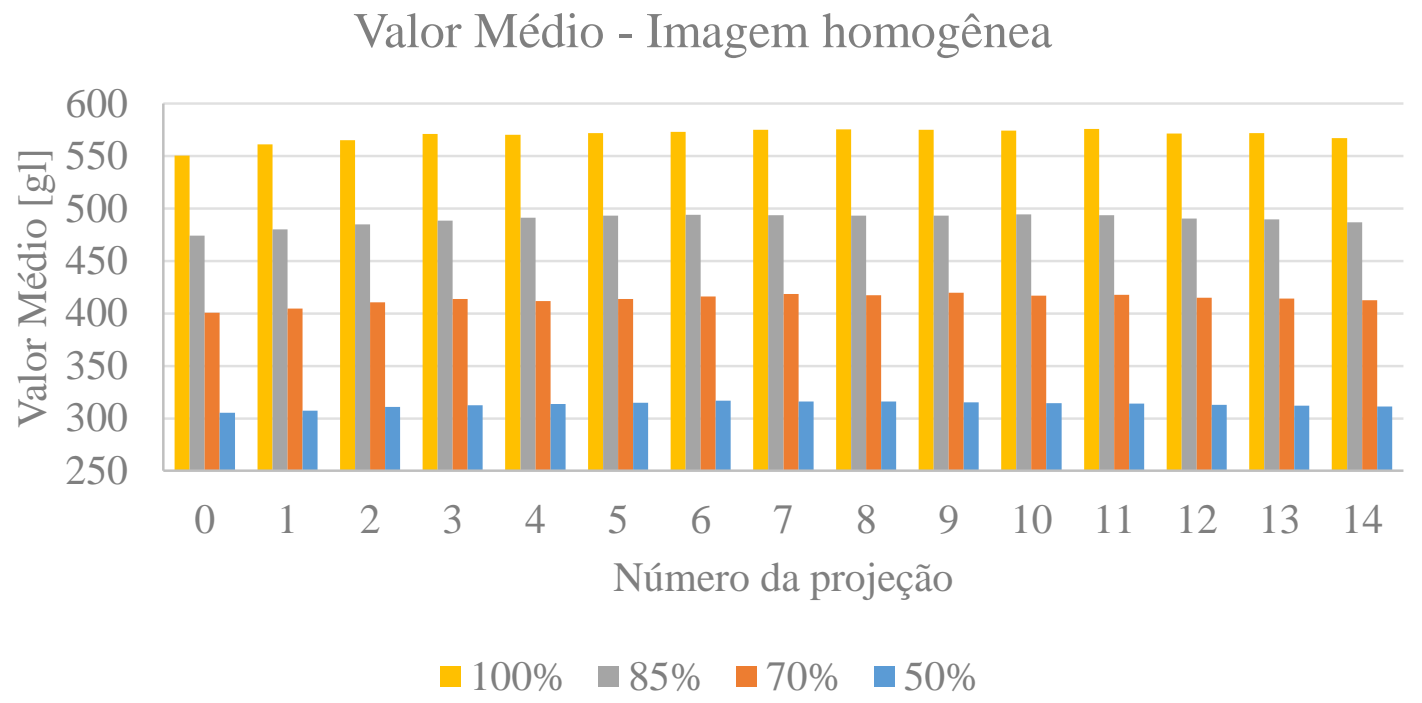

Figura 36: Comparação do valor médio da imagem nas 15 projeções em 4 doses de radiação.

A Tabela 6 apresenta os valores quantitativos do erro percentual encontrado entre as projeções com maior e menor valor médio.

Tabela 6: Erro percentual do valor médio dos valores de pixel entre as projeções.

\begin{tabular}{ccccc}
\hline Dose & $100 \%$ & $85 \%$ & $70 \%$ & $50 \%$ \\
\hline $\begin{array}{c}\text { Erro percentual entre a projeção } \\
\text { com maior e menor valor médio }\end{array}$ & $4,38 \%$ & $4,15 \%$ & $4,50 \%$ & $3,70 \%$ \\
\hline
\end{tabular}

\subsubsection{Offset do detector}

Utilizando a relação entre o valor médio dos níveis de cinza de cada projeção e a dose de entrada é possível calcular o valor de offset que é adicionado à matriz de detectores, como exemplificado na Figura 11.

É possível observar, na Figura 37, que a característica da curva apresenta comportamento semelhante ao descrito pela Equação 15. Através do cálculo do coeficiente linear da regressão linear, temos que o valor do offset é de 56,935gl. 


\section{Relação entre dose de entrada e valor médio}

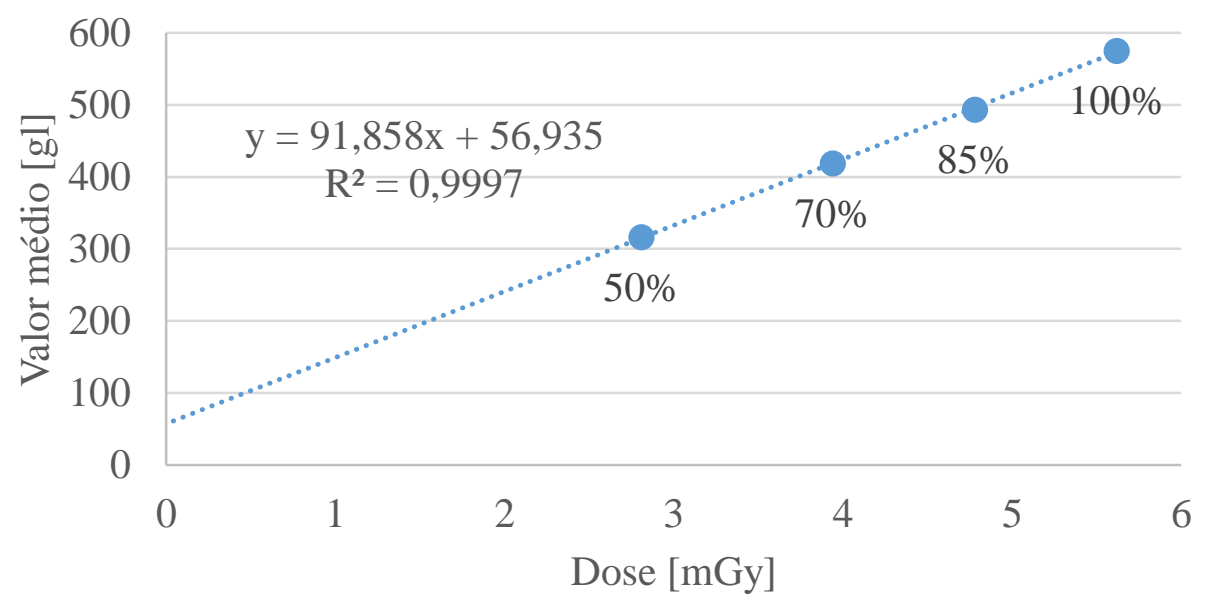

Figura 37: Relação entre dose de entrada e valor médio dos níveis de cinza da projeção central (7) de um exame de DBT adquirido com o bloco uniforme de PMMA.

Realizando o mesmo cálculo, mas considerando todos os pixels da imagem, temos na Figura 38 que a região central/esquerda da imagem apresenta comportamento uniforme com valor de offset próximo de $55 \mathrm{gl}$, enquanto as bordas à direita apresentam valores mais elevados, chegando próximos de 60gl. Como o valor de offset deve ser igual para todos os pixels, essa distinção nas bordas provavelmente é causada pelo cálculo errôneo do valor médio dos valores de pixel. Esse erro é devido ao maior nível de ruído da extremidade direita da imagem, causada pela correção de não-uniformidade (flat-fielding).

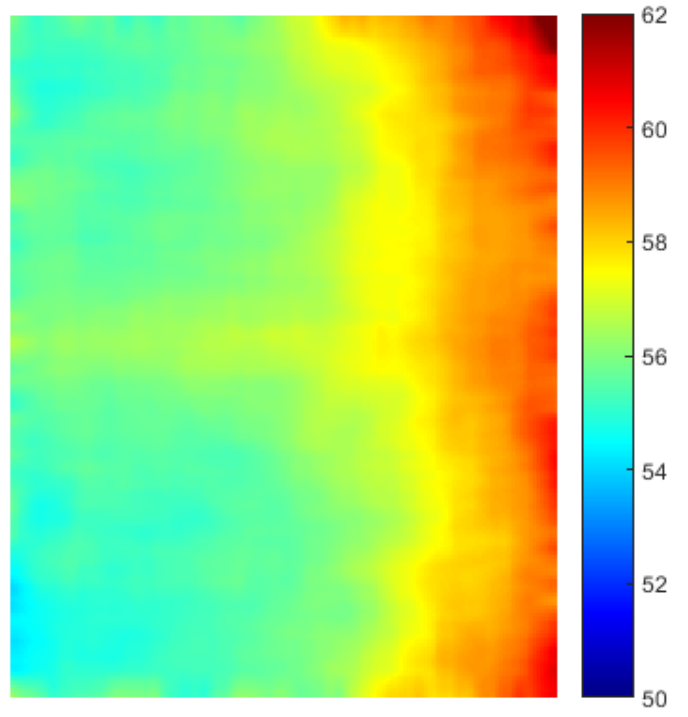

Figura 38: Valor do offset de uma projeção de DBT pixel a pixel (projeção 07). 
O valor médio dos offsets em cada uma das projeções está representado na Figura 39. Apesar de pequenas diferenças, pode-se observar que o valor de offset, que na prática é constante entre as projeções, apresenta valor medido de 55,31 $\pm 2,11 \mathrm{gl}$.

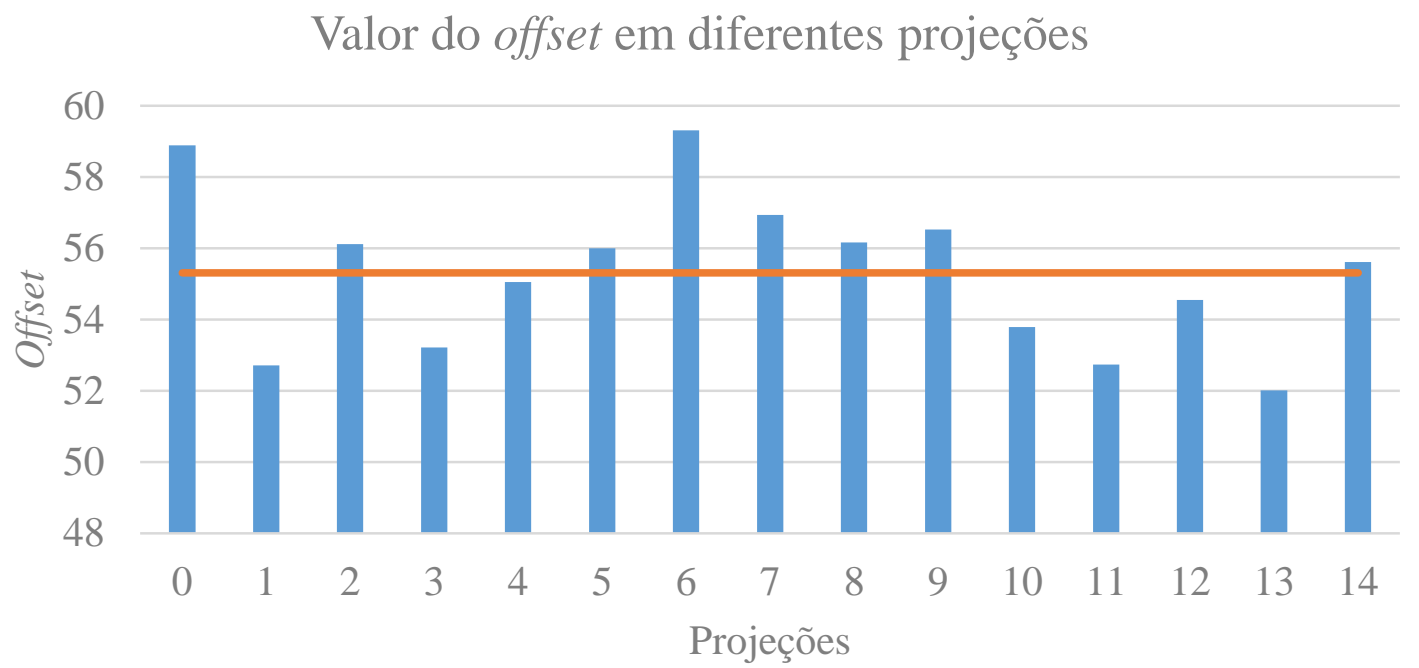

Figura 39: Cálculo do Offset em diferentes projeções.

\subsubsection{Desvio padrão local dos níveis de cinza das imagens homogêneas (ruído)}

A Figura 40 mostra o desvio padrão local (calculado com janela de 32x32 pixels) obtido em diferentes projeções com dose de entrada 100\%. Similarmente ao valor médio local, o desvio padrão apresenta características de translação de sua região mais intensa com o decorrer das projeções.

Nota-se que a região central apresenta valores próximos de $8 \mathrm{gl}$, enquanto a borda direita apresenta valores próximos de 16gl. Essa variação evidencia o efeito do flat-fielding no ruído das imagens de DBT, que faz com que os valores médios dos níveis de cinza sejam praticamente uniformes, mas o ruído não, apresentando grande variação principalmente na extremidade direita (mais distante do tórax do paciente), onde a influência do efeito heel é mais intensa. 

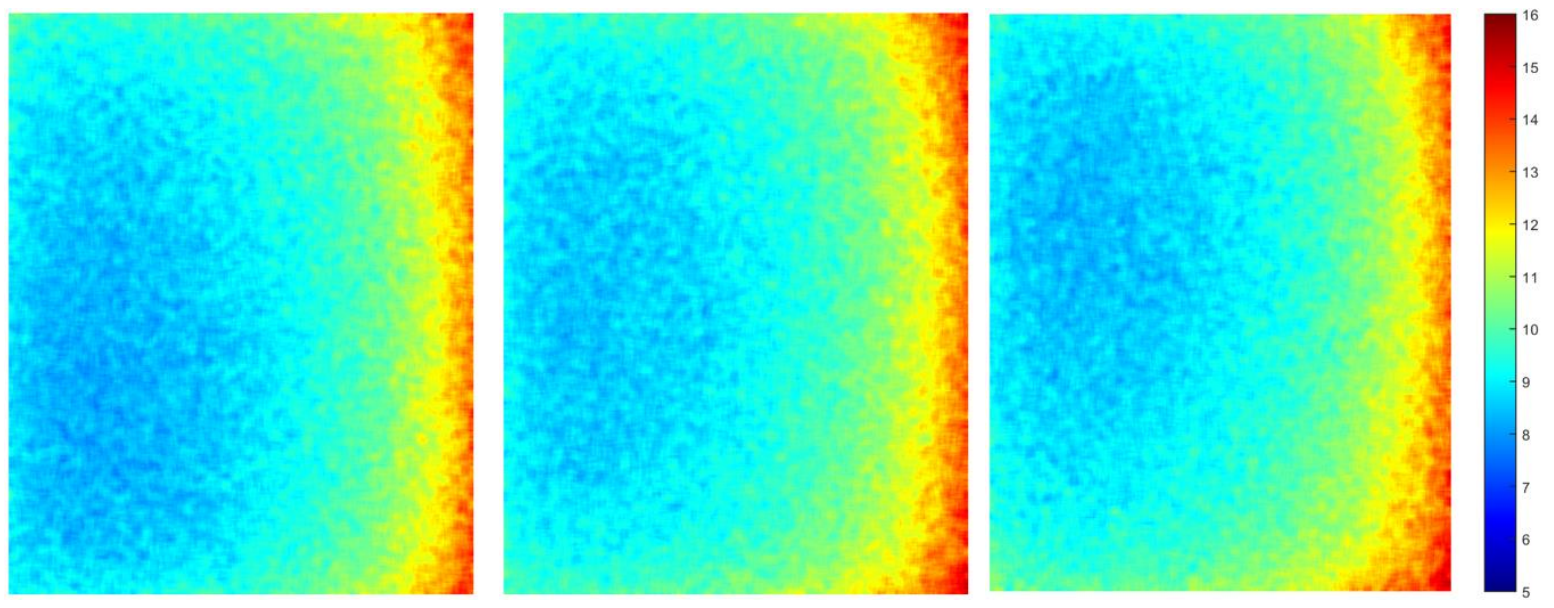

Figura 40: Desvio padrão de imagens homogêneas em diferentes projeções $(0,7$ e 14 respectivamente).

Utilizando a mesma lógica de segmentação de colunas apresentado na Figura 33, podese observar, na Figura 41, que o desvio padrão sofre alteração pouco significativa entre as projeções, com exceção nas extremidades das imagens que sofrem grande mudança. Nota-se que nas projeções iniciais as primeiras linhas apresentam valores de desvio padrão menores que as últimas linhas. No entanto, nas projeções finais esse padrão se inverte. Esse deslocamento é ocasionado pela movimentação do tubo de raios $\mathrm{X}$ do equipamento.

A Figura 42 apresenta a comparação entre as projeções e as quatro doses, levando em conta o valor médio do desvio padrão em toda a imagem.

Assim como no valor médio, o desvio padrão apresenta valores maiores nas projeções centrais e menores nas projeções iniciais e finais. A Tabela 7 mostra quantitativamente a diferença percentual entre as projeções com maior e menor valor de desvio padrão para 4 doses diferentes de radiação. 


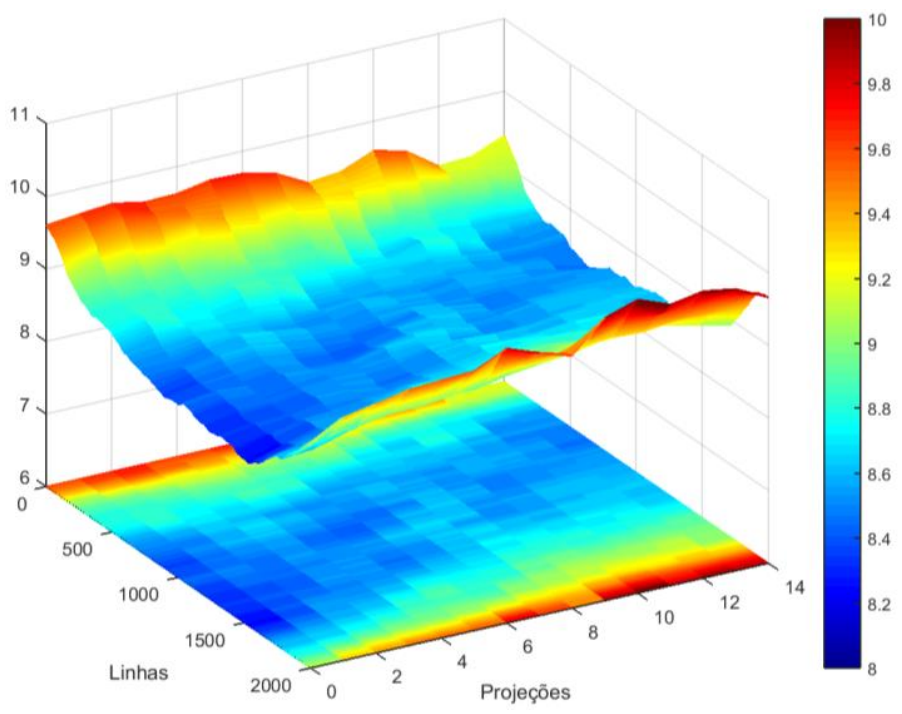

Figura 41: Desvio padrão dos valores de níveis de cinza - Comparação de uma coluna de cada projeção.

Desvio padrão - Imagem homogênea

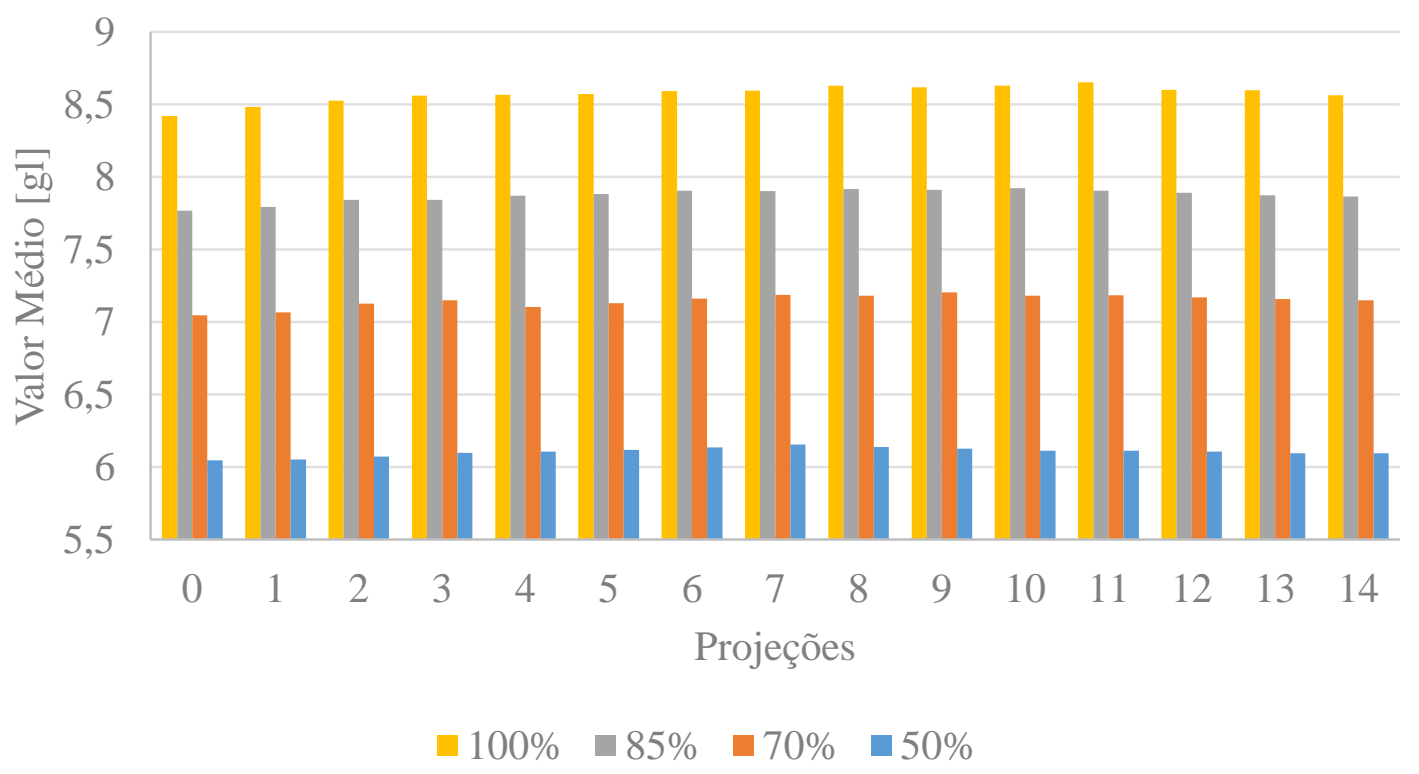

Figura 42: Comparação do desvio padrão da imagem nas 15 projeções em 4 doses.

Tabela 7: Erro percentual do desvio padrão entre projeções.

\begin{tabular}{ccccc}
\hline Dose & $100 \%$ & $85 \%$ & $70 \%$ & $50 \%$ \\
\hline $\begin{array}{c}\text { Erro percentual entre a projeção } \\
\text { com maior e menor valor médio }\end{array}$ & $2.68 \%$ & $1.99 \%$ & $2.19 \%$ & $1.79 \%$ \\
\hline
\end{tabular}




\subsubsection{Fator de escala do ruído Poisson}

Como o ruído predominante em imagens de tomossíntese segue o padrão de uma variável Poisson, a relação entre variância do ruído e média do sinal é um parâmetro importante para a análise do ruído pois corresponde ao fator de escala do ruído Poisson. A Figura 43 mostra que o valor do fator de escala, assim como o valor médio e de desvio padrão, apresenta alta dependência espacial em cada projeção. Com magnitude que varia de aproximadamente 0,1 a 0,4 entre uma extremidade e outra da imagem. Esse parâmetro indica que o ruído presente em imagens de tomossíntese é do tipo Poisson com fator de escala diferente de 1, como descrito na Equação 6.

Diferentemente das medidas anteriores, o valor médio do fator de escala não apresenta padrão característico entre projeções. Na Figura 44 é possível observar uma aleatoriedade da relação, em contrapartida ao padrão facilmente reconhecido anteriormente. Essa aleatoriedade mostra que, apesar do valor da média e desvio padrão variar em relação às projeções, sua relação permanece aproximadamente constante. Logo, o tipo de ruído é o mesmo para todas as projeções.
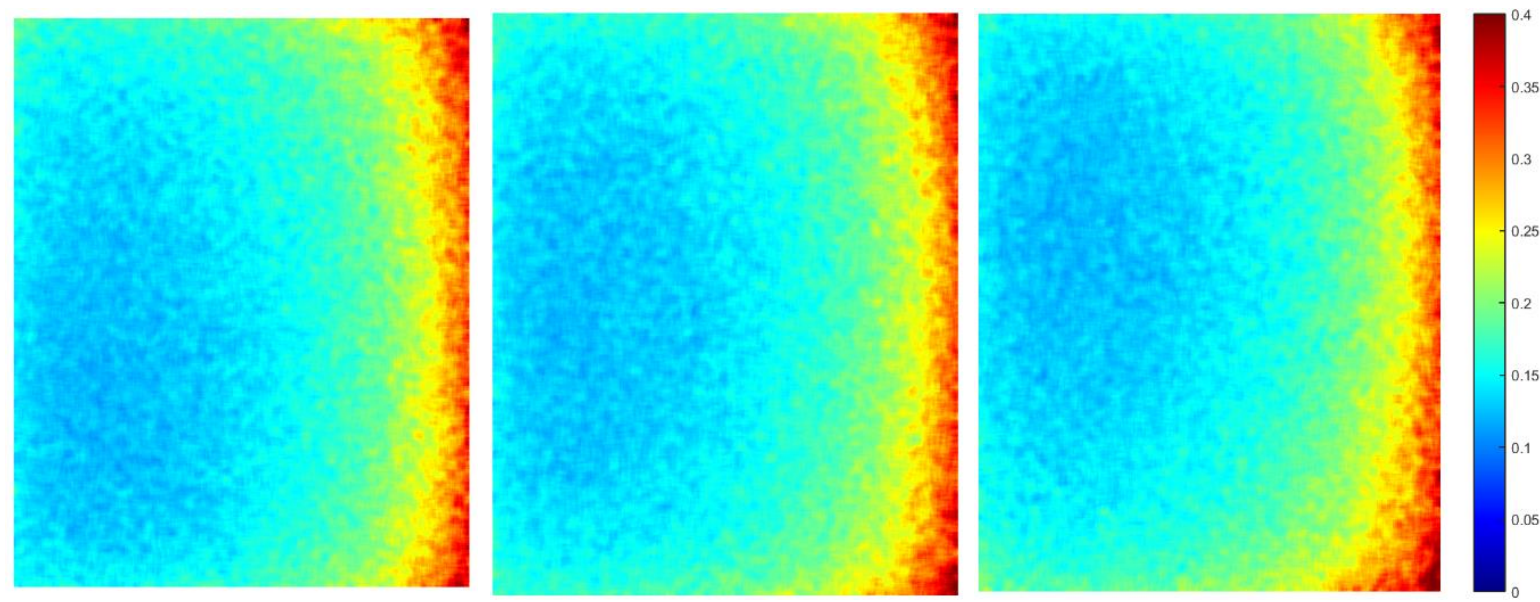

Figura 43: Fator de escala do ruído Poisson de imagens homogêneas em diferentes projeções $(0,7$ e 14 respectivamente). 


\section{Relação do fator de escala - Imagem homogênea}

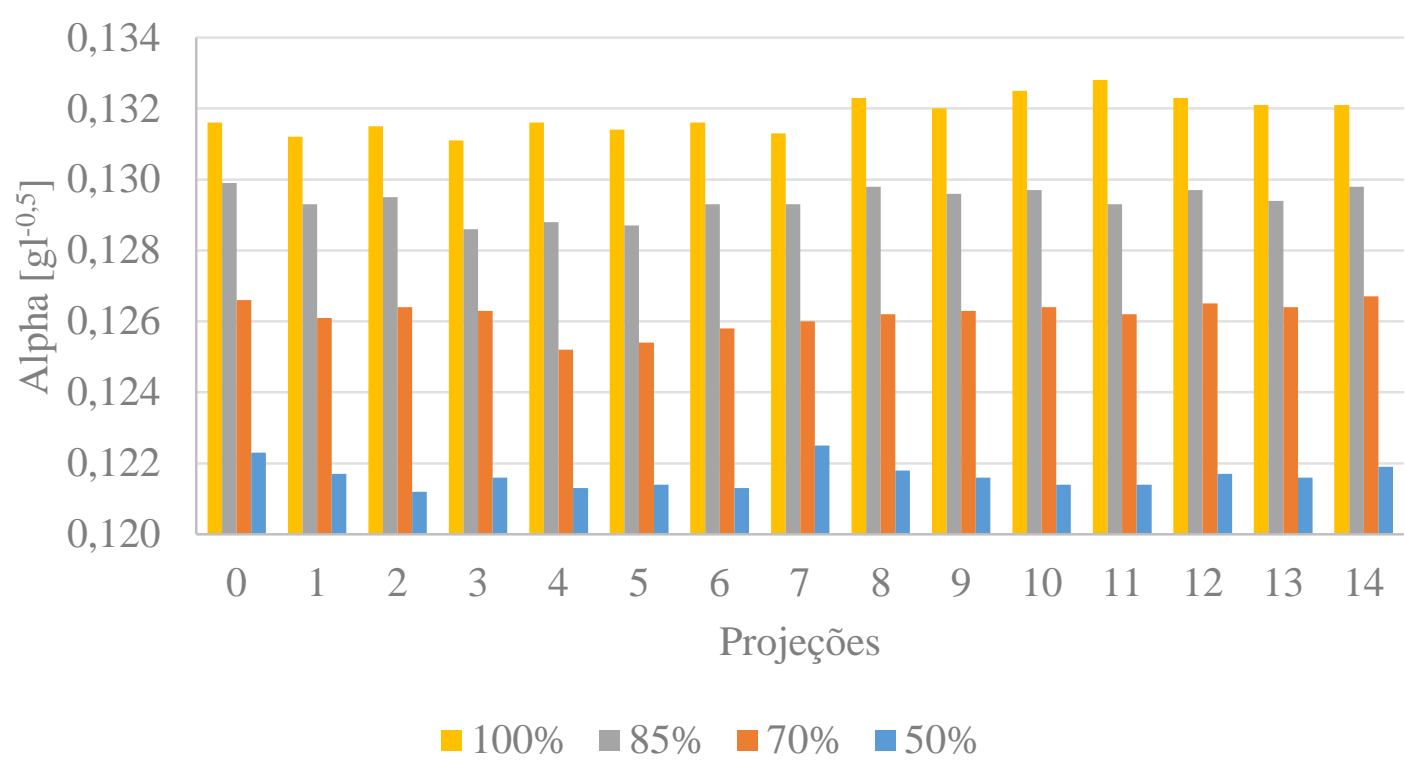

Figura 44: Comparação do fator de escala do ruído Poisson nas 15 projeções de DBT em 4 diferentes doses de radiação.

Por meio desses resultados é possível concluir que, apesar das imagens homogêneas apresentarem o mesmo tipo de ruído em todas as projeções, a disposição espacial de seus pontos de maior e menor intensidade, tanto de sinal quanto de ruído, comprova que as imagens são diferentes em si. Os algoritmos de simulação devem casar as projeções das imagens clínicas com as imagens homogêneas para a obtenção de melhores resultados.

\subsection{Tomossíntese vs. Mamografia}

Para realizar a comparação entre as imagens de mamografia digital e tomossíntese digital mamária, foram utilizadas imagens do phantom antropomórfico com $100 \%$ de dose de entrada. Para simplificar a comparação, todas as imagens de tomossíntese utilizadas são referentes à projeção central.

Devido a pequenas disparidades entre o valor absoluto da dose de radiação medido em unidades Gray, as imagens de tomossíntese sofreram uma pequena correção de ganho para equiparar os valores de doses. 
À primeira vista, a diferença mais nítida entre as imagens é a quantidade de pixels. Com resolução de 3328 x 4096, as imagens de mamografia apresentam quatro vezes mais pixels que a de tomossíntese, com sua resolução de 1664 x 2048. Essa discrepância ocorre devido ao binning de quatro pixels realizado pela eletrônica do aparelho para garantir uma maior contagem de fótons e menor ruído na imagem, com explicado no item 2.3. Na Figura 45 é possível observar diferença de tamanho entre as imagens.

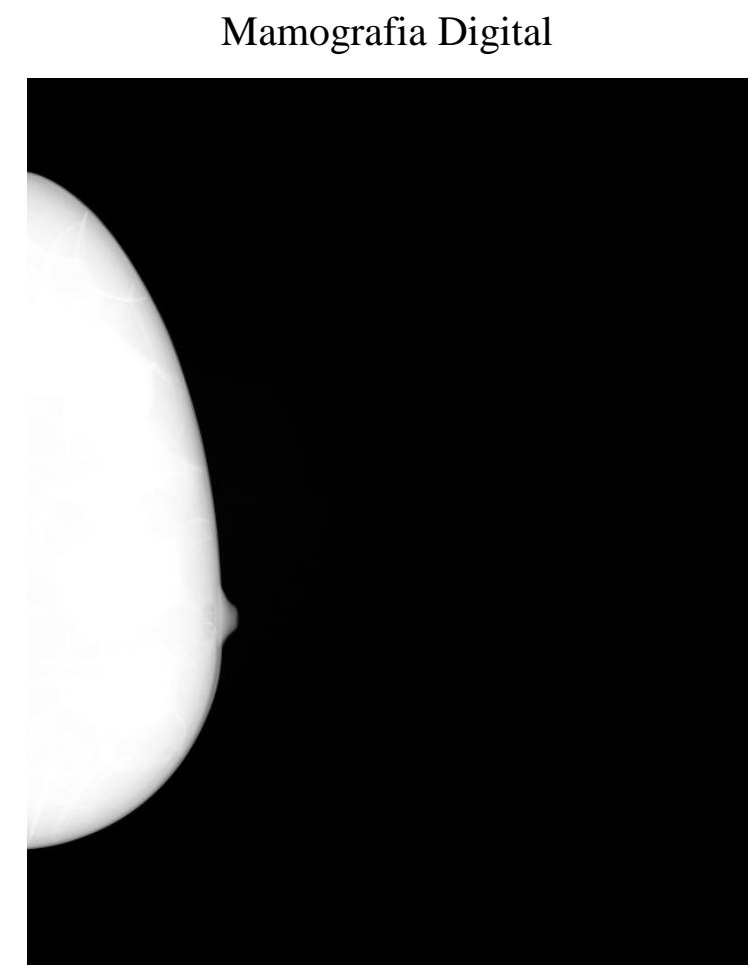

Projeção da Tomossíntese

3328 x 4096

Figura 45: Comparação entre o tamanho das imagens de Mamografia digital e da projeção da tomossíntese mamária.

A imagem do phantom da mama apresenta alta variação entre os valores de pixels, interferindo na escala e dificultando a avaliação do fundo da imagem. Como o interesse da análise é a relação entre as imagens, e não o conteúdo propriamente dito, foi utilizado uma máscara para remover a região predominante da mama.

Devido ao maior tamanho das imagens de mamografia, essas tiveram suas dimensões ajustadas para que os tamanhos de ambos os exames coincidissem. É importante ressaltar que o redimensionamento foi realizado após utilização dos filtros para cálculo do valor médio e desvio padrão locais. 
Para uma comparação quantitativa, foi escolhido utilizar as mesmas métricas utilizadas também para a análise das projeções e das fatias da tomossíntese. A Figura 46 mostra a relação em cor falsa do valor médio local de cada uma das imagens. Por meio da escala de cores é possível notar que na imagem de mamografia, com valor médio próximo de $7.400 \mathrm{gl}$, apresenta intensidade de pixel muito superior à imagem de tomossíntese, com aproximadamente 2.900gl.

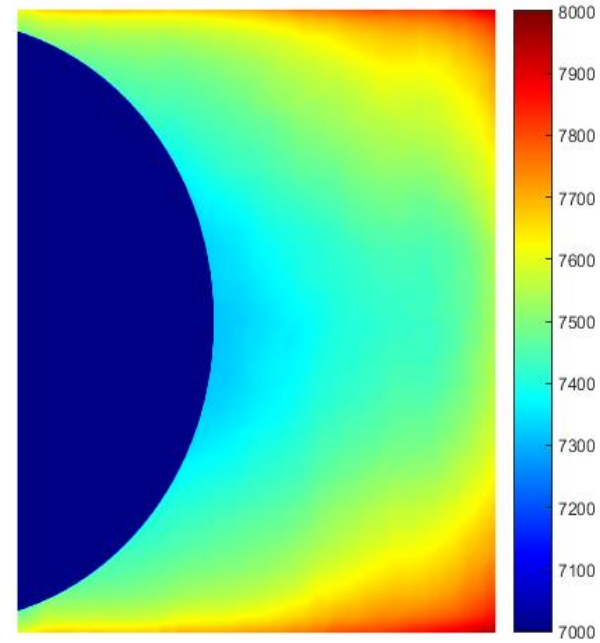

Mamografia digital

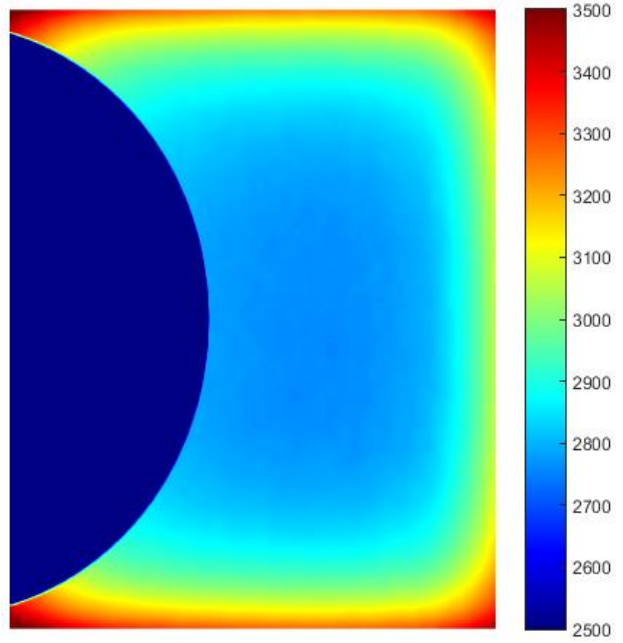

Projeção de tomossíntese

Figura 46: Comparação entre o valor médio dos níveis de cinza entre as imagens de mamografia digital e projeção de tomossíntese.

A Figura 47(a) apresenta a imagem obtida através da divisão pixel a pixel da imagem de mamografia em relação à imagem de tomossíntese. Comparando a relação entre os valores médios é possível observar homogeneidade na região central $(\sim 2,5 \mathrm{gl} / \mathrm{gl})$, em contraponto a uma pequena distorção nas bordas $(\sim 2,2 \mathrm{gl} / \mathrm{gl})$.

A Figura 48 mostra as imagens resultantes do cálculo do desvio padrão local em cada um dos exames. Nas imagens de mamografia utilizou-se janela quadrada de 64 x 64 pixels, enquanto nas imagens de tomossíntese a janela foi de 32 × 32 pixels.

As imagens de mamografia apresentam desvio padrão próximo de $40 \mathrm{gl}$ na região central, contra $22 \mathrm{gl}$ nas imagens de tomossíntese. Na Figura 47(b) pode-se observar que na região central a relação é próxima de $1,7 \mathrm{gl} / \mathrm{gl}$. 


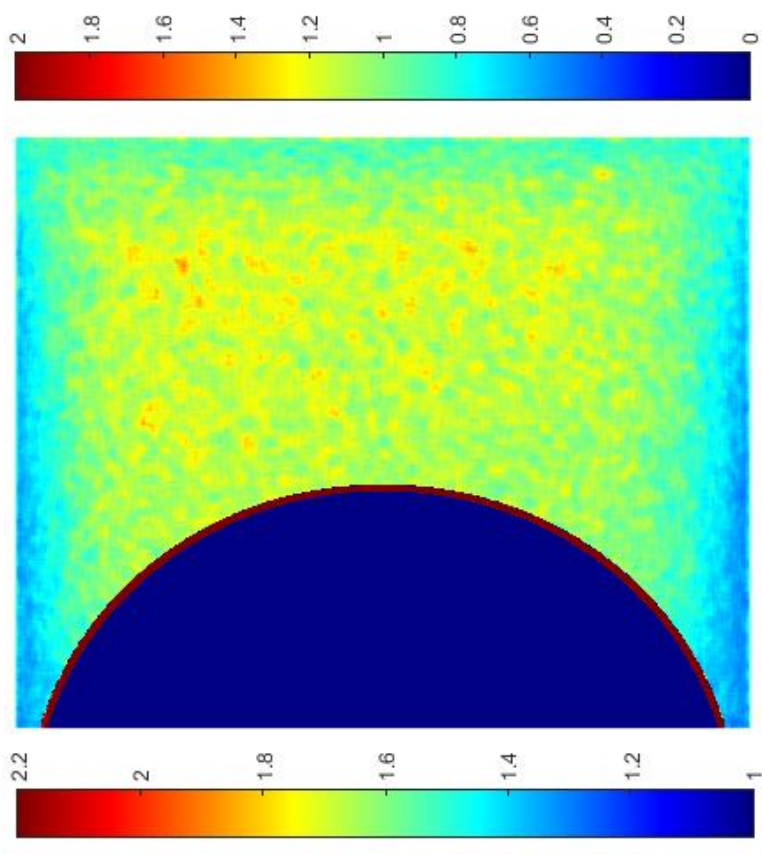

0
0
0
0
0
0
0
0
$\vdots$
0
0
$\frac{0}{7}$
0
0
0
0
0
0
0
0
0
0

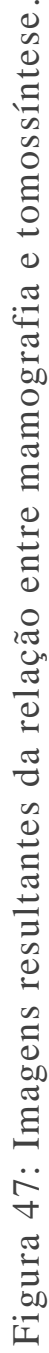

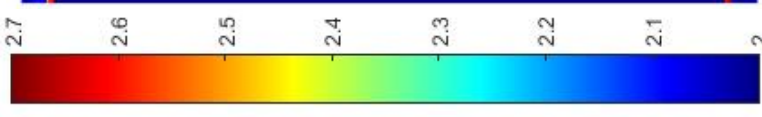

$\frac{\pi}{0}$
0
0
0
0
0
0
0
0

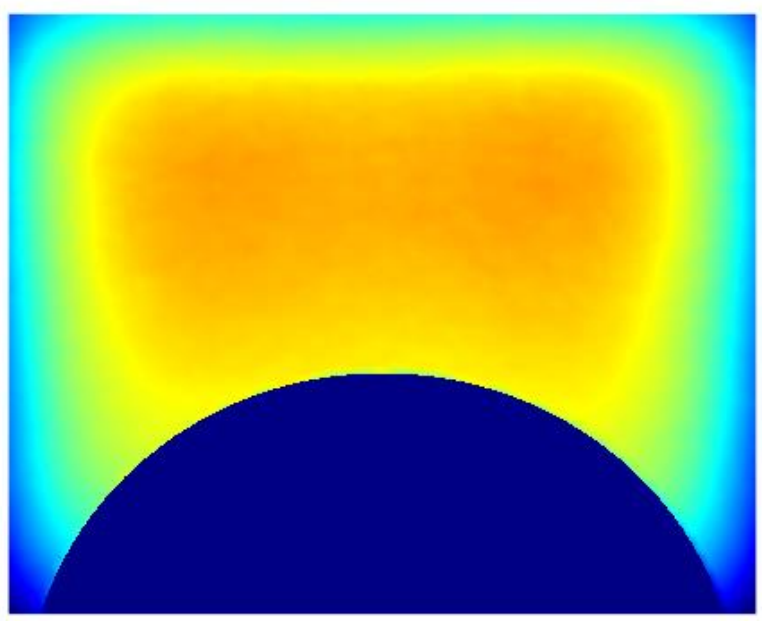

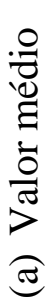




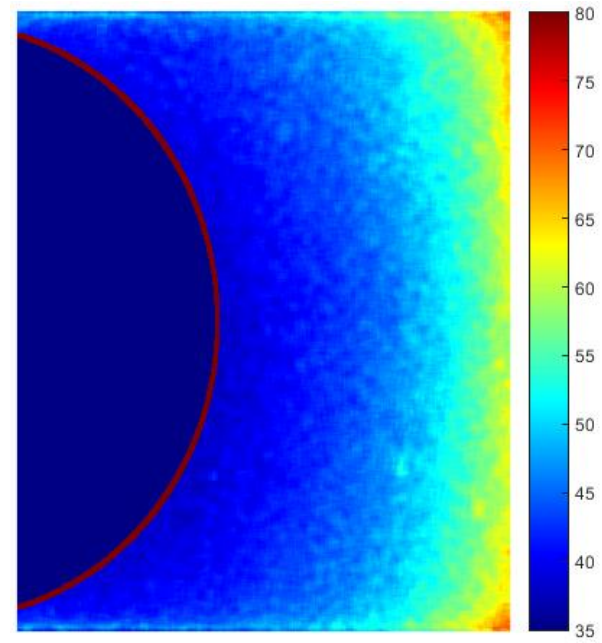

Mamografia digital

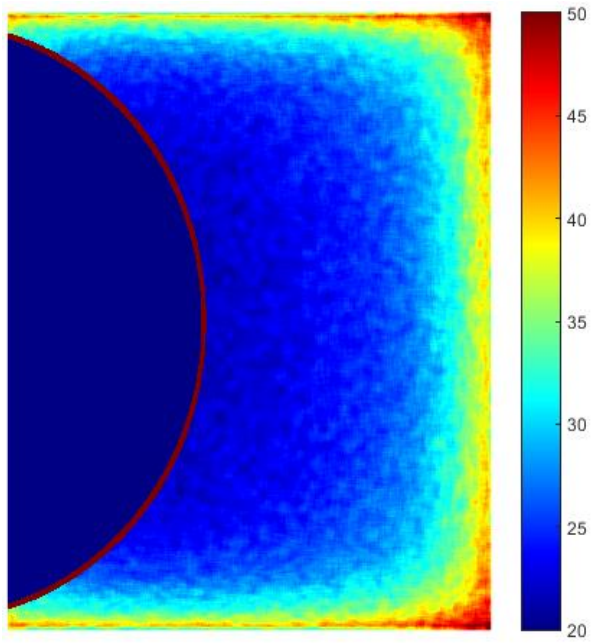

Projeção de tomossíntese

Figura 48: Comparação entre o desvio padrão dos níveis de cinza entre as imagens de mamografia digital e projeção da tomossíntese mamária.

A Figura 49 mostra as imagens com o valor pixel a pixel do fator de escala do ruído Poisson. Apesar da similaridade entre as imagens, observa-se uma disparidade entre as bordas, indicando que os ruídos entre as duas imagens são espacialmente diferentes. Essa característica pode ser melhor visualizada na Figura 47(c).

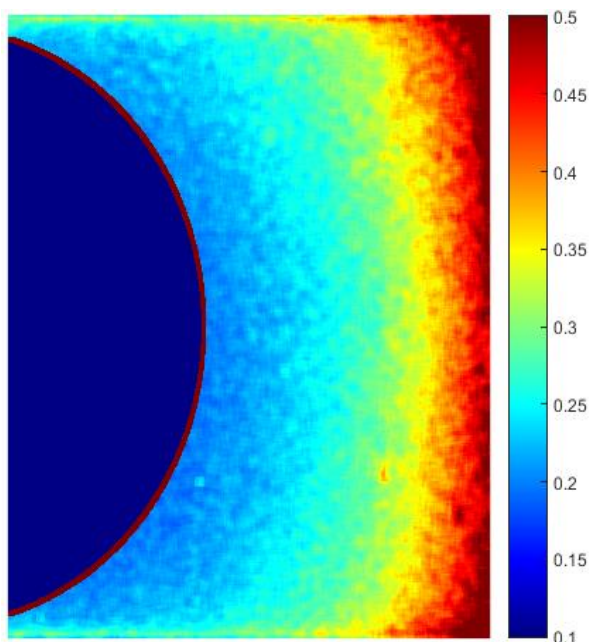

Mamografia digital

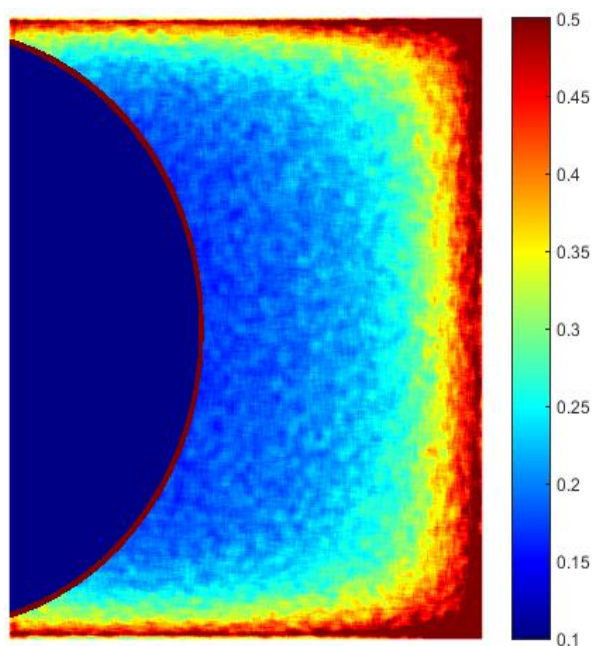

Projeção de tomossíntese

Figura 49: Comparação entre o fator de escala do ruído Poisson entre as imagens de mamografia digital e tomossíntese mamária. 
Tabela 8: Comparação quantitativa entre mamografia e tomossíntese.

\begin{tabular}{cccc}
\hline & Valor médio & Desvio Padrão & Fator de Escala \\
\hline Mamografia & $7356,6 \mathrm{gl}$ & $40,3161 \mathrm{gl}$ & $0,2211 \mathrm{gl}$ \\
\hline Tomossíntese & $2765,7 \mathrm{gl}$ & $22,5749 \mathrm{gl}$ & $0,1844 \mathrm{gl}$ \\
\hline Relação & 2,4709 & 1,6596 & 1,1157
\end{tabular}

A Tabela 8 apresenta os valores médios e a relação entre as imagens nas três métricas utilizadas. Para esse cálculo utilizou-se o valor médio de uma região quadrada de 256 x 256 pixels no centro da imagem.

Através dos valores de média e desvio padrão pode-se calcular a relação sinal-ruído (SNR) de cada exame:

$$
\begin{aligned}
& S N R_{\text {Mamografia }}=\frac{7356,6}{40,3}=182,5 \\
& S N R_{\text {Tomossintese }}=\frac{2765,7}{22,6}=122,4
\end{aligned}
$$

É possível notar que o valor da relação sinal-ruído é maior nas imagens de mamografia digital, mostrando que neste exame o sinal apresenta dominância sobre o ruído. Nas imagens de projeção da tomossíntese, como o este valor é inferior, caracteriza um maior peso para o ruído quando comparado com o nível de sinal.

\subsection{Simulação da redução da dose de radiação pelo método de Borges et al}

\subsubsection{Simulação das projeções}

Utilizando o algoritmo detalhado no item 3.5, foram realizadas as simulações de redução de dose de entrada para exames de DBT considerando três doses de radiação diferentes: $85 \%, 70 \%$ e 50\%, sempre utilizando a imagem padrão de $100 \%$ como referência.

Na Figura 50 é possível observar a semelhança entre as imagens simuladas e as imagens de phantom equivalentes. Para a representação, foram utilizadas regiões quadradas de 256 x 256 pixels e ajuste automático de contraste. Nota-se que a diferença entre a imagem real e simulada é imperceptível ao olho humano, sendo necessárias medidas quantitativas para comprovar a eficiência do método. 
Imagens reais

$85 \%$

$70 \%$

$50 \%$
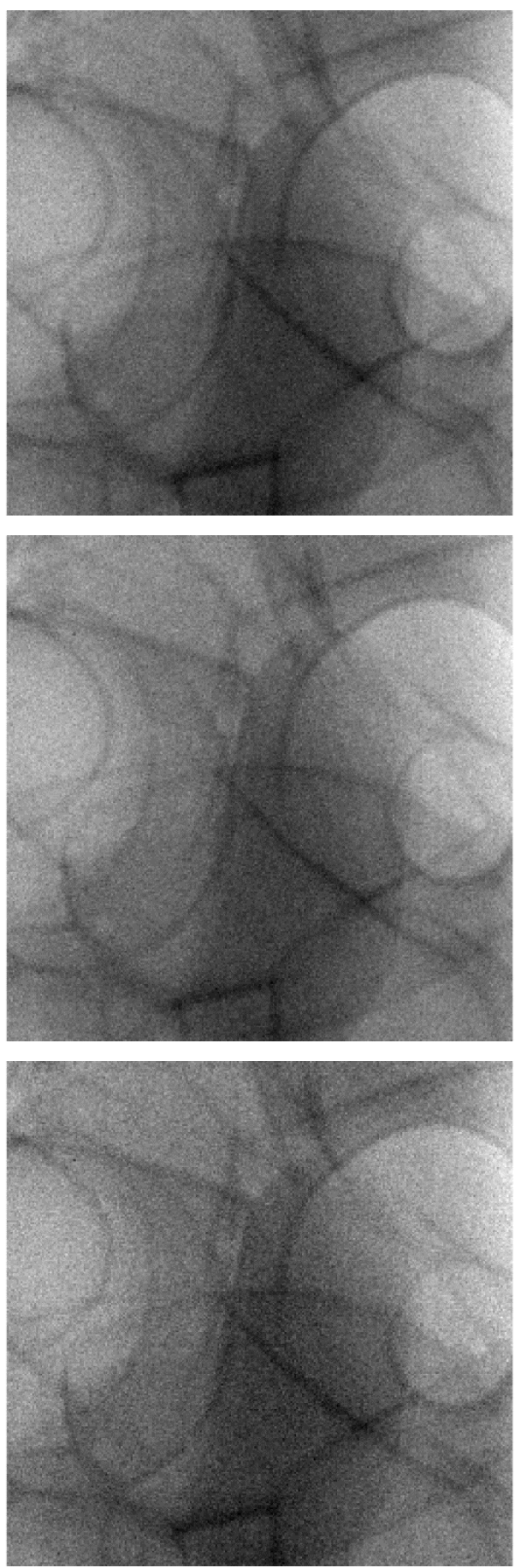

Imagens simuladas
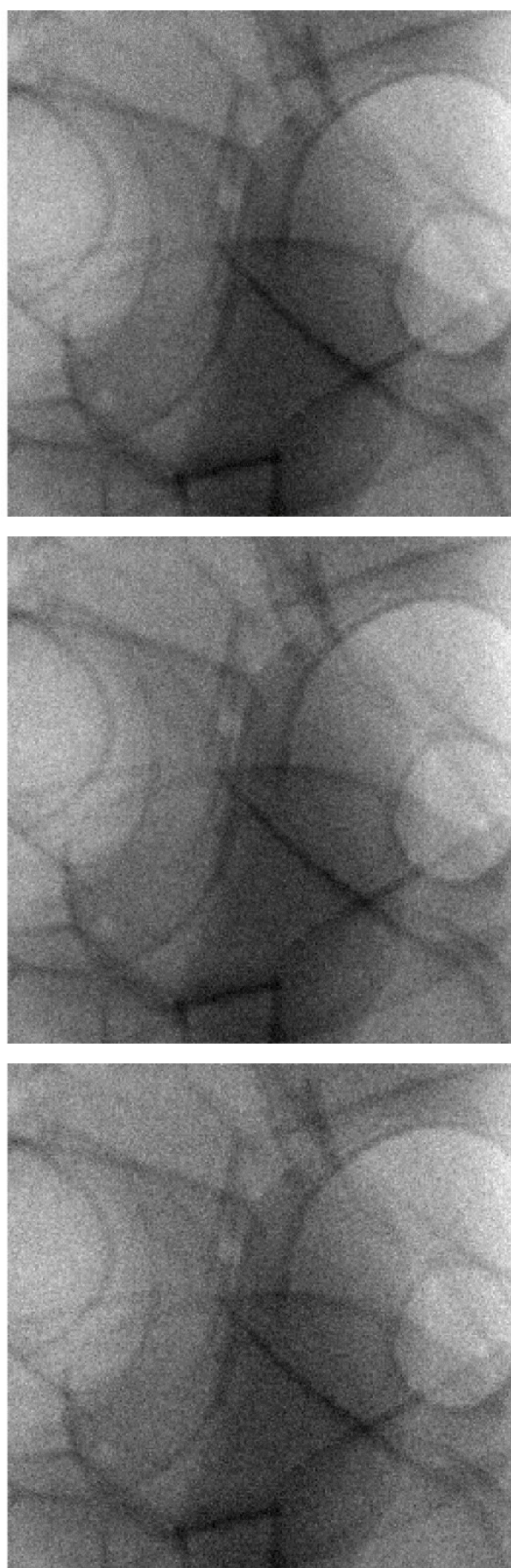

Figura 50: Comparação entre imagens de projeção reais e simuladas pelo método de Borges et al. sem kernel de ruído. 


\subsubsection{Média local dos níveis de cinza entre as projeções}

Utilizando as regiões descritas no item 4.3.1 e o método de avaliação cruzada do item 4.3.4, foi calculado o erro percentual médio entre os valores médios da intensidade de pixel de cada imagem para todas as projeções (originais e simuladas). Analisando os valores apresentados na Figura 51 é possível notar que a simulação de redução para $85 \%$ da dose apresenta o menor erro (pico menor que 1\%), e as reduções para $70 \%$ e $50 \%$ apresentam valores próximos, com picos inferiores a 1,5\%. É perceptível também que o erro apresenta caráter aleatório quanto às projeções. A Tabela 9 apresenta os valores finais do erro percentual médio entre as projeções.

Tabela 9: Erro percentual médio do valor médio da intensidade do pixel nas projeções simuladas pelo método de Borges et al sem kernel de ruído.

\begin{tabular}{cccc}
\hline Dose simulada & $85 \%$ & $70 \%$ & $50 \%$ \\
\hline $\begin{array}{c}\text { Erro percentual do valor médio } \\
\text { (Média entre todas as projeções) }\end{array}$ & $0,603 \%$ & $0,799 \%$ & $0,748 \%$ \\
\hline
\end{tabular}

\section{Erro médio - Valor médio}

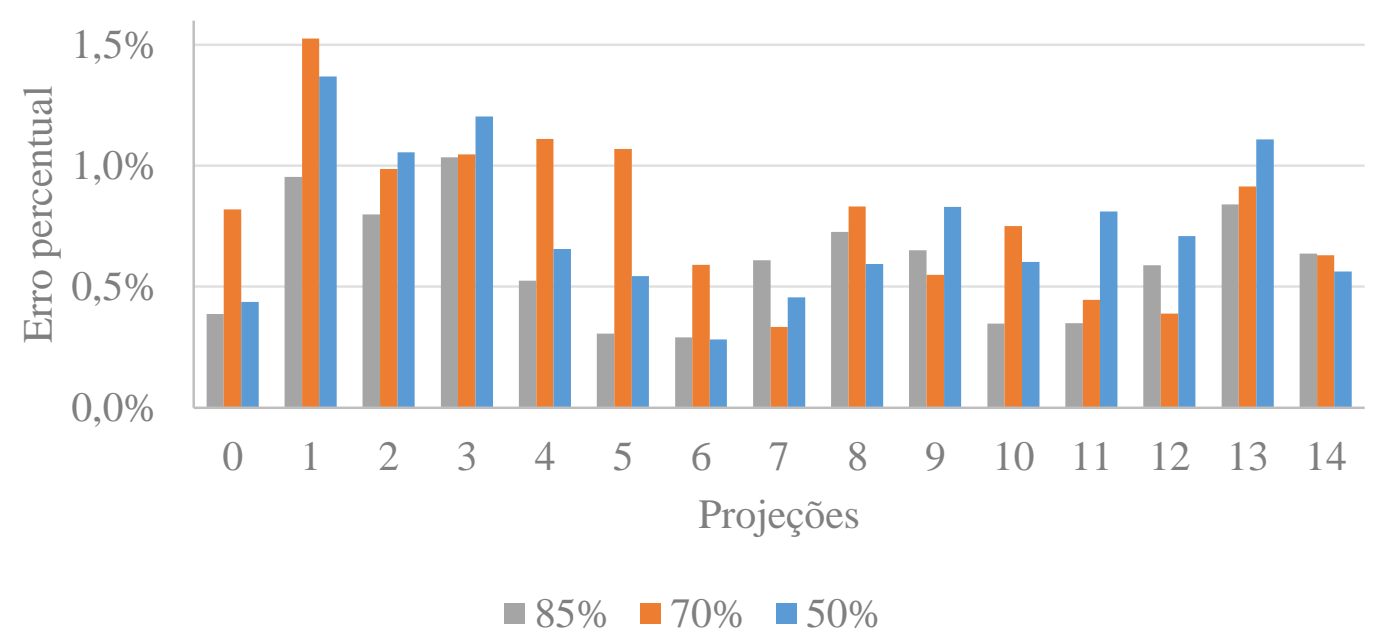

Figura 51: Erro percentual do valor médio entre as projeções simuladas pelo método de Borges et al sem kernel de ruído. 


\subsubsection{Desvio padrão do valor dos níveis de cinza (ruído) entre as projeções}

Assim como para o valor médio, a análise do desvio padrão (ruído) foi realizada utilizando o método do item 4.3.4 e as regiões do item 4.3.2. A Figura 52 mostra os valores médios do desvio padrão em cada projeção e nas três doses simuladas.

É possível observar que a simulação de dose $85 \%$ apresenta menor erro percentual, inferior a $2,4 \%$. A simulação de dose $75 \%$ ficando em segundo local com erro percentual inferior a $2,6 \%$ e a simulação de $50 \%$ apresentando o pior resultado, mas mesmo assim com erro inferior a 3,0\%. Isso mostra que o erro aumenta à medida que a simulação considera taxas mais baixas de redução da dose de radiação.

A Tabela 10 apresenta os valores finais do erro percentual entre os valores de desvio padrão médio entre todas as projeções. Assim como para o valor médio, não é nítida a dependência do erro em relação à projeção.

Tabela 10: Erro percentual médio do desvio padrão entre as projeções simuladas sem kernel de ruído.

\begin{tabular}{cccc}
\hline Dose simulada & $85 \%$ & $70 \%$ & $50 \%$ \\
\hline $\begin{array}{c}\text { Erro percentual do desvio padrão } \\
\text { (Média entre todas as projeções) }\end{array}$ & $2,192 \%$ & $2,406 \%$ & $2,775 \%$ \\
\hline
\end{tabular}

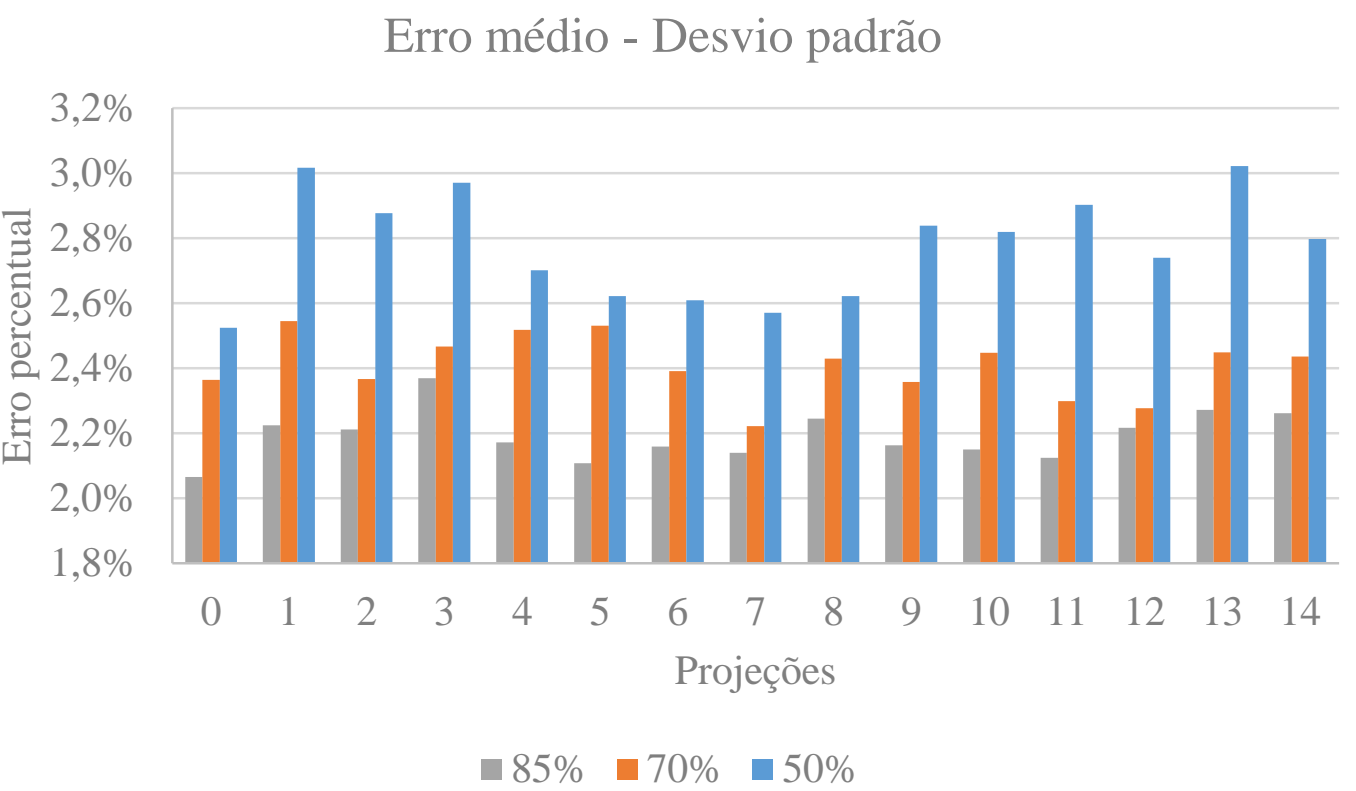

Figura 52: Erro percentual do desvio padrão entre as projeções simuladas sem kernel de ruído e de phantom. 


\subsubsection{Espectro de potência entre as projeções}

Os resultados da análise do espectro de potência seguem as regiões descritas no item 4.3.3. A Figura 54 mostra a região de interesse grande da projeção central convertida para o domínio da frequência. As linhas contínuas representam os valores das imagens reais, enquanto os pontos representam os valores obtidos das imagens simuladas. O gráfico inferior indica somente uma reprodução ampliada da região final do espectro.

Apesar dos valores simulados se encontrarem muito próximos aos valores reais, é necessário realizar uma análise quantitativa da relação. A Figura 53 apresenta o erro percentual entre os valores simulados e reais.

A simulação de redução para $85 \%$ da dose apresenta os valores mais semelhantes às medidas nas imagens clínicas (inferior a 3,0\%). A simulação de $70 \%$ apresenta resultados intermediários com erro inferior a 3,5\%, enquanto a simulação de $50 \%$ apresenta os piores valores, com pico de $4,5 \%$.

Assim como nos resultados anteriores, o erro apresenta aleatoriedade quanto à posição da projeção. A Tabela 11 indica os valores médios entre as projeções.

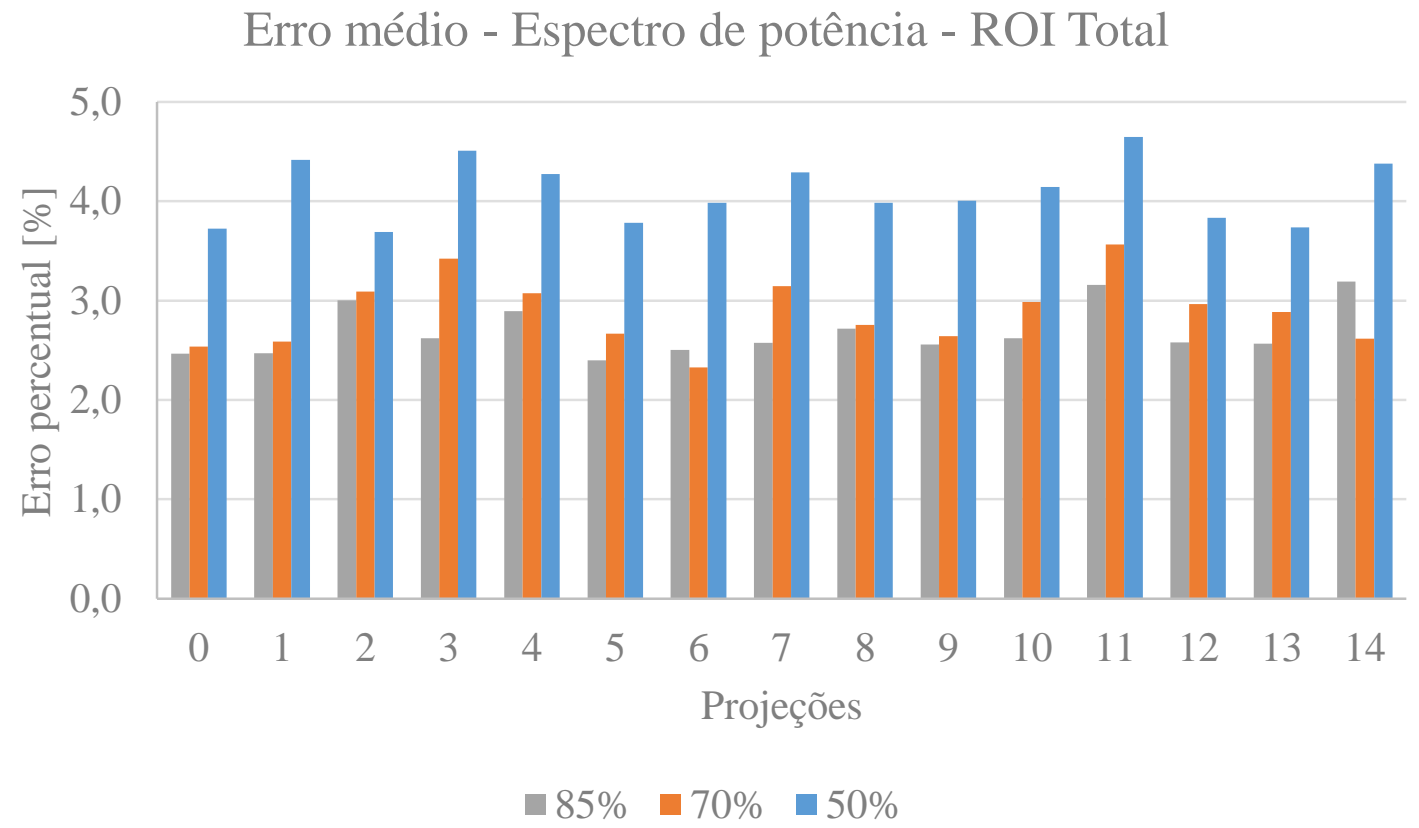

Figura 53: Erro percentual do espectro de potência entre as projeções reais e simuladas pelo método de Borges et al sem kernel de ruído (ROI grande). 
Espectro de potência

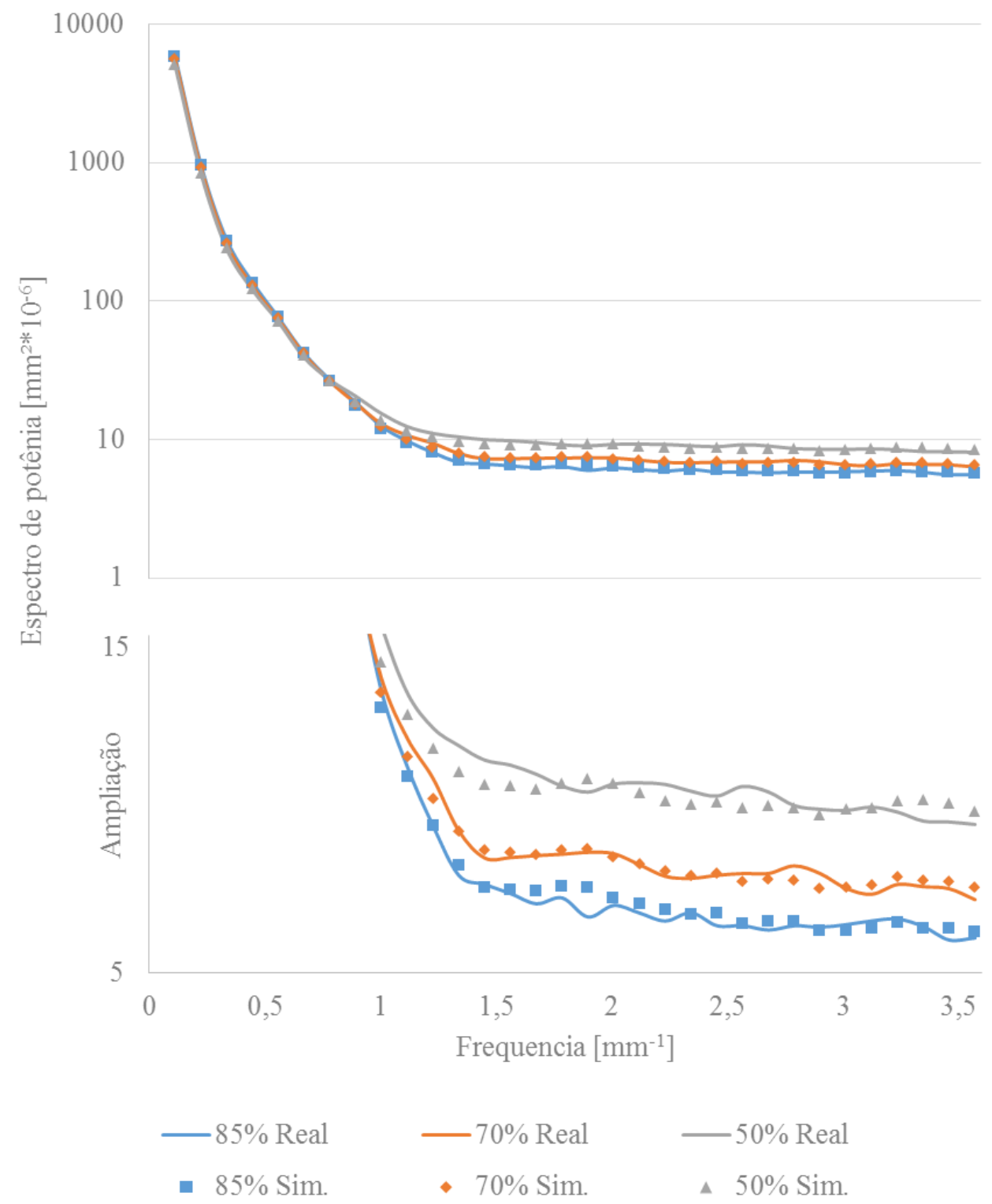

Figura 54: Espectro de potência das projeções reais e simuladas pelo método de Borges et al sem kernel de ruído para 3 doses de radiação diferentes.

Tabela 11: Erro percentual médio do espectro de potência (ROI grande) entre as projeções reais e simuladas pelo método de Borges et al sem kernel de ruído.

\begin{tabular}{cccc}
\hline Dose simulada & $85 \%$ & $70 \%$ & $50 \%$ \\
\hline $\begin{array}{c}\text { Erro percentual do espectro de potência } \\
\text { (Média entre todas as projeções) }\end{array}$ & $2,689 \%$ & $2,885 \%$ & $4,094 \%$ \\
\hline
\end{tabular}


Conforme mencionado no item 4.3.3, adicionalmente a uma ROI grande, as imagens foram segmentadas em quatro ROIs menores. Os erros percentuais para cada projeção podem ser vistos na Figura 55. Apesar de apresentarem erro percentual levemente superior ao encontrado na ROI grande, os quatro quadrantes não apresentam distinção entre si, mostrando que, apesar do flat-fielding introduzir mais ruído para as regiões mais afastadas da região em que a mama é posicionada, esse efeito não é significativo.

A Tabela 12 mostra os valores máximos de erro para cada quadrante independentemente da projeção. Já a Tabela 13 mostra os valores médios do erro considerando todas as projeções.

\section{Erro médio - Espectro de potência}

Quadrante 1

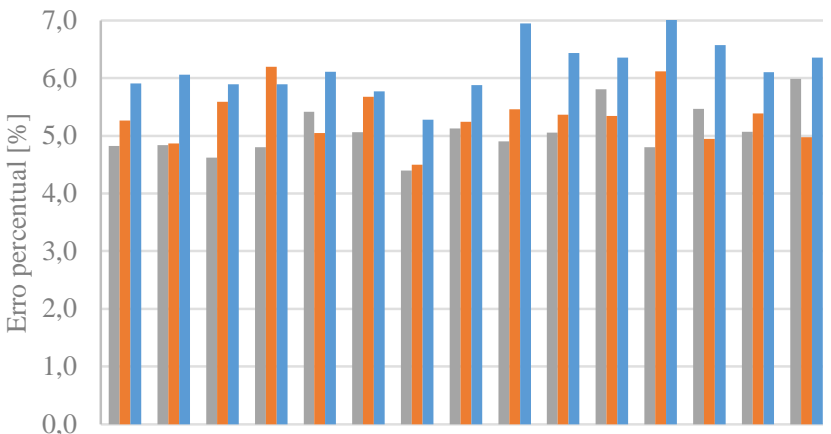

Quadrante 3

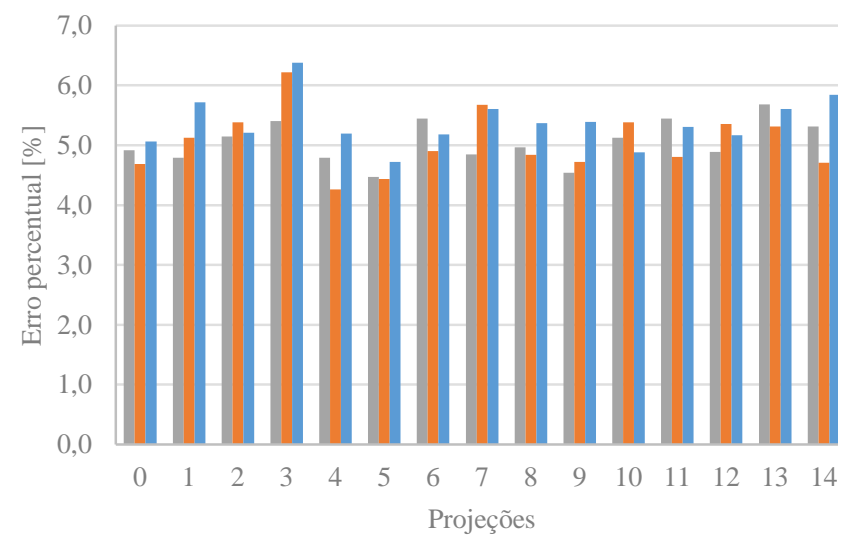

Quadrante 2

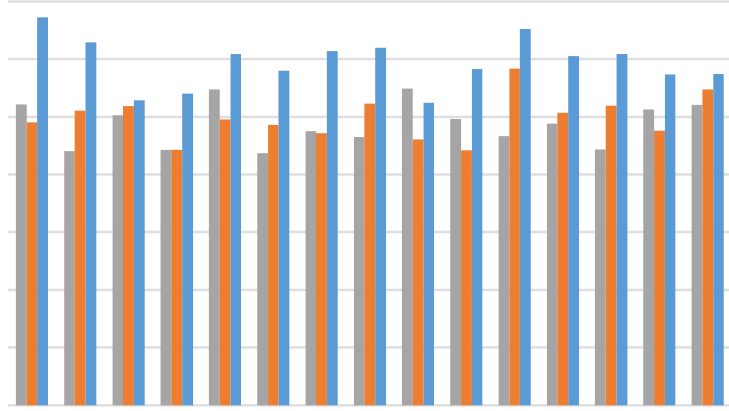

Quadrante 4

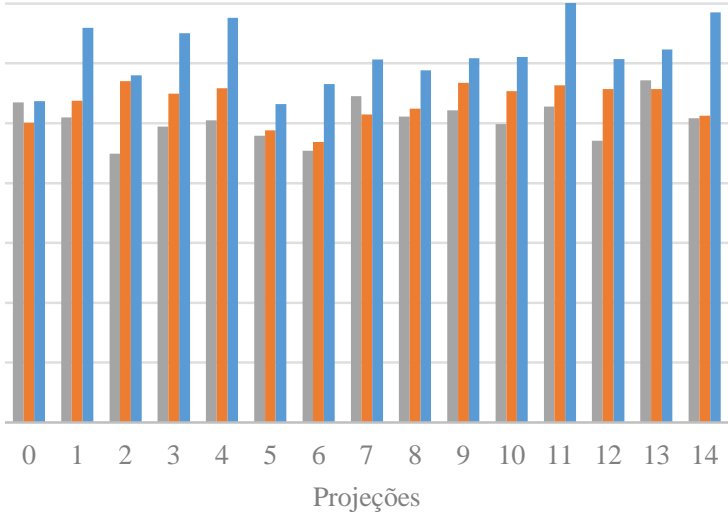

$-85 \% \quad \square 70 \% \quad \square 50 \%$

Figura 55: Erro percentual do espectro de potência entre as projeções reais e simuladas pelo método de Borges et al sem kernel de ruído em 4 quadrantes para 3 doses de radiação diferentes (ROI pequeno). 
Tabela 12: Erro percentual máximo do espectro de potência (ROI pequena) - projeções simuladas sem kernel de ruído.

\begin{tabular}{cccc}
\hline Dose simulada & $85 \%$ & $70 \%$ & $50 \%$ \\
\hline Erro percentual máximo - Quadrante 1 & $5,988 \%$ & $6,193 \%$ & $7,022 \%$ \\
\hline Erro percentual máximo - Quadrante 2 & $5,488 \%$ & $5,835 \%$ & $6,721 \%$ \\
\hline Erro percentual máximo - Quadrante 3 & $5,685 \%$ & $6,215 \%$ & $6,376 \%$ \\
\hline Erro percentual máximo - Quadrante 4 & $5,717 \%$ & $5,703 \%$ & $7,134 \%$ \\
\hline
\end{tabular}

Tabela 13: Erro percentual médio do espectro de potência (ROI pequena) - projeções simuladas sem kernel de ruído.

\begin{tabular}{cccc}
\hline Dose simulada & $85 \%$ & $70 \%$ & $50 \%$ \\
\hline Erro percentual médio - Quadrante 1 & $5,078 \%$ & $5,331 \%$ & $6,171 \%$ \\
\hline Erro percentual médio - Quadrante 2 & $4,873 \%$ & $4,982 \%$ & $5,942 \%$ \\
\hline Erro percentual médio - Quadrante 3 & $5,051 \%$ & $5,055 \%$ & $5,375 \%$ \\
\hline Erro percentual médio - Quadrante 4 & $5,054 \%$ & $5,349 \%$ & $6,162 \%$ \\
\hline
\end{tabular}

\subsubsection{Análise das fatias reconstruídas}

As imagens resultantes da simulação serviram de entrada para o software de reconstrução, que as processa e gera como saída a mama reconstruída, segmentada em fatias tomográficas.

Devido à espessura do phantom utilizado, foram geradas 51 fatias espaçadas em $1 \mathrm{~mm}$. A Figura 56 possibilita uma comparação visual de uma janela de tamanho 128 x 128 pixels retirada da região central da mama. Assim como na análise das projeções, esses segmentos apresentam diferenças praticamente imperceptíveis ao olho humano.

As análises a seguir seguem exatamente o mesmo processo que a análise das projeções.

\subsubsection{Média local dos níveis de cinza das fatias reconstruídas}

Para a melhor visualização do exame, o algoritmo de reconstrução faz alterações muito significativas nas projeções. Observando a Figura 57, é possível notar que, independentemente da fatia, o valor médio da simulação comparado com o real praticamente não sofreu alterações, permanecendo em um patamar constante para as três doses. 
Imagens de phantom

$85 \%$

$70 \%$

$50 \%$
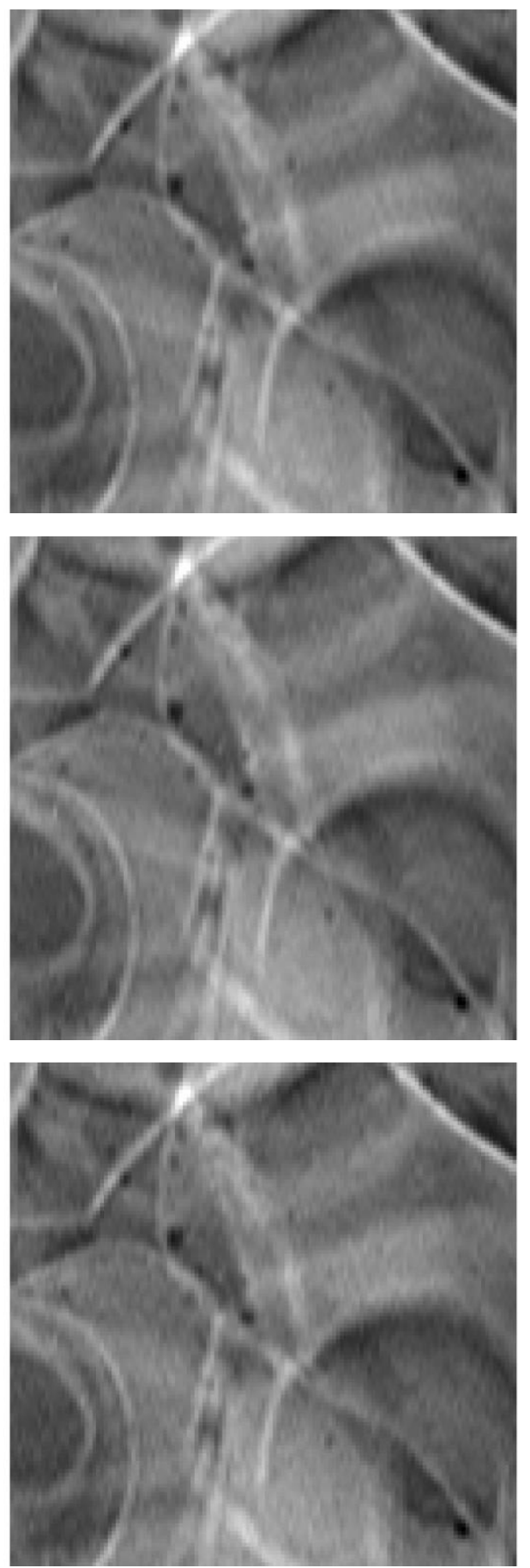

Imagens simuladas
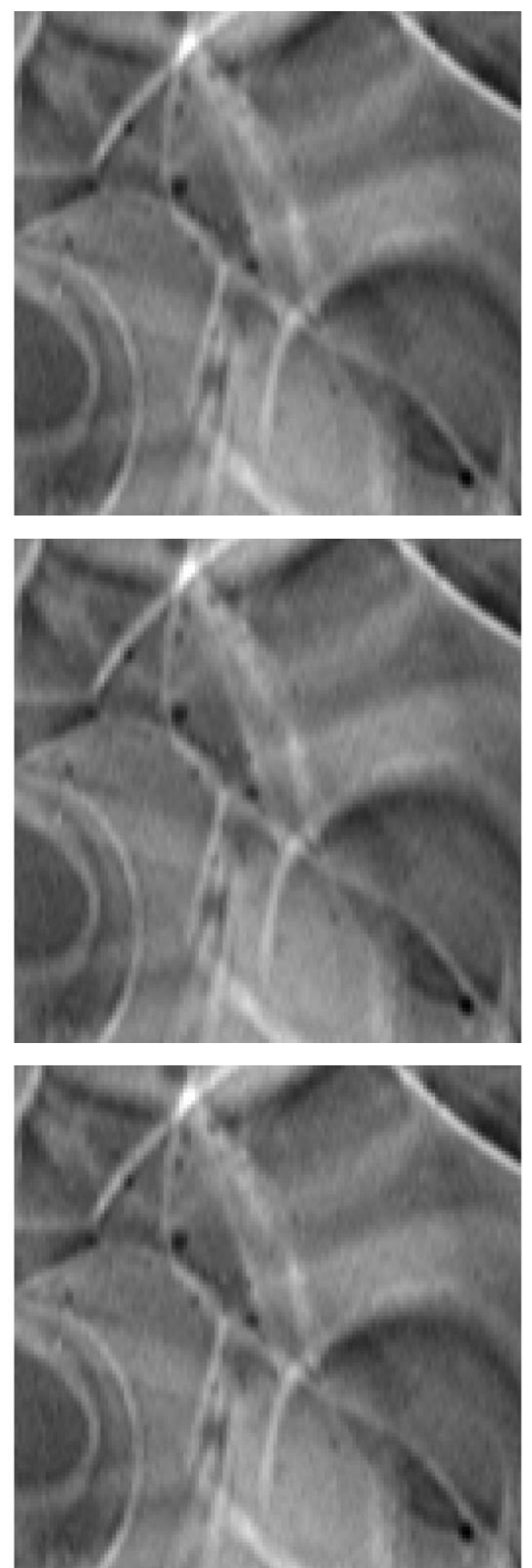

Figura 56: Comparação entre fatias reconstruídas das imagens reais e simuladas pelo método de Borges et al sem kernel de ruído. 
A reconstrução da simulação para redução de dose em $85 \%$ apresentou menor erro se comparado com as outras simulações (erro máximo de $0,288 \%$ ). A reconstrução da simulação de $70 \%$ apresentou resultados intermediários e erro máximo de $0,317 \%$, enquanto a dose de $50 \%$ apresentou erro máximo de 0,419\%. A Tabela 14 mostra o erro percentual médio entre todas as fatias.

Tabela 14: Erro percentual médio do valor médio dos níveis de cinza entre as fatias reconstruídas das imagens reais e simuladas pelo método de Borges et al sem kernel de ruído.

\begin{tabular}{cccc}
\hline Dose simulada & $85 \%$ & $70 \%$ & $50 \%$ \\
\hline $\begin{array}{c}\text { Erro percentual do valor médio } \\
\text { (Média entre todas as fatias) }\end{array}$ & $0,285 \%$ & $0,315 \%$ & $0,416 \%$ \\
\hline
\end{tabular}

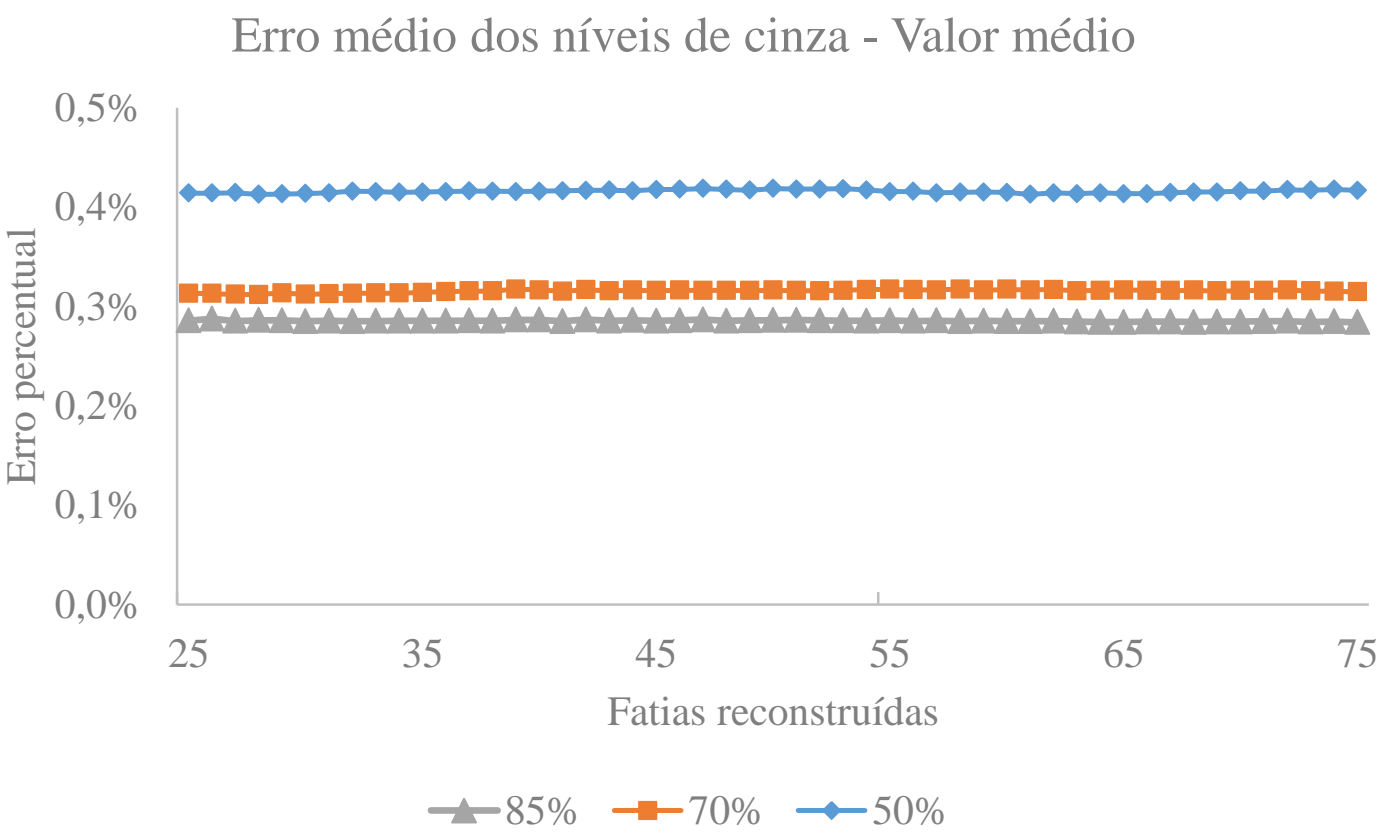

Figura 57: Erro percentual entre as fatias reconstruídas das imagens reais e simuladas pelo método de Borges et al sem kernel de ruído. 


\subsubsection{Desvio padrão dos níveis de cinza das fatias reconstruídas}

O erro percentual entre o desvio padrão dos níveis de cinza das fatias reconstruídas pelas imagens reais e simuladas apresenta comportamento semelhante ao demostrado na análise do valor médio. Por meio da Figura 58 é possível observar uma maior estabilidade do erro em relação ao número da fatia. A simulação para uma redução de $70 \%$ da dose apresentou o maior erro médio e um valor máximo de $0,931 \%$. A redução para $50 \%$ da dose apresentou valores intermediários com máxima em $0,765 \%$ enquanto a redução para $85 \%$ da dose apresentou o menor erro médio e valor máximo de $0,552 \%$. A Tabela 15 apresenta os valores médios do desvio padrão dos níveis de cinza em todas as fatias reconstruídas.

Tabela 15: Erro percentual médio do desvio padrão dos níveis de cinza entre as fatias reconstruídas das imagens reais e simuladas pelo método de Borges et al sem kernel de ruído.

\begin{tabular}{cccc}
\hline Dose simulada & $85 \%$ & $70 \%$ & $50 \%$ \\
\hline $\begin{array}{c}\text { Erro percentual do desvio padrão } \\
\text { (Média entre todas as fatias) }\end{array}$ & $0,456 \%$ & $0,873 \%$ & $0,679 \%$ \\
\hline
\end{tabular}

\section{Erro médio - Desvio padrão}

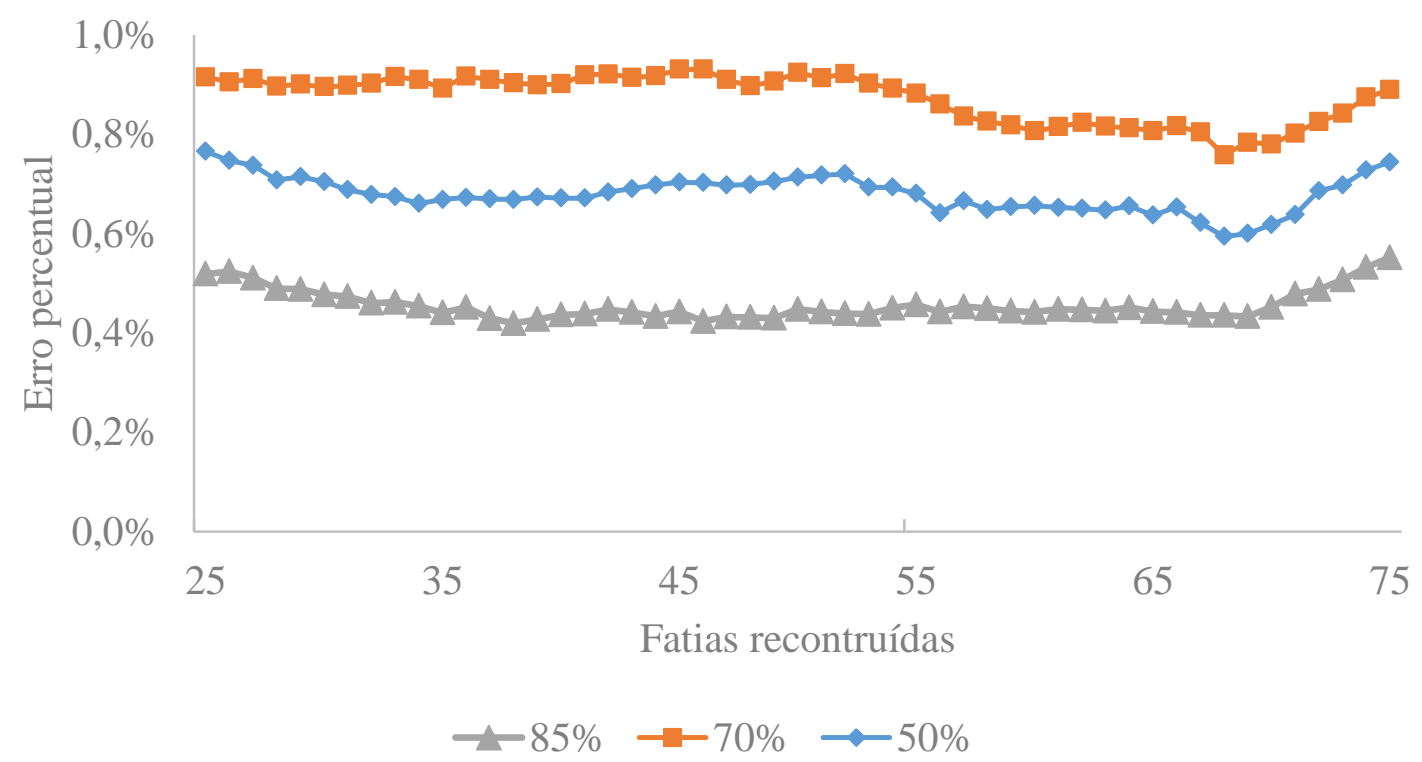

Figura 58: Erro percentual do desvio padrão dos níveis de cinza (ruído) entre as fatias reconstruídas das imagens reais simuladas pelo método de Borges et al sem kernel de ruído. 


\subsubsection{Espectro de potência entre as fatias reconstruídas}

Do mesmo modo como na análise das projeções, a Figura 59 mostra o espectro de potência na ROI grande extraída da projeção central das fatias reconstruídas das imagens reais e simuladas em 3 doses de radiação diferentes. As linhas contínuas representam os valores das imagens reais enquanto os pontos representam os valores obtidos das imagens simuladas. Devido ao processamento da reconstrução, a magnitude do espectro das fatias tem um formato completamente diferente do espectro das projeções. Apesar da diferença, é possível verificar que os pontos simulados apresentam valores muito próximos aos das curvas reais.

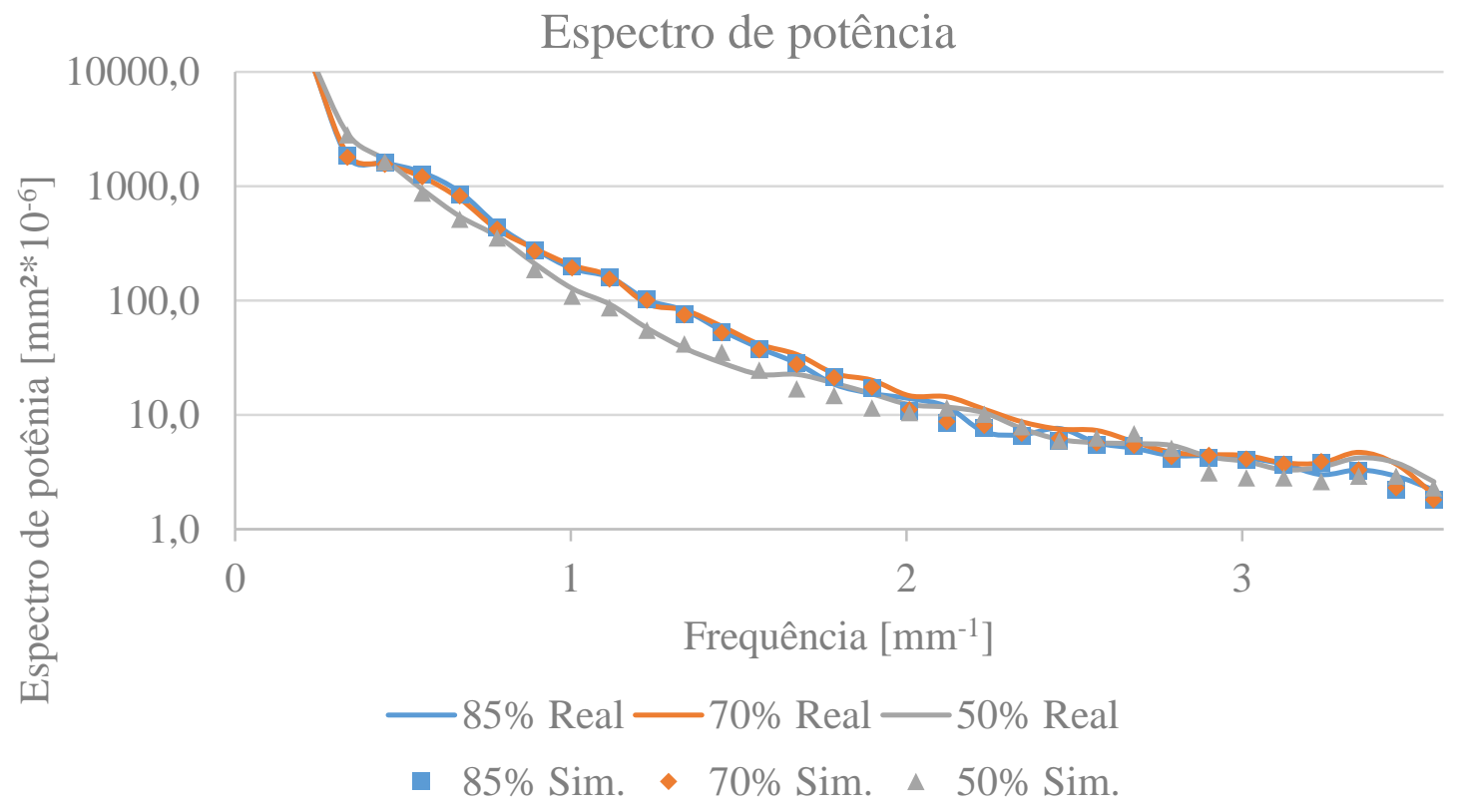

Figura 59: Espectro de potência das fatias reconstruídas das imagens reais e simuladas sem kernel de ruído em 3 diferentes doses de radiação.

Analisando o erro percentual apresentado na Figura 60 é possível perceber uma pequena tendência em que na região das fatias 40 a 45 o erro tende a apresentar seu maior valor.

A reconstrução da simulação de redução para $85 \%$ da dose apresenta os menores valores de erro, variando de 4,55\% a 6,18\%. Para a simulação de $70 \%$ da dose os resultados apresentam uma leve piora, variando de 7,98 a 12,50\%. Já para o caso 50\%, o erro percentual chega a $17,64 \%$ em seu valor máximo e em $9,30 \%$ no mínimo. A Tabela 16 apresenta o erro percentual médio entre todas as fatias reconstruídas. 
Tabela 16: Erro percentual médio do espectro de potência (ROI grande) entre as fatias reconstruídas com imagens reais e simuladas pelo método de Borges et al sem kernel de ruído.

\begin{tabular}{cccc}
\hline Dose simulada & $85 \%$ & $70 \%$ & $50 \%$ \\
\hline $\begin{array}{c}\text { Erro percentual do espectro de potência } \\
\text { (Média entre todas as fatias) }\end{array}$ & $5,263 \%$ & $10,793 \%$ & $14,906 \%$ \\
\hline
\end{tabular}

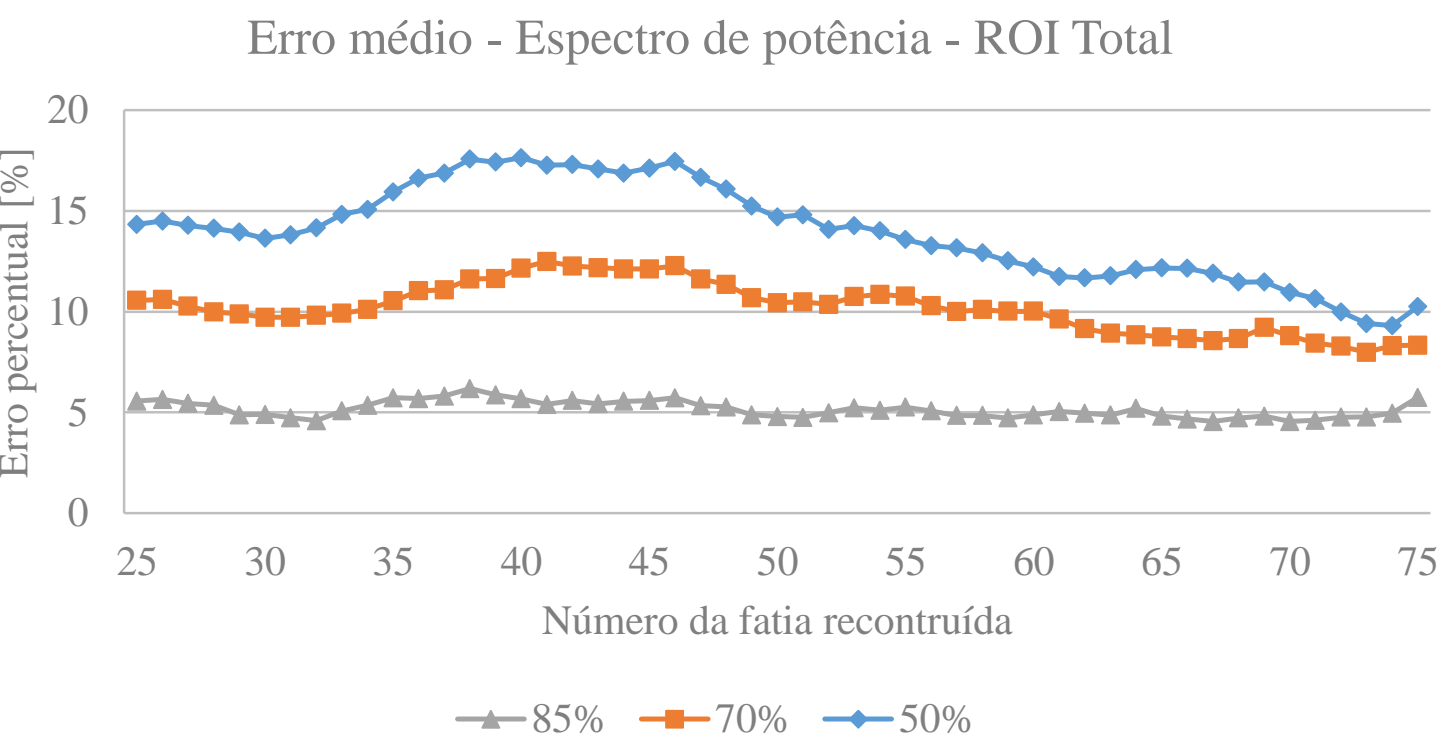

Figura 60: Erro percentual do espectro de potência (ROI grande) entre as fatias reconstruídas com imagens reais e simuladas pelo método de Borges et al sem kernel de ruído.

Os resultados dos erros percentuais nas ROIs pequenas são apresentados na Figura 61. Apesar da diferença numérica, os quatro quadrantes seguem as mesmas características da ROI grande, e não é possível identificar diferenças significativas entre os quadrantes. Os valores médios entre as fatias estão na Tabela 17.

Tabela 17: Erro percentual médio do espectro de potência (ROI pequena) entre as fatias reconstruídas com imagens reais e simuladas pelo método de Borges et al sem kernel de ruído.

\begin{tabular}{cccc}
\hline Dose simulada & $85 \%$ & $70 \%$ & $50 \%$ \\
\hline Erro percentual médio - Quadrante 1 & $8,992 \%$ & $12,348 \%$ & $17,411 \%$ \\
\hline Erro percentual médio - Quadrante 2 & $8,119 \%$ & $11,460 \%$ & $13,302 \%$ \\
\hline Erro percentual médio - Quadrante 3 & $9,712 \%$ & $12,433 \%$ & $17,001 \%$ \\
\hline Erro percentual médio - Quadrante 4 & $10,463 \%$ & $15,128 \%$ & $18,245 \%$ \\
\hline
\end{tabular}



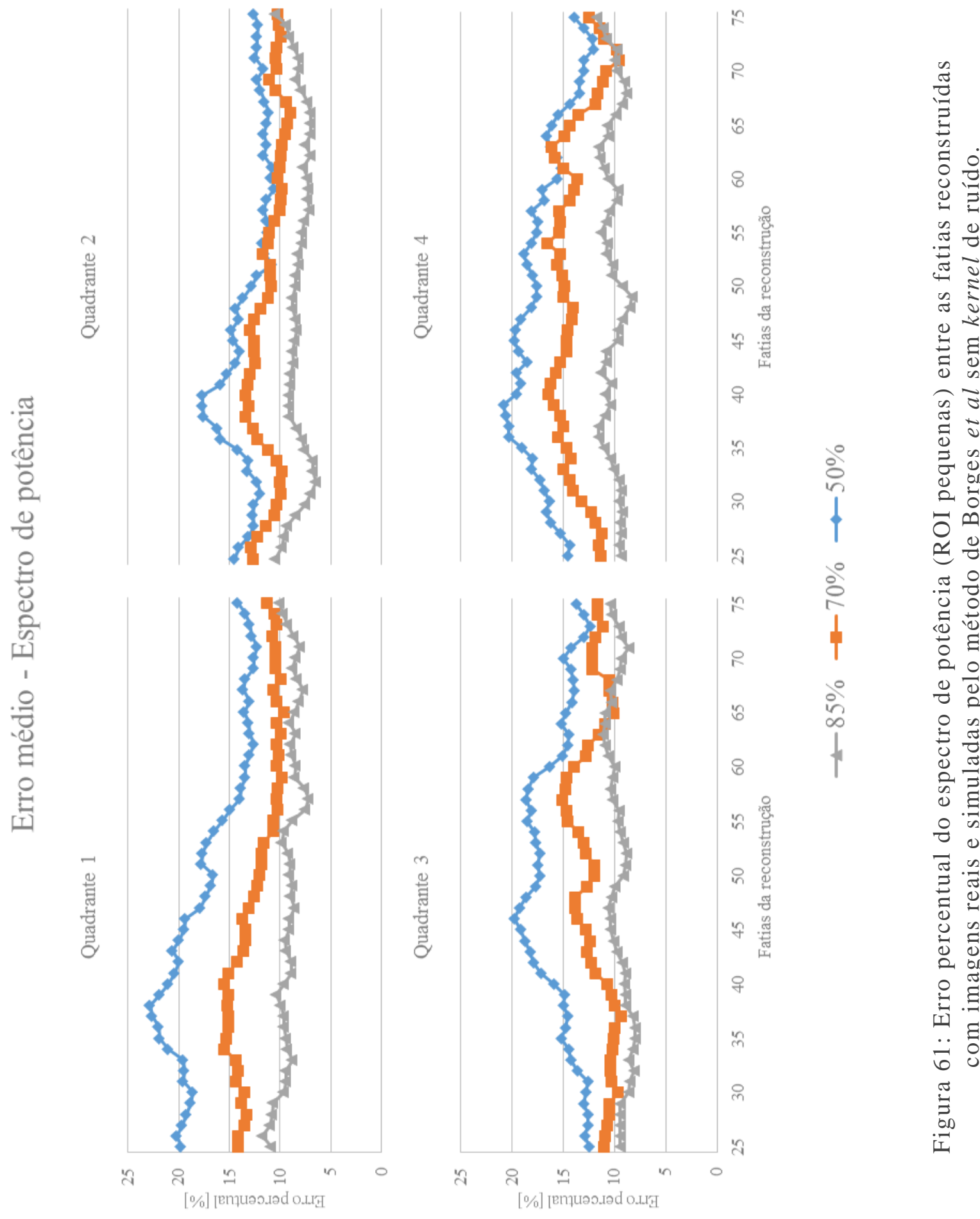


\subsection{Correção pelo espectro de potência do ruído na simulação da redução da dose de radiação}

\subsubsection{O kernel de ruído}

O método proposto por este trabalho é detalhado no item 4.2.2 e tem os resultados de sua aplicação apresentados a seguir. A maior diferença entre esse método e o desenvolvido anteriormente pelo grupo de pesquisa está na presença do kernel de ruído. Assim, seguindo as etapas descritas na Figura 26, foram inicialmente calculados os kernels de ruído necessários para as simulações.

A Figura 62 exibe um exemplo de kernel obtido com base na projeção central de um set de imagens homogêneas com dose 100\%. Com dimensões de 64 x 64 pixels, é possível observar vários componentes presentes no domínio da frequência, porém, no domínio do espaço, somente um ponto central é visualizado.

Kernel de ruído no dominio da frequência
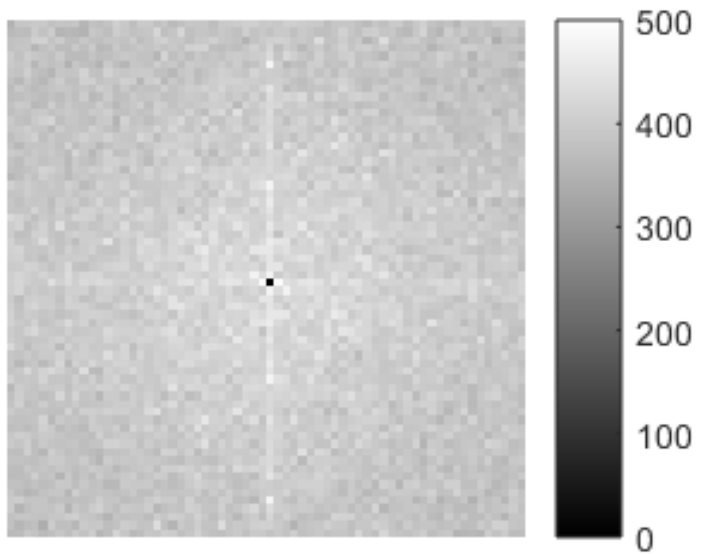

Kernel de ruído no domínio do espaço

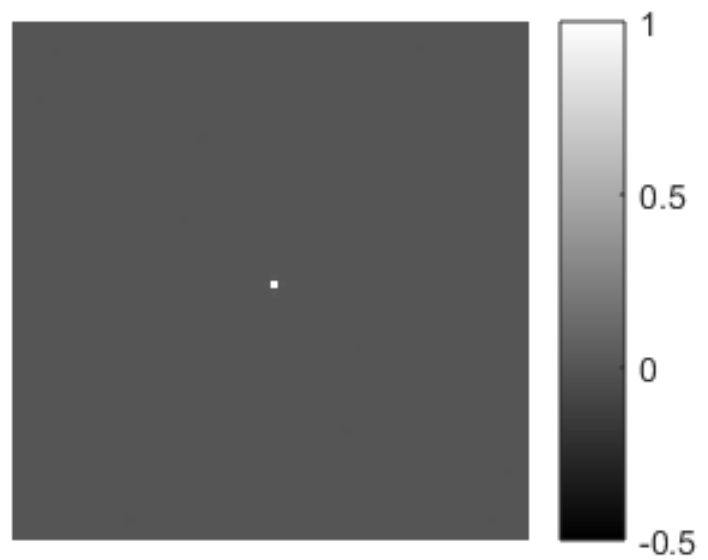

Figura 62: Exemplo de kernel de ruído no domínio da frequência e espaço.

A Figura 63 exibe com detalhes o kernel no domínio do espaço mostrando que, apesar da baixa intensidade, o núcleo apresenta um sinal ruidoso em toda sua extensão. Esse sinal de baixa intensidade é responsável por corrigir o espetro de potência na simulação. 


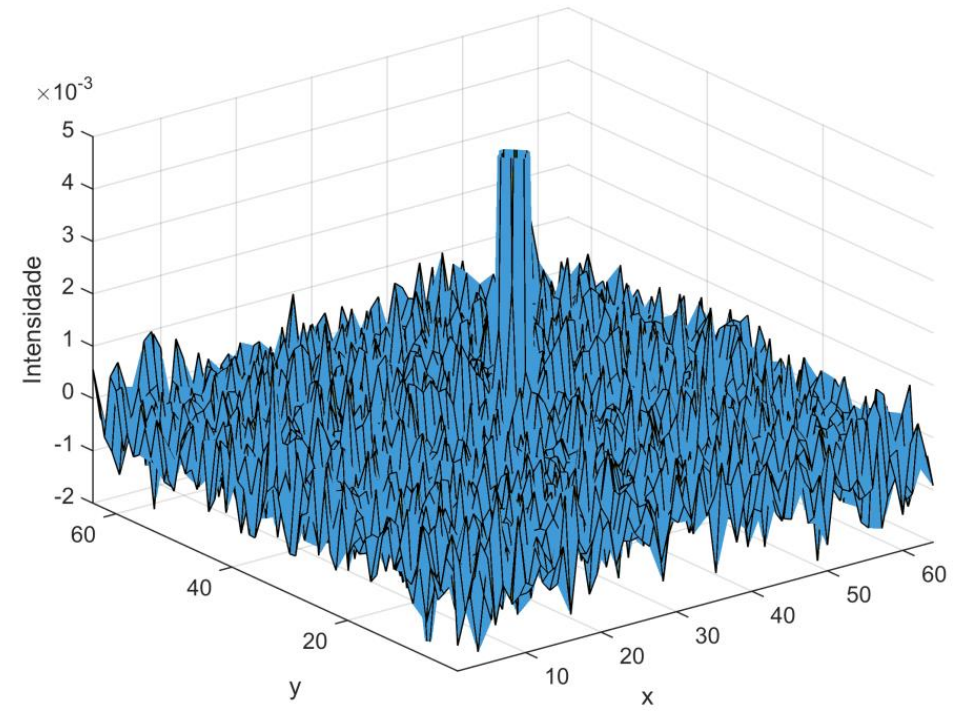

Figura 63: Detalhes do kernel de ruído no domínio do espaço.

A importância da utilização deste kernel pode ser visualizada na Figura 64. Uma única projeção de uniforme de tomossíntese tem seu espectro de potência normalizado representado pela linha cinza e é utilizada como referência para o cálculo do kernel de ruído.

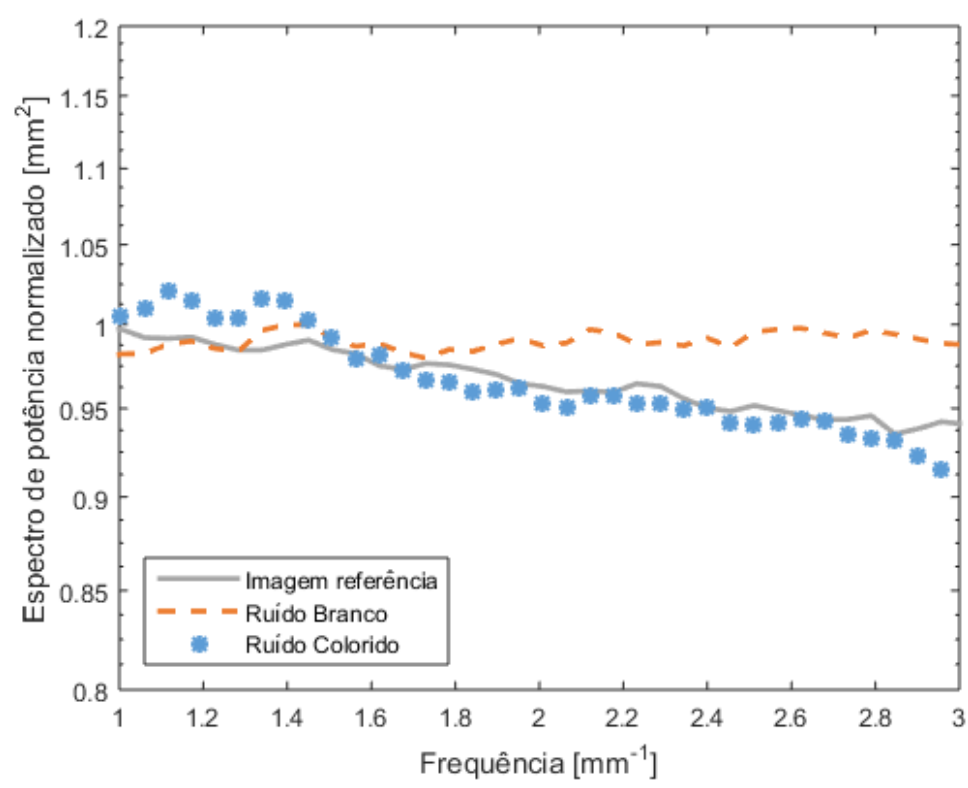

Figura 64: Resultado da correção do espectro de potencia através da utilização do kernel de ruído em um ruído branco. A linha cinza representa o espectro de potência de uma projeção de tomossíntese, a linha tracejada laranja o espectro de uma máscara de ruído branco, que, após a correção induzida pelo kernel apresenta como resultado o espectro representado pelos pontos em azul. 
Uma máscara de ruído branco exatamente com a utilizada no método de Borges et al foi recriada e teve seu uniforme espectro de potência calculado e representado pela linha tracejada laranja. A convolução do kernel de ruído com essa máscara ocasiona na alteração do valor do espectro de potência do ruído resultante, representado pelos pontos em azul.

Assim é possível visualizar que a utilização do kernel de ruído ocasiona a conversão do espectro de potência do ruído aproximando-o ao encontrado na imagem de referência.

\subsubsection{Simulação da redução da dose de radiação das projeções de tomossíntese}

Analogamente aos resultados exibidos anteriormente, foram realizadas simulações de redução de dose também para o novo método proposto no item 4.2.2. Para essa simulação foi utilizado o mesmo conjunto de imagens que anteriormente tanto para as três doses de redução quando para a imagem $100 \%$ da dose padrão de radiação. A Figura 65 exibe a semelhança entre as imagens de phantom e as simuladas. Para a representação foram utilizadas as mesmas regiões de 256 x 256 pixels que no Figura 50. Assim como nos resultados anteriores é necessário uma análise quantitativa para uma correta análise do novo método.

\subsubsection{Média local das projeções}

A análise do erro percentual entre o valor médio da intensidade de pixel das imagens simuladas quando comparadas com as imagens de referência pode ser vista na Tabela 18.

Tabela 18: Erro percentual médio do valor médio da intensidade do pixel nas projeções simuladas com kernel de ruído.

\begin{tabular}{cccc}
\hline $\begin{array}{c}\text { Dose simulada } \\
\begin{array}{c}\text { Erro percentual do valor médio } \\
\text { (Média entre todas as projeções) }\end{array}\end{array}$ & $85 \%$ & $70 \%$ & $50 \%$ \\
\hline Método proposto & $0,604 \%$ & $0,802 \%$ & $0,753 \%$ \\
\hline Método Borges $\boldsymbol{e t}$ al & $0,603 \%$ & $0,799 \%$ & $0,748 \%$ \\
\hline
\end{tabular}


Imagens de phantom

$85 \%$

$70 \%$

$50 \%$
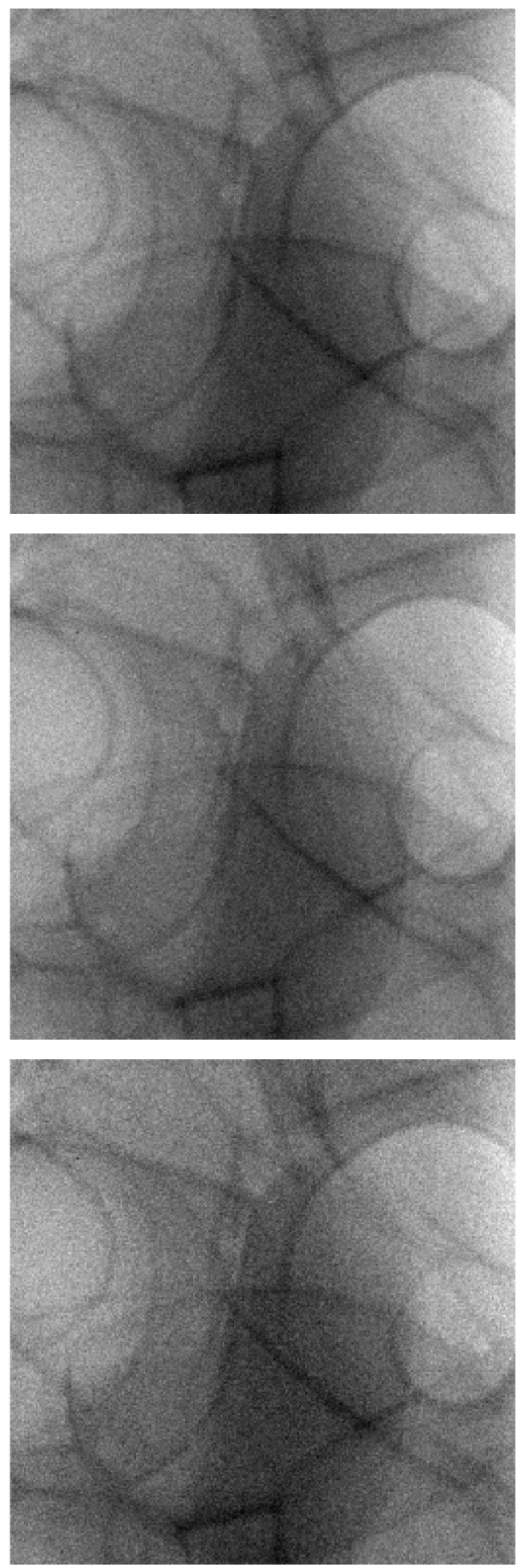

Imagens simuladas
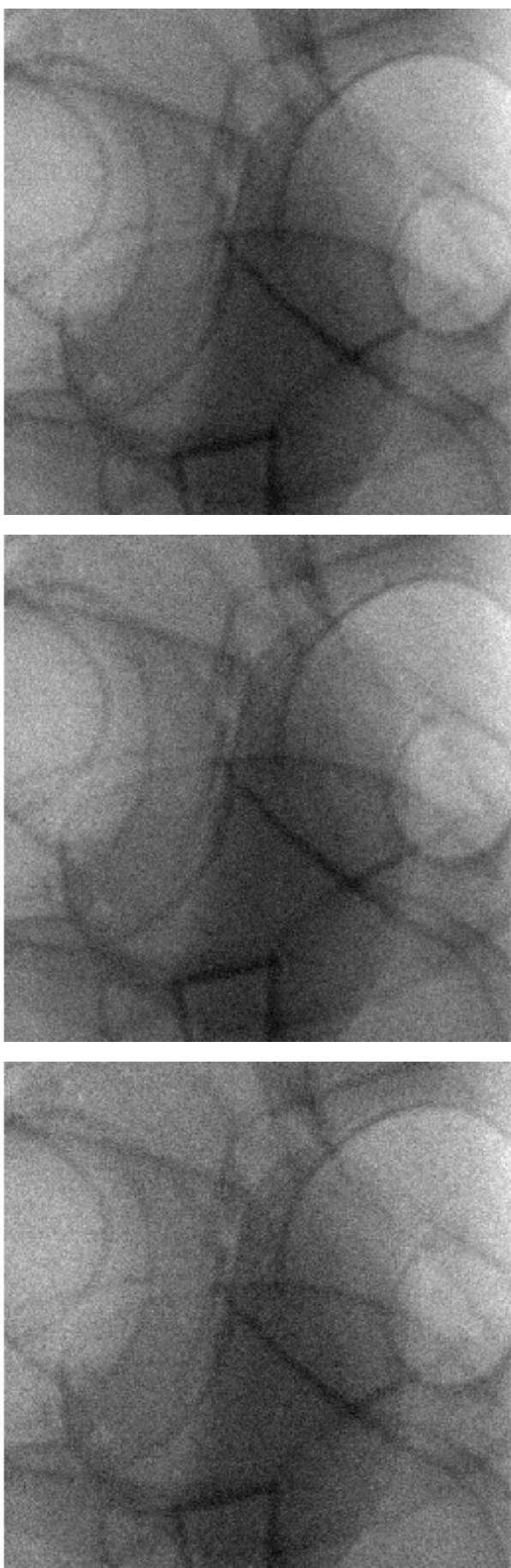

Figura 65: Comparação entre imagens de phantom e simuladas com kernel de ruído projeções. 


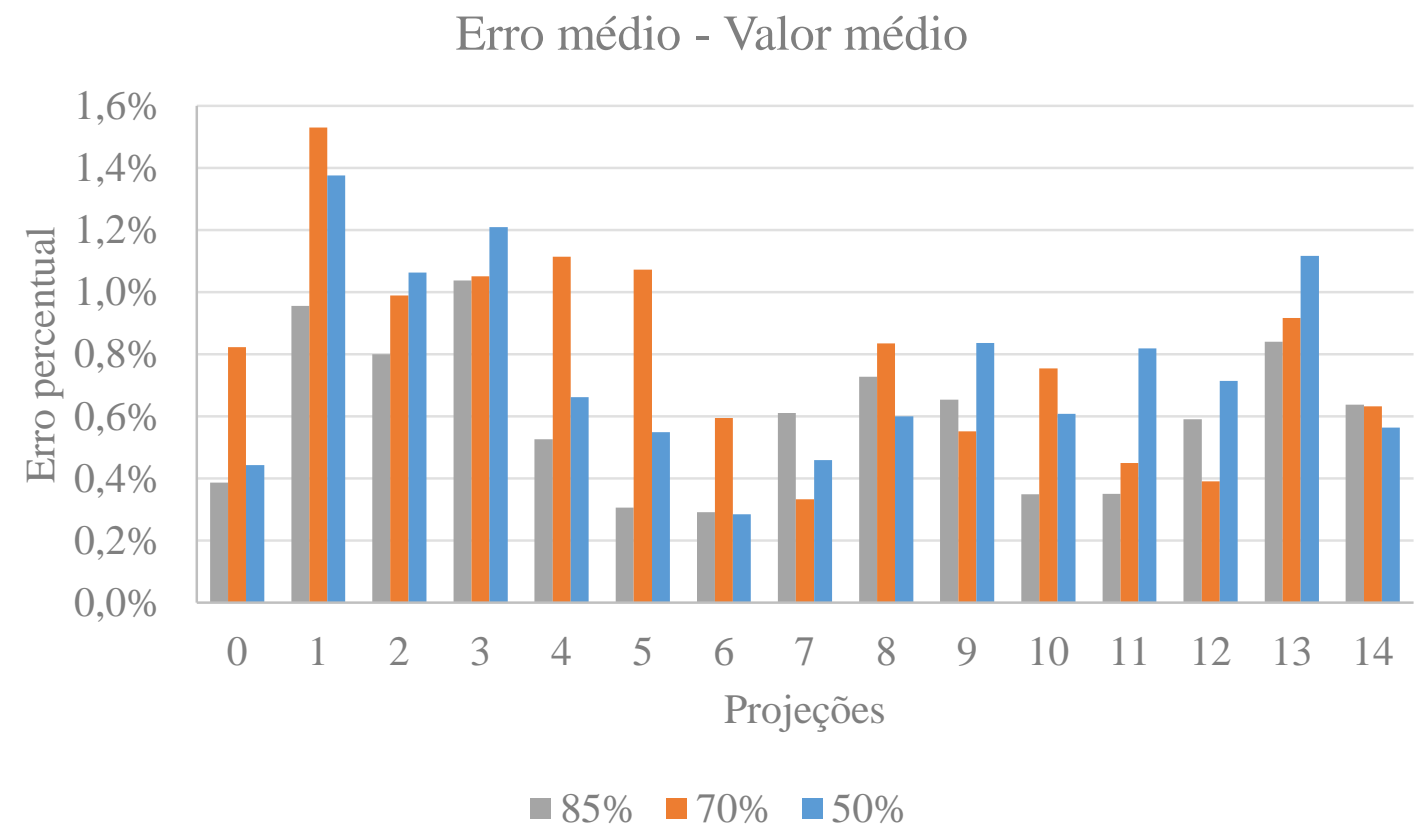

Figura 66: Erro percentual do valor médio entre as projeções simuladas com kernel de ruído e de phantom.

De maneira expandida, a Figura 66 exibe o erro percentual em cada projeção. De maneira análoga aos resultados da Figura 51, é possível notar que para uma simulação de redução de dose de $85 \%$ o erro percentual máximo tem pico próximo a $1 \%$, enquanto para redução de $70 \%$ e $50 \%$ o valor máximo é próximo de 1,5\%. Esses resultados mostram que, em relação a analise do valor médio de intensidade de pixel, ambas as simulações apresentam resultados extremamente semelhantes.

\subsubsection{Desvio padrão das projeções}

A análise do desvio padrão seguiu o mesmo padrão de testes que os resultados descritos no item 5.3.1.2. A Tabela 19 apresentem os valores médios do erro percentual entre todas as projeções.

A Figura 67 apresenta o erro percentual do desvio padrão entre as imagens simuladas e as de referencia de forma discriminada nas projeções. Os resultados obtidos são semelhantes aos da Figura 52: uma redução de $85 \%$ apresenta o menor erro, inferior a 2,4\%. A simulação de redução para $70 \%$ apresenta erro máximo de $2,6 \%$ enquanto que os piores resultados são próximos a 3,1\% para uma redução de $50 \%$ da dose. 
Tabela 19: Erro percentual médio do desvio padrão entre as projeções simuladas com kernel de ruído.

\begin{tabular}{cccc}
\hline $\begin{array}{c}\text { Dose simulada } \\
\text { Erro percentual do desvio padrão } \\
\text { (Média entre todas as projeções) }\end{array}$ & $85 \%$ & $70 \%$ & $50 \%$ \\
\hline Método proposto & $2,214 \%$ & $2,458 \%$ & $2,835 \%$ \\
\hline Método Borges et al & $2,192 \%$ & $2,406 \%$ & $2,775 \%$ \\
\hline
\end{tabular}

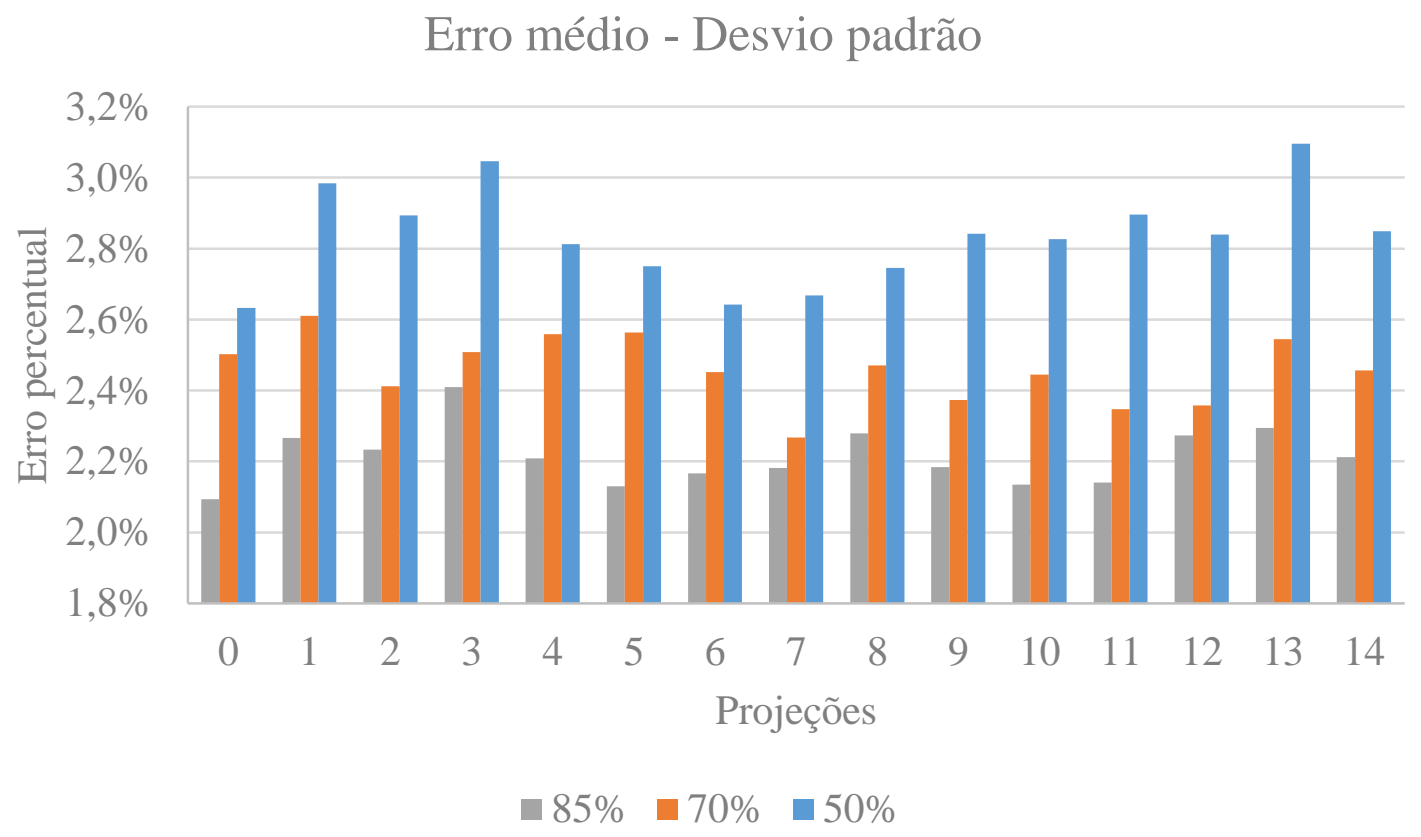

Figura 67: Erro percentual do desvio padrão entre as projeções simuladas com kernel de ruído e de phantom.

\subsubsection{Espectro de potência das projeções}

A análise do espectro de potência segue os mesmos procedimentos adotados no item 5.3.1.3. A Figura 68 exibe os valores de espectro de potência da região de interesse maior detalhada no item 4.3.3. Devido ao fato desses dados terem uma grande relevância para o novo método proposto, é desejável fazer uma análise mais detalhada dos resultados. Com isso, o gráfico exibe os valores relativos a uma imagem de phantom em linhas cheias, os valores obtidos pela simulação do método de Borges et al em cores mais claras e os valores obtidos pelo novo método em cores mais escuras. A região inferior do gráfico é uma simples ampliação para melhor visualização. 
Espectro de potência

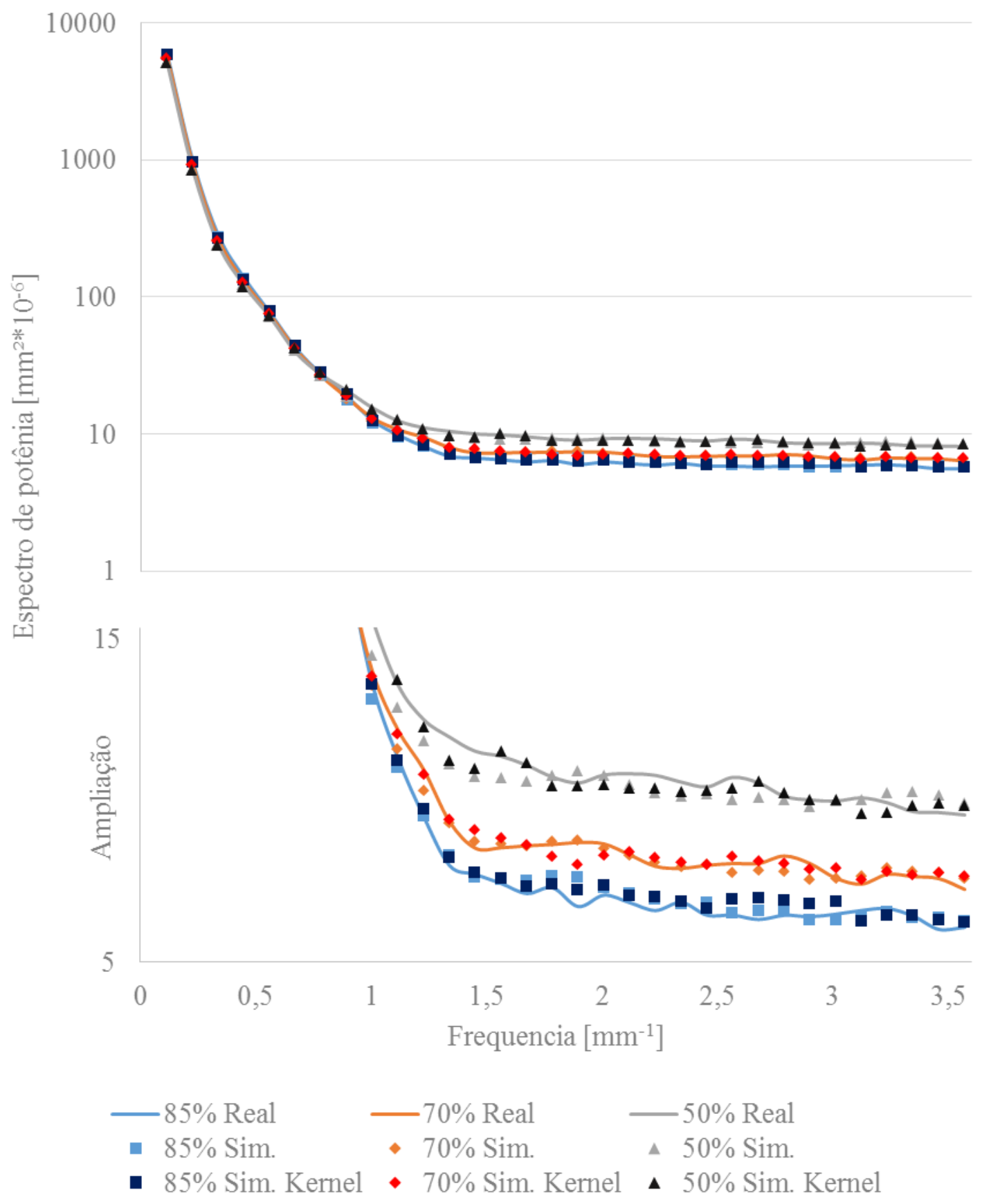

Figura 68: Espectro de potência das projeções simuladas e de phantom. Comparação entre imagem real, imagem simulada sem e com kernel de ruído. 
Apesar de ser visível que em algumas regiões os pontos mais escuros estão mais próximos da linha contínua do que os pontos em cores claras, é necessário realizar uma análise quantitativa dos resultados. A Figura 69 exibe o erro percentual médio do espectro de potência em cada projeção. É possível notar uma grande discrepância desses resultados com os exibidos na Figura 53. A inserção da kernel de ruído equalizou o erro percentual para as três as doses de redução em um nível próximo de 3\% de erro. Especialmente na simulação de redução para $50 \%$ da dose, a diferença entre o novo método e o antigo chega a atingir 1,5\%.

O valor médio de erro do espectro de potência está presente na Tabela 20 e pode ser comparado com os valores da Tabela 11. Analisando ambas as tabelas é possível afirmar que para uma pequena redução (85\%) ambos os métodos são praticamente iguais, porém, quando considerada a relação para uma grande redução de dose de radiação (50\%), o novo método apresenta erro percentual médio 1,12\% menor.

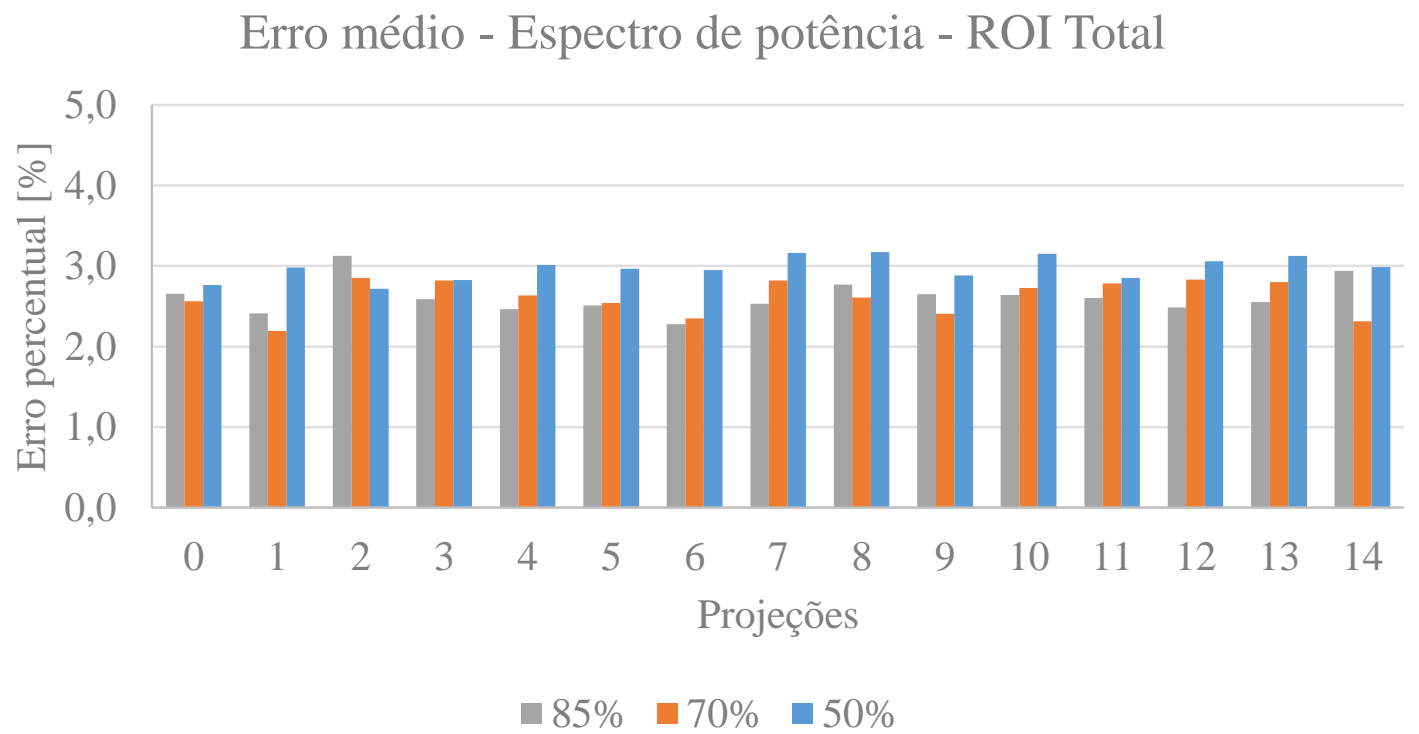

Figura 69: Erro percentual do espectro de potência entre as projeções simuladas com kernel de ruído e de phantom (ROI grande).

Tabela 20: Erro percentual médio do espectro de potência (ROI grande) - projeções simuladas com kernel de ruído.

\begin{tabular}{cccc}
\hline $\begin{array}{c}\text { Dose simulada } \\
\text { Erro percentual do espectro de potência } \\
\text { (Média entre todas as projeções) }\end{array}$ & $85 \%$ & $70 \%$ & $50 \%$ \\
\hline Método proposto & $2,613 \%$ & $2,617 \%$ & $2,974 \%$ \\
\hline Método Borges et al & $2,689 \%$ & $2,885 \%$ & $4,094 \%$ \\
\hline
\end{tabular}


De maneira análoga ao item 5.3.1.3, adicionalmente à análise da potência de ruído em uma grande região de interesse foi realizada a análise em quatro ROIs menores. A Figura 70 apresenta os erros percentuais para cada projeção nos quatro quadrantes. Os resultados apresentam homogeneidade em todas as regiões, mostrando baixa influência do efeito heel e, quando comparados à Figura 55, é possível notar uma ausência de picos na cor azul, mostrando uma diminuição significativa do erro percentual do espectro de potência com o método proposto.

A Tabela 21 quantifica os valores de erro percentual máximo em cada quadrante independente da projeção enquanto a Tabela 22 apresenta o erro médio em cada quadrante.

\section{Erro médio - Espectro de potência}

Quadrante 1

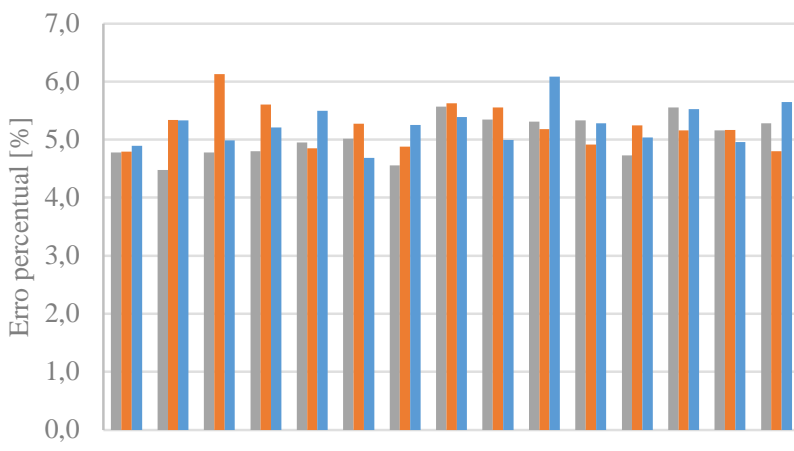

Quadrante 3

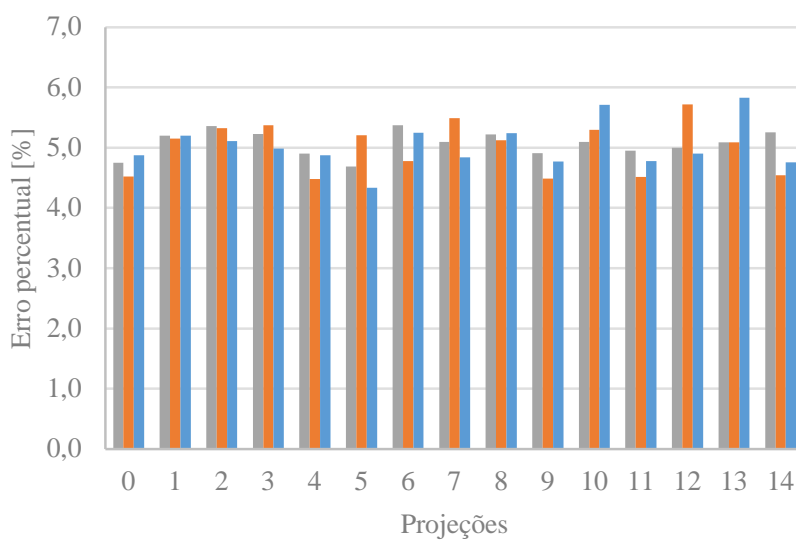

Quadrante 2

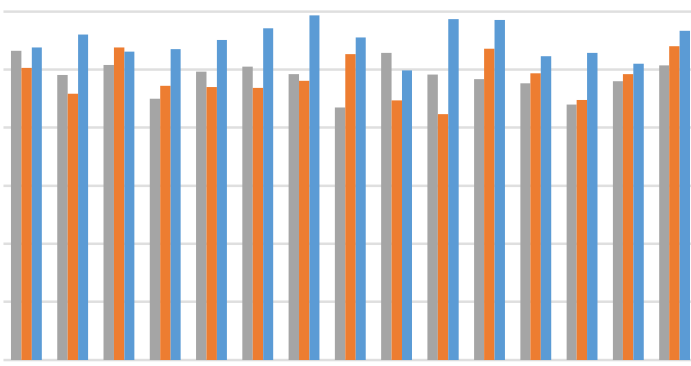

Quadrante 4

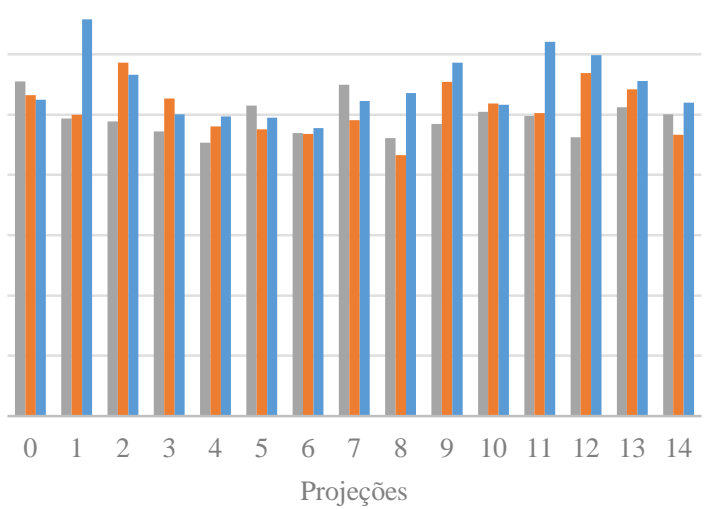

$-85 \% \quad-70 \% \quad-50 \%$

Figura 70: Erro percentual do espectro de potência entre as projeções simuladas com kernel de ruído e de phantom (ROI pequeno). 
Tabela 21: Erro percentual máximo do espectro de potência (ROI pequeno) - projeções simuladas com kernel de ruído.

\begin{tabular}{cccc}
\hline Dose simulada & $85 \%$ & $70 \%$ & $50 \%$ \\
\hline Erro percentual máximo - Quadrante 1 & 5,565 & 6,125 & 6,087 \\
\hline Erro percentual máximo - Quadrante 2 & 5,326 & 5,406 & 5,933 \\
\hline Erro percentual máximo - Quadrante 3 & 5,376 & 5,717 & 5,830 \\
\hline Erro percentual máximo - Quadrante 4 & 5,552 & 5,866 & 6,581 \\
\hline
\end{tabular}

Tabela 22: Erro percentual médio do espectro de potência (ROI pequeno) - projeções simuladas com kernel de ruído.

\begin{tabular}{cccc}
\hline Dose simulada & $85 \%$ & $70 \%$ & $50 \%$ \\
\hline Erro percentual médio - Quadrante 1 & 5,041 & 5,235 & 5,252 \\
\hline Erro percentual médio - Quadrante 2 & 4,878 & 4,866 & 5,490 \\
\hline Erro percentual médio - Quadrante 3 & 5,074 & 5,006 & 5,031 \\
\hline Erro percentual médio - Quadrante 4 & 4,948 & 5,099 & 5,451 \\
\hline
\end{tabular}

\subsubsection{Simulação das fatias tomográficas}

Analogamente as resultados apresentados no item 0 foi realizado a análise das fatias da mama reconstruída, porém desta vez, tomando como base as imagens simuladas através do algoritmo proposto por esse trabalho, levando em conta o kernel para correção do espectro de potência do ruído.

Na Figura 71, de maneira análoga à Figura 56, estão representadas regiões de 128 x 128 pixels retiradas da fatia reconstruída central. Apesar das imagens reconstruídas com e sem kernel de ruído serem distintas, não é possível detectar diferenças visíveis ao olho humano.

\subsubsection{Média local das fatias}

O erro percentual médio de cada fatia pode ser visualizado na Figura 72. Assim como os resultados do item 5.3.2.1, o algoritmo de reconstrução ocasiona uma estabilização do valor médio. Para uma redução de dose de $50 \%$, o valor máximo de erro chegou a $0,433 \%$ com uma diferença absoluta de apenas $0,006 \%$ para o menor valor. As reduções para $70 \%$ e $85 \%$ da dose apresentaram valores máximos de $0,310 \%$ e $0,291 \%$, respectivamente.

Os valores médios do erro percentual podem ser vistos na Tabela 23. 
Imagens de phantom

$85 \%$

$70 \%$

$50 \%$
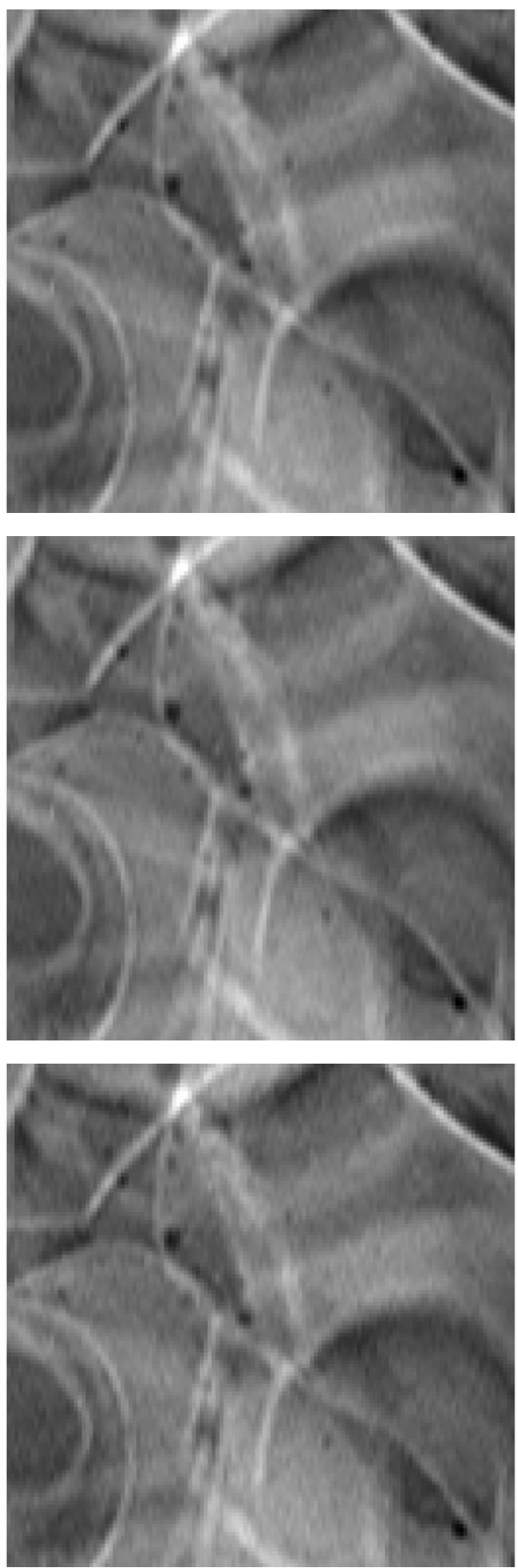

Imagens simuladas
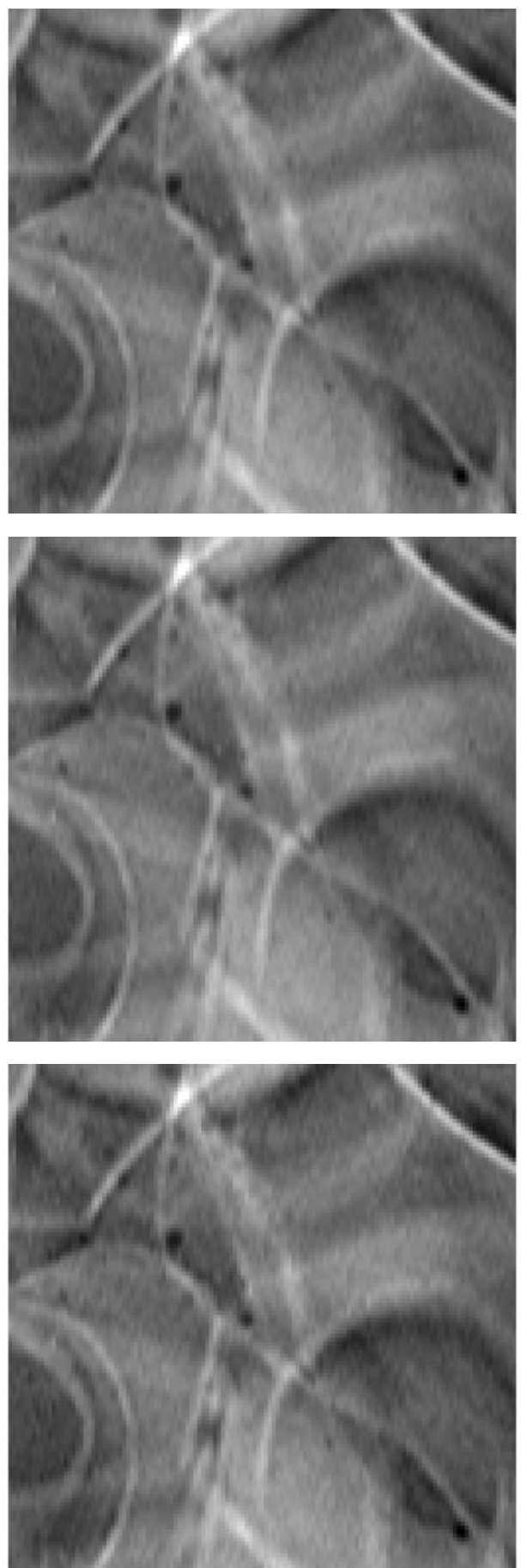

Figura 71: Comparação entre imagens de phantom e simuladas com kernel de ruído reconstruções. 
Tabela 23: Erro percentual médio do valor médio da intensidade do pixel nas fatias simuladas com kernel de ruído.

\begin{tabular}{cccc}
\hline $\begin{array}{c}\text { Dose simulada } \\
\begin{array}{l}\text { Erro percentual do valor médio } \\
\text { (Média entre todas as fatias) }\end{array}\end{array}$ & $85 \%$ & $70 \%$ & $50 \%$ \\
\hline Método proposto & $0,289 \%$ & $0,307 \%$ & $0,430 \%$ \\
\hline Método Borges $\boldsymbol{e t}$ al & $0,285 \%$ & $0,315 \%$ & $0,416 \%$ \\
\hline
\end{tabular}

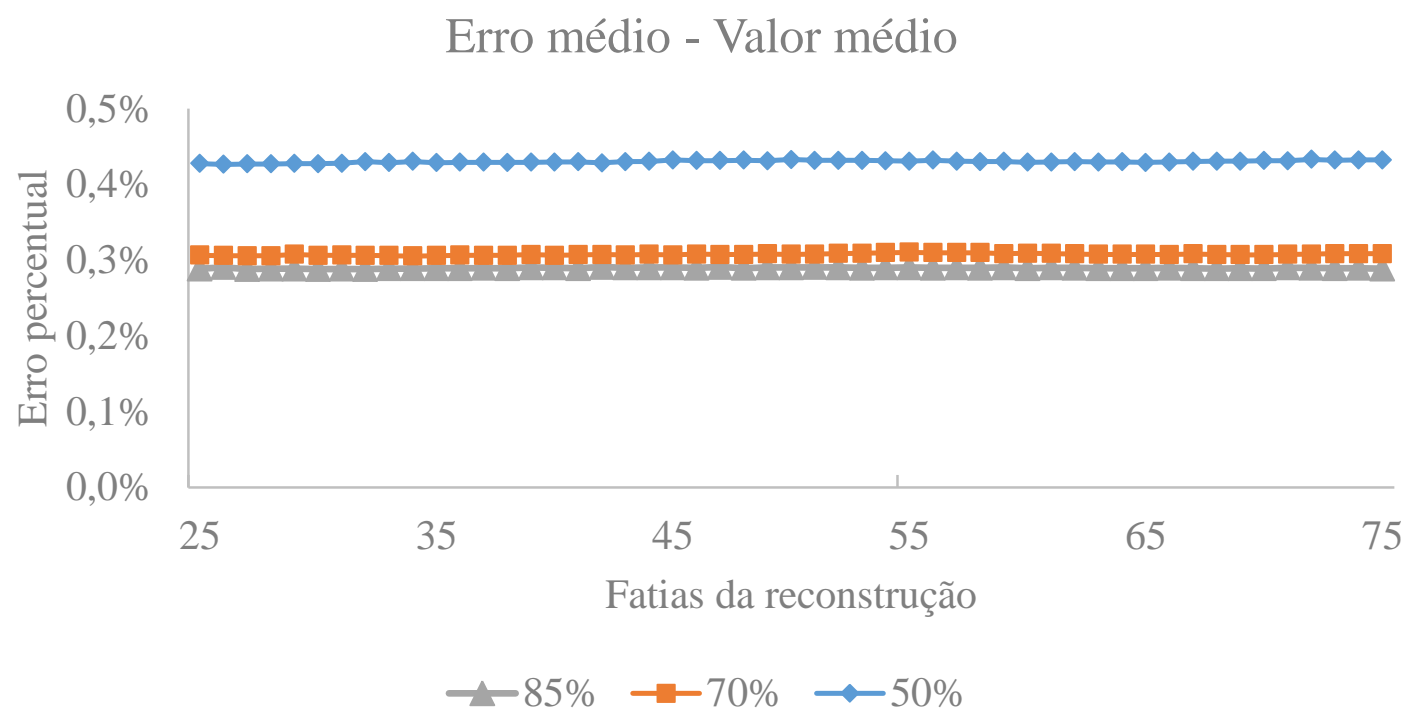

Figura 72: Erro percentual do valor médio entre as fatias simuladas com kernel de ruído e de phantom.

\subsubsection{Desvio padrão das fatias}

Apesar da grande semelhança entre os valores médios de intensidade das fatias simuladas com e sem kernel de ruído, a análise do valor do desvio padrão mostra que a reconstrução da simulação através do algoritmo proposto por este trabalho apresentou melhores resultados, principalmente para uma simulação reduzindo a dose em $70 \%$.

De maneira análoga à Figura 58, a Figura 73 apresenta os valores do erro médio do desvio padrão em cada fatia. Para as dose de $50 \%$ e $85 \%$, com valores máximos de $0,727 \%$ e 0,566\%, respectivamente, não ouve diferença significativas, no entanto, com um erro máximo de $0,727 \%$, uma redução para $70 \%$ apresentou $0,204 \%$ de melhora.

Os valores médios do erro percentual do desvio padrão em cada dose de redução podem ser vistos na Tabela 24. 
Tabela 24: Erro percentual médio do desvio padrão entre as fatias simuladas com kernel de ruído.

\begin{tabular}{cccc}
\hline $\begin{array}{c}\text { Dose simulada } \\
\begin{array}{l}\text { Erro percentual do desvio padrão } \\
\text { (Média entre todas as fatias) }\end{array}\end{array}$ & $85 \%$ & $70 \%$ & $50 \%$ \\
\hline Método proposto & $0,457 \%$ & $0,606 \%$ & $0,623 \%$ \\
\hline Método Borges et al & $0,456 \%$ & $0,873 \%$ & $0,679 \%$ \\
\hline
\end{tabular}

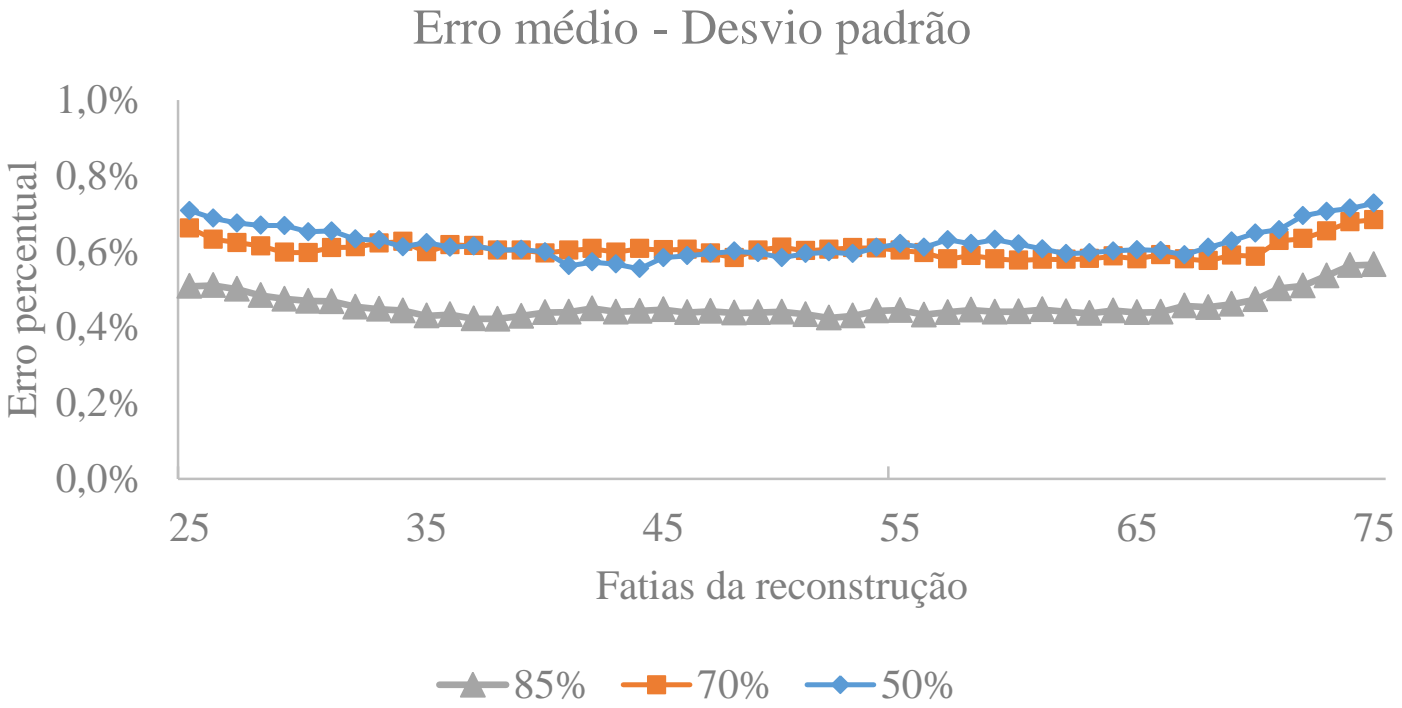

Figura 73: Erro percentual do desvio padrão entre as fatias simuladas com kernel de ruído e de phantom.

\subsubsection{Espectro de potência das fatias}

De maneira análoga ao item 5.3.2.3, é realizada a análise do espectro de potência das fatias reconstruídas a partir das imagens simuladas com kernel de ruído. A Figura 74 apresenta um trecho espectro de potência da fatia central. As linhas contínuas representam os valores obtidos das imagens de phantom enquanto os pontos representam os valores obtidos das imagens reconstruídas. De maneira semelhante à Figura 59, os valores simulados e reais estão muito próximos e é difícil realizar a análise visual. 


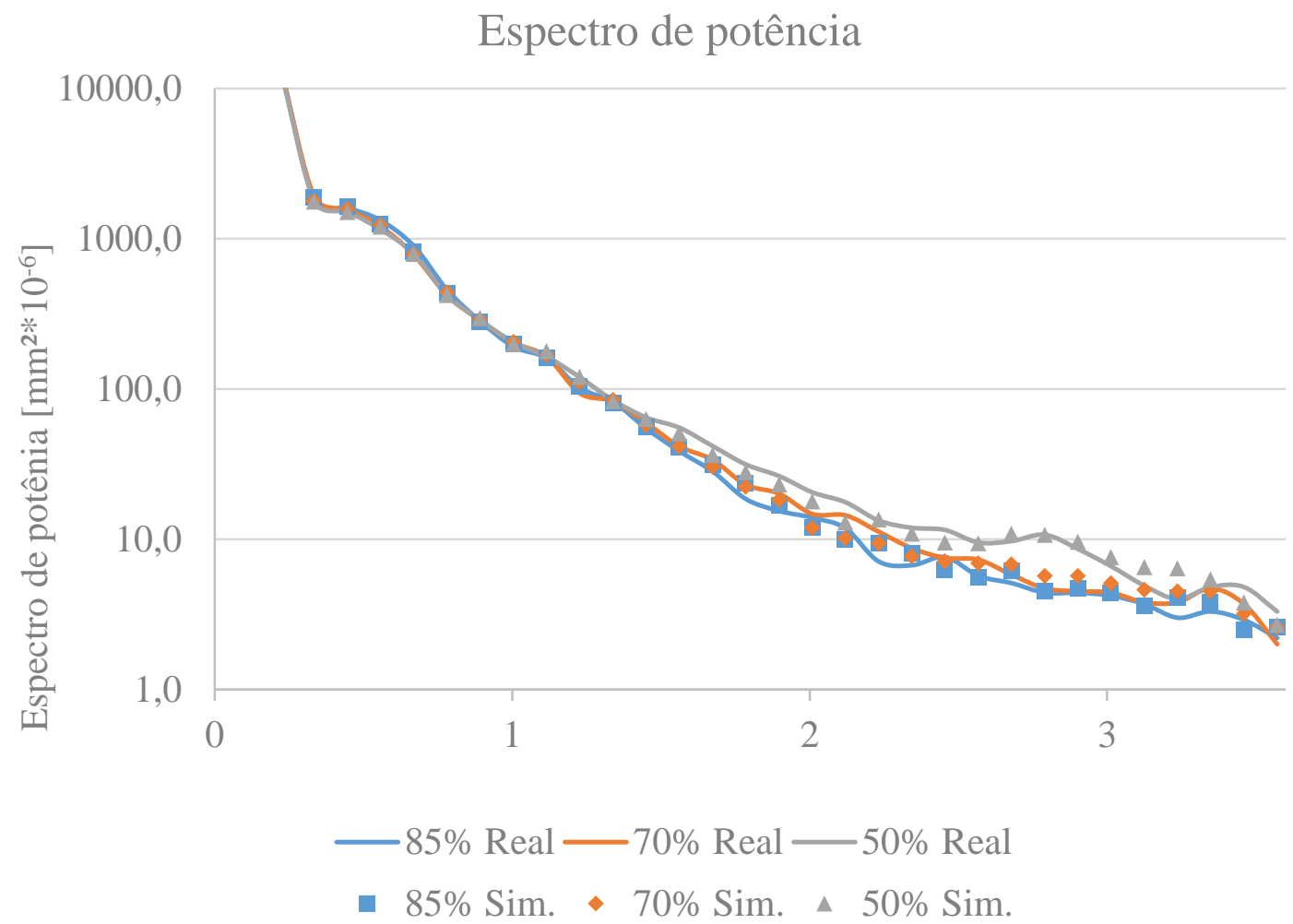

Figura 74: Espectro de potência das fatias simuladas com kernel de ruído e de phantom.

A Figura 75 apresenta o valor médio do erro percentual do espectro de potência do ruído em cada fatia. De uma maneira distinta dos valores apresentados na Figura 60, os resultados não apresentam nítida distinção entre as diferentes doses de radiação simuladas.

Nas fatias relativas a uma redução para $85 \%$ da dose de radiação o valor máximo encontrado foi de 5,922\%, para a dose de $70 \%$ esse valor foi de 5,838\%. Porém, a maior diferença foi para a dose de $50 \%$, com erro percentual máximo de $6,393 \%$.

Os valores do erro percentual médio para cada dose de redução podem ser vistos na Tabela 25 e, quando comparados à Tabela 16, indicam que o método proposto por este trabalho, quando comparado à simulação sem kernel de ruído, melhora em 16,61\% caso a redução de dose seja para $85 \%, 53,96 \%$ no caso de uma redução para $70 \%$ e 64,03\% quando se reduz o máximo de $50 \%$. Os resultados do erro percentual médio para os ROIs pequenos podem ser vistos na Figura 76 e seus valores médios na Tabela 26. 


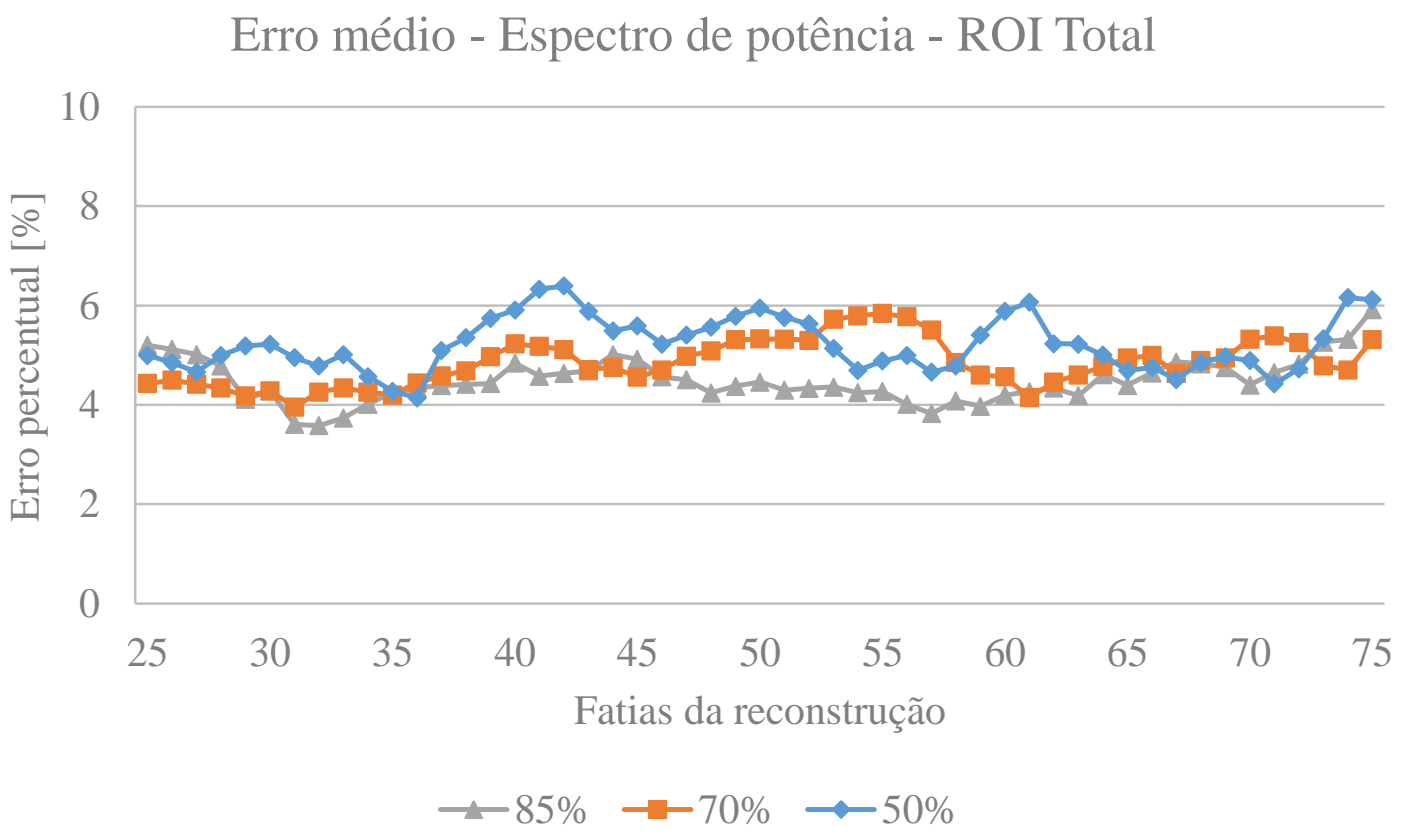

Figura 75: Erro percentual do espectro de potência entre as fatias simuladas com kernel de ruído e de phantom (ROI grande).

Tabela 25: Erro percentual médio do espectro de potência (ROI grande) - fatias reconstruídas com kernel de ruído.

\begin{tabular}{cccc}
\hline $\begin{array}{c}\text { Dose simulada } \\
\begin{array}{c}\text { Erro percentual do espectro de potência } \\
\text { (Média entre todas as fatias) }\end{array}\end{array}$ & $85 \%$ & $70 \%$ & $50 \%$ \\
\hline Método proposto & $4,389 \%$ & $4,969 \%$ & $5,361 \%$ \\
\hline Método Borges et al & $5,263 \%$ & $10,793 \%$ & $14,906 \%$ \\
\hline
\end{tabular}

Tabela 26: Erro percentual médio do espectro de potência (ROI pequeno) - fatias reconstruídas com kernel de ruído.

\begin{tabular}{cccc}
\hline Dose simulada & $85 \%$ & $70 \%$ & $50 \%$ \\
\hline Erro percentual médio - Quadrante 1 & $9,637 \%$ & $9,799 \%$ & $10,719 \%$ \\
\hline Erro percentual médio - Quadrante 2 & $8,090 \%$ & $8,622 \%$ & $8,987 \%$ \\
\hline Erro percentual médio - Quadrante 3 & $9,577 \%$ & $10,005 \%$ & $10,673 \%$ \\
\hline Erro percentual médio - Quadrante 4 & $10,370 \%$ & $11,199 \%$ & $12,153 \%$ \\
\hline
\end{tabular}




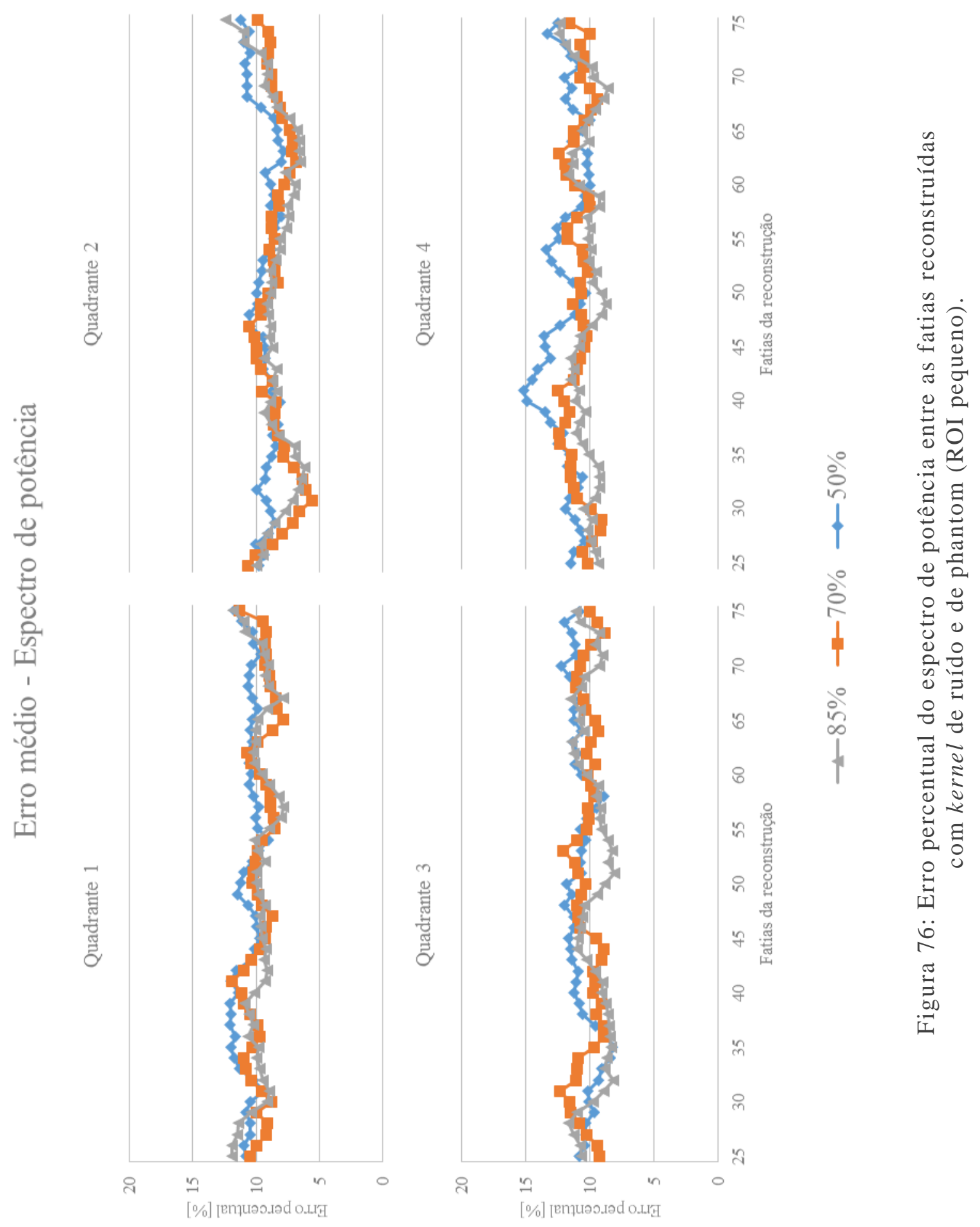


Comparando os resultados obtidos com os apresentados na Tabela 17 é possível concluir que o método apresentado neste trabalho acarreta em uma diferença significativa no espectro de potência. Os valores absolutos da comparação entre os dos métodos de simulação são apresentadas na Tabela 27.

Tabela 27: Melhora percentual entre o erro percentual médio do espectro de potência dos ROI pequeno os dois algoritmos de simulação.

\begin{tabular}{cccc}
\hline Dose simulada & $85 \%$ & $70 \%$ & $50 \%$ \\
\hline Erro percentual médio - Quadrante 1 & $7,17 \%$ & $20,64 \%$ & $38,44 \%$ \\
\hline Erro percentual médio - Quadrante 2 & $0,36 \%$ & $24,76 \%$ & $32,44 \%$ \\
\hline Erro percentual médio - Quadrante 3 & $1,39 \%$ & $19,53 \%$ & $37,22 \%$ \\
\hline Erro percentual médio - Quadrante 4 & $0,89 \%$ & $25,97 \%$ & $33,39 \%$ \\
\hline
\end{tabular}




\section{Discussão e Conclusão}

Este capítulo é subdividido em quatro seções e visa exibir as informações finais do trabalho. A primeira seção apresenta uma discussão acerca dos resultados obtidos, seguido por uma conclusão geral na segunda seção. Adicionalmente, são relatados possíveis modos de continuidade do estudo de redução de dose em DBT e finalmente são listadas as contribuições desenvolvidas durante esta pesquisa.

\subsection{Discussão}

O objetivo principal deste trabalho é apresentar um método de simulação de redução de dose de radiação para imagens de tomossíntese digital mamária a partir da modificação de um método desenvolvido originalmente para mamografia digital utilizando a inserção de um kernel de ruído para a correção do espectro de potência.

A análise das imagens homogêneas mostra que cada projeção apresenta uma característica de ruído diferente e altamente dependente da posição espacial dos elementos sensores. Devido à calibração de não-uniformidade do equipamento mamográfico (flatfielding), o valor médio da imagem apresenta pouca variação dentro de uma mesma imagem e entre projeções. Em compensação, o desvio padrão apresenta maior divergência, mostrando a grande influência do flat-fielding no ruído da imagem. Esse aumento de ruído é danoso e pode induzir erros no diagnóstico médico caso uma mama com grande volume entre na região mais ruidosa. A alta dependência espacial do ruído nas imagens homogêneas implica que, para a simulação de ruído, devem-se adquirir as informações sobre o ruído localmente na própria imagem ou de uma imagem homogênea com projeção equivalente.

A comparação entre as imagens dos exames mostra que, apesar das imagens de mamografia apresentar maior valor absoluto de valor médio e desvio padrão, o cálculo da relação sinal-ruído indica que as imagens de mamografia digital apresentam menor ruído relativo se comparadas às imagens de projeção da tomossíntese digital mamária.

Os resultados da simulação de redução de dose em imagens de tomossíntese digital mamária por meio da utilização de um algoritmo proposto inicialmente para mamografia digital se mostraram satisfatórios. O nível médio de sinal das imagens de projeção simuladas 
apresentou erro inferior a $1 \%$ nas três reduções de doses simuladas quando comparadas a imagens reais de um phantom antropomórfico obtidas no mesmo equipamento, e com a dose de entrada equivalente às das simulações. O erro no valor de desvio padrão foi próximo de $3 \%$, e, do espectro de potência, $4 \%$.

As imagens simuladas em três doses sofreram o processo de reconstrução, resultando nas fatias tomográficas espaçadas em 1mm. A comparação dessas fatais apresentou erros superiores aos resultados da projeção. O nível médio de sinal das imagens simuladas e reconstruídas apresentou erro inferior a $0,5 \%$. O valor do desvio padrão apresentou valor médio inferior a $1 \%$. O erro percentual do espectro de potência apresentou os piores resultados, sendo que para uma redução de dose para $85 \%$, o erro fica próximo de 5\%, mas para uma redução de $50 \%$, eleva-se a $15 \%$.

Com o intuito de melhorar os resultados obtidos, foi proposta a inserção de um kernel de ruído a fim de alterar o espectro de potência da simulação e aproximar os resultados da simulação a dados reais deixando o método mais próximo das características da tomossíntese digital mamária.

Com o novo método de simulação os resultados obtidos para o nível médio de sinal e desvio padrão, tanto na análise das projeções quanto nas fatias, não sofreram nítidas alterações, permanecendo no mesmo nível de erro percentual. Entretanto, na análise do espectro de potência nas projeções, o erro percentual médio caiu de 4\% para 3\% no caso de uma redução para $50 \%$ da dose.

Apesar disso, a maior diferença encontrada foi na análise do espectro de potência nas fatias reconstruídas: o erro percentual médio caiu de $15 \%$ para a simulação sem o kernel de ruído para 5\% na simulação com o kernel.

Nota-se que os resultados para a simulação de doses maiores (85\%) sempre superaram os resultados para doses menores (50\%). Apesar de esperado, pode ser visto que o método proposto neste trabalho e o proposto por (BORGES et al., 2015) possibilitam a simulação de qualquer dose, desde que a margem de erro estipulada seja considerada. 


\subsection{Conclusão}

O método proposto por Borges et al para simulação da redução da dose de radiação em mamografia digital pode ser utilizado para a simulação de redução de dose em tomossíntese digital mamária desde que sejam utilizadas as projeções equivalentes tanto nas imagens mamográficas quanto nas uniformes. A inclusão do método de correção do espectro de potência através da inclusão de um kernel de ruído não apresentou diferenças significativas na análise de valor médio e desvio padrão, porém melhorou significativamente a simulação do espectro de potencia, deixando o método de simulação mais preciso.

\subsection{Sugestões para trabalhos futuros}

Apesar da finalização deste trabalho a pesquisa de simulação de redução de dose de radiação em DBT possui uma ampla gama de utilização e diversas possibilidades de melhorias.

O método de simulação apresentado, mesmo sendo uma melhoria de um método previamente desenvolvido, pode ser modificado para modelar com maior precisão o exame real. Uma sugestão seria a utilização da transformada de Anscombe generalizada, deste modo, considerando a influência individual do ruído eletrônico na formação da imagem. Para isto seria necessário segregar as componentes de ruído Poisson e eletrônico presentes no exame utilizando, por exemplo, o método desenvolvido por Foi et al. (FOI et al., 2008).

As imagens de tomossíntese com dose reduzida obtida pelo algoritmo de simulação podem ser utilizadas em trabalhos futuros para o estabelecimento do ponto ótimo de operação entre a relação dose de radiação e qualidade de imagem para os exames de DBT. Podendo assim alimentar métodos de filtragem de ruído que visam assegurar a qualidade da imagem no ponto de vista de detecção de anomalias mesmo com a utilização de uma menor dose de radiação. Se esses estudos obtiverem resultados satisfatórios, possibilitarão uma diminuição na dose de radiação recebida pela paciente, diminuindo os casos de câncer induzido pelos exames de rastreio do câncer de mama. 


\subsection{Contribuições}

Essa seção apresenta os trabalhos desenvolvidos e publicados durante o curso de mestrado em engenharia elétrica.

- BORGES, L.R.; GUERRERO, I.; BAKIC, P.R.; MAIDMENT, A.D.A.; SCHIABEL, H.; VIEIRA, M.A.C. "Simulation of dose reduction in digital breast tomosynthesis", Lectures Notes in Computer Science, v.9699, p.343-350, Springer International Publishing, 2016.

- BORGES, L.R.; GUERRERO, I.; BAKIC, P.R.; MAIDMENT, A.D.A.; VIEIRA, M.A.C. "Gaussian-Poisson noise estimation from individual mammography images". In: Anais do XII Workshop de Visão Computacional, Campo Grande (MS), p.364-368, 2016.

- BORGES, L.R.; GUERRERO, I.; BAKIC, PR.; FOI, A.; MAIDMENT, A.D.A., VIEIRA, M.A.C. "Method for simulating dose reduction in digital breast tomosynthesis", IEEE Transactions on Medical Imaging, v.36(11), p. 2331-2342, 2017.

- GUERRERO, I.; BORGES, L.R.; VIEIRA, M.A.C. "Correção do espectro de potência do ruído na simulação de redução da dose de radiação em imagens de tomossíntese digital mamária” In: Anais do XXII Congresso Brasileiro de Física Médica, Ribeirão Preto (SP), 2017. 


\section{Bibliografia}

AMERICAN CANCER SOCIETY. Breast density and your mammogram report. [S.1.]. 2015.

ANSCOMBE, F. J. The Transformation of Poisson, Binomial and Negative-Binomial Data.

Biometrika, v. 35, n. 3/4, p. 246-254, December 1948.

ARS MEDICINAS CENTRS. Breast tomosynthesis: introducing a new machine. ARS

Medicinas Centrs, 2017. Disponivel em: <http://ars-med.lv/>. Acesso em: 2017.

BATH, M. et al. Method of simulating dose reduction for digital radiographic systems.

Radiation Protection Dosietry, v. 114, n. 1-3, p. 253-259, 2005.

BEUTEL, J.; KUNDEL, H. L.; METTER, R. L. V. (Eds.). Handbook of medical imaging. [S.1.]: SPIE, 2000.

BOONE, J. M. X-ray production interaction, and detection in diagnostic imaging. In: BEUTEL, J.; KUNDEL, H. L.; METTER, R. L. V. Handboo of Medical Imaging. [S.1.]: SPIE Press, 2000. Cap. 1.

BORGES, L. R. et al. Method for inserting noise in digital mammography to simulate reduction in radiation dose. Medical Imaging 2015: Physics of Medical Imaging, v. Proc. SPIE 9412, 2015.

BUADES, A.; COLL, B.; MOREL, J.-M. A review of image denoising algorithms, with a new one. SIAM Journal on Multiscale Modeling and Simulation: A SIAM Interdisciplinary Journal, v. 4, n. 2, p. 490-530, July 2005.

CHAWLA, A. S. et al. Effect of dose reduction on the detection of mammographic lesions: A mathematical observer model analysis. Medical Physics, v. 34, n. 8, 2007.

CHEN, Y.; LO, J. Y.; DOBBINS, J. T. A comparison between traditional shift-and-add (SAA) and point-by-point back projection (BP) -- relevance to morphology of microcalcifications for isocentric motion in Digital Breast tomosynthesis (DBT). 2007 IEEE 7th International Symposium on BioInformatics and BioEngineering, p. 563 - 569, Outubro 2007.

COCKMARTIN, L. et al. Power spectrum analysis of an anthropomorphic breast phantom compared to Patient Data in 2D Digital Mammography and Breast Tomosynthesis. In: 
Breast Imaging Volume 8359. Gifu City, Japan: Springer International

Publishing, 2014. p. 423-429.

DABOV, K. et al. Image Denoising by Sparse 3-D Transform-Domain Collaborative Filtering.

IEEE Transactions on Image Processing, v. 16, n. 18, p. 2080-2095, August 2007.

DAVIS, D. The Secret History Of Mammography. The Huffington Post, 2010. Disponivel

em: <http://www.huffingtonpost.com/devra-davis-phd/the-secret-history-ofmam_b_364733.html>. Acesso em: Junho 2016.

DOLINSKY, C.; HILL-KAYSER, C. All about breast cancer, 2016. Disponivel em: <http://www.oncolink.org/>. Acesso em: Março 2016.

ELAD, M. On the Origin of the Bilateral Filter and Ways to Improve it. IEEE Transactions on Image Processing, v. 11, n. 10, p. 1141-1151, October 2002.

FOI, A. Optimization of variance-stabilizing transformations. Em andamento., 2016.

FOI, A. et al. Practical Poissonian-Gaussian noise modeling and fitting for single-image rawdata. IEEE Transactions on Image Processing, v. 17, n. 10, p. 1737-1754, Outubro 2008.

GE HEALTHCARE. Digital Breast Tomosynthesis Fundamentals. [S.1.]: [s.n.], 2014.

GE HEALTHCARE. GE Breast Tomosynthesis Operator Manual, 5415894-4-1EN. 1. ed. [S.1.]: [s.n.], 2014.

GLICK, S. J. System design and acquisition parameters for breast tomosynthesis. In:

Tomosynthesis Imaging. [S.1.]: Taylor \& Francis Book, 2014. Cap. 2.

GOLD, R. H.; BASSETT, L. W.; WIDOFF, B. E. Highlights from the history of Mammography. RadioGraphics, v. 10, n. 6, p. 1111-1131, 1990.

GOODSITT, M. M. The history of tomosynthesis. In: REISER, I.; GLICK, S. Tomosynthesis Imaging. [S.1.]: Taylos \& Francis Book, 2014. Cap. 1.

HARDESTY, L. A.; KREIDLER, S. M.; GLUECK, D. H. Digital Breast Tomosynthesis Utilization in the United States: A Survey of Physician Members of the Society of Breast Imaging. American College of Radiology, 2014.

HENDEE, W. R. Imaging in medical diagnosis and therapy. [S.l.]: [s.n.].

HOLOGIC. Selenia Dimensions Mammography System. [S.1.]: [s.n.], 2016.

ICRP. Implications of Commission Recommendations that Doses be Kept as Low as Readily Achievable. ICRP Publication, v. 22, 1973. 
INCA. Instituto Nacional de Câncer José Alencar Gomes da Silva, 2016. Disponivel em: <http://www2.inca.gov.br/>. Acesso em: Março 2016.

JOE, B. N. Advance in Breast Imaging - Mammography and Much More. San Francisco Medicine - Journal of the San Francisco Medical Society, v. 22, n. 2, Março 2015.

JR., R. S. S. et al. Does image quality atter? Impact of resolution and noise on mammographic task performance. Medical Physics, v. 34, n. 10, 2007.

KIMME-SMITH, C. New Digital Mammography Systems May Require Different X-ray Spectra and, Therefore, More General Normalized Glandular Dose Values. Radiology, v. 213, n. 1, p. 7-10, Outubro 1999.

KROFT, L. J. M. et al. Detection of Simulated Nodules on Clinical Radiographs: Dose Reduction at Digital Posteroanterior Chest Radiography. Radiology, v. 241, n. 2, p. 392-398, November 2006.

KUO, J. et al. Dynamic Reconstruction and Rendering of 3D Tomosynthesis Images. Medical Imaging: Physics of Medical Imaging, v. 7961, 2011.

MACKENZIE, A. et al. Image simulation and a model of noise power spectra across a range of mammographic beam qualities. Medical Physics, v. 41, n. 12, Dezembro 2014.

MAKITALO, M.; FOI, A. Optimal Inversion of the Anscombe Transformation in Low-Count Poisson Image Denoising. IEEE Transactions on Image Processing, v. 20, n. 1, p. 99 109, jul. 2010.

MAKITALO, M.; FOI, A. Poisson-Gaussian Denoising Using The Exact Unbiased Inverse Of The Generalized Anscombe Transformation. Acoustics, Speech and Signal Processing (ICASSP), IEEE International Conference, 2012. 1081-1084.

MÄKITALO, M.; FOI, A. Noise Parameter Mismatch in Variance Stabilization, With an Application to Poisson-Gaussian Noise Estimation. IEEE Transactions on Image Processing, v. 23, n. 12, December 2014.

MURTAGH, F.; STARCK, J.-L.; BIJAOUI, A. Image restoration with noise suppression using a multiresolution support. Astronomy and Astrophysics Supplement, v. 112, p. 179189, 1995.

NUNES, P. F. et al. Using The Non-Local Means Algorithm To Denoise Mammographic Images Acquired With Reduced Radiation Dose. XI Workshop De Visão Computacional, São Carlos, 2015. 458-463. 
OLIVEIRA, H. C. R. D. et al. Use Of Wavelet Multiresolution Analysis To Reduce Radiation Dose In Digital Mammography. IEEE 28th International Symposium On Computerbased Medical Systems, 2015. 33-37.

OLIVEIRA, H. C. R. et al. Evaluation Of Block-Matching And 3d Filtering And Wavelet Transform With Shrink-Thresholding Technique For Digital Mammography Denoising. XI Workshop De Visão Computacional, São Carlos, 2015. 452-457.

OMS. Organização Mundial da Saúde, 2016. Disponivel em: <http://www.who.int/>. Acesso em: Março 2016.

REZENTES, P. S.; ALMEIDA, A. D.; BARNES, G. T. Mammography Grid Performance. Medical Physics - Radiology, v. 210, n. 1, p. 227-232, Janeiro 1999.

RUSCHIN, M. et al. Dose dependence of mass and microcalcification detection in digital mammography: Free response human observer studies. Medical Physics, v. 2, p. 24, 2007.

SAMEI, E. et al. Digital Mammography: Effects of Reduced Radiation Dose on Diagnostic Performance. Radiology, v. 243, n. 2, p. 396-404, Maio 2007.

SAUNDERS JR, R. S. et al. Does image quality atter? Impact of resolution and noise on mammographic task performance. Medical Physics, v. 34, n. 10, 2007.

SAUNDERS JR, R. S.; SAMEI, E. A method for modifying the image quality parameters of digital radiographic images. Med. Phys., v. 30, n. 11, p. 3006-3017, November 2003.

SECHOPOULOS, I. A review of breast tomosynthesis. Part I. The image acquisition process. Med. Phys., v. 40, January 2013.

SECHOPOULOS, I. A review of breast tomosynthesis. Part II. Image reconstruction, processing and analysis, and advanced applications. Med. Phys., v. 40, January 2013.

SECHOPOULOS, I.; GHETTI, C. Optimization of the acquisition geometry in digital tomosynthesis of the breast. Medical Physics, v. 36, n. 4, p. 1199-1207, Abril 2009.

SIEMENS HEALTHINNERS. Mammomat Inspiration with Prime Technology. [S.1.]:

[s.n.], 2016. Disponivel em:

<http://www.healthcare.siemens.com/mammography/tomosynthesis>. Acesso em: 2016.

STARCK, J.-L.; MURTAGH, F. Astronomical Image ans Data Analysis. 2nd. ed. [S.1.]: Springer, 2006. 
STEVENS, G. M.; PELC, N. J. Tomosynthesis with circular orbits. In: REISER, I.; GLICK, S. Tomosynthesis Imaging. [S.1.]: Taylos \& Francis Book, 2014. Cap. 5.

SVALKVIST, A.; BATH, M. Simulation of dose reduction in tomosynthesis. Med. Phys. 37, p. $258-269,2010$.

SVALKVIST, A.; BÅTH, M. Simulation of dose reduction in tomosynthesis. Med. Phys. 37, p. 258-269, 2010.

TEERTSTRA, H. J. et al. Breast tomosynthesis in clinical practice: initial results. European Radiology, v. 20, n. 1, p. 16-24, Janeiro 2010.

VELDKAMP, W. J. et al. A technique for simulating the effect of dose reduction on image quality in digital chest radiography. Journal of Digital Imaging , v. 22, n. 2, p. 114125, Fevereiro 2008.

VELDKAMP, W. J. H. et al. A Technique for Simulating the Effect of Dose Reduction on Image Quality in Digital Chest Radiography. Journal of Digital Imaging, v. 22, n. 2, p. 114-125, April 2009.

VIEIRA, M. A. C. et al. Feasibility study of dose reduction in digital breast tomosynthesis using non-local denoising algorithms. Proc. SPIE 9412, Medical Imaging 2015: Physics of Medical Imaging, 18 March 2015.

YAFFE, M. Digital Mammography. In: Handbook of Medical Imaging Volume 1. Physics and Psychophysics. [S.1.]: SPIE PRESS, 2000. p. 329-367.

YAFFE, M.; MAINPRIZE, J. Risk of radiation-induced breast cancer from mammographc screening. Radiology, v. 258, n. 1, p. 98-105, 2011.

YOUNG, K. C.; ODUJO, J. M. NHSBSP Equipment Report 0801 - Technical evaluation of the hologic selenia full field digital mammography system with a tungsten tube. National Coordinating Centre for the Physics of Mammography, Abril 2008. 